LIQUID PHASE METHANOL LAPORTE PROCESS DEVELOPMENT UNIT: MODIFICATION, OPERATION, AND SUPPORT STUDIES

Toplcal Report for the Perlod April 9, 1987-March 31, 1991

Task 3.5: Development of Fundamental Rate Models for Methanol Synthesis in a Slurry Reactor

March 11, 1991

Work Performed Under Contract No. AC22-87PC90005

For

U.S. Department of Energy

Plttsburgh Energy Technology Center

Pittsburgh, Pennsylvania

By

Alr Products and Chemicals, Inc.

Allentown, Pennsylvania

and

Chem Systems, Inc.

Tarrytown, New York 


\title{
LIQUID PHASE METHANOL LAPORTE PROCESS DEVELOPMENT UNIT: MODIFICATION, OPERATION, AND SUPPORT STUDIES
}

\author{
Topical Report
}

Task 3.5: Development of Fundamental Rate Models for Methanol Synthesis in a Slurry Reactor

\author{
Contractor
}

AIR PRODUCTS AND CHEMICALS, INC.

Allentown, PA 18195

and

Subcontractor to Air Products

CHEM SYSTEMS INC.

Tarrytown, NY 10591

11 March 1991

Prepared for the United States Department of Energy

Under Contract No. DE-AC22-87PC90005

Contract Period 9 April 1987 - 31 March 1991 


\section{Contents}

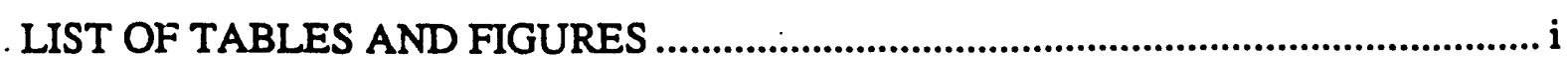

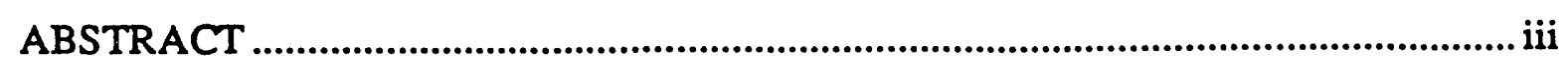

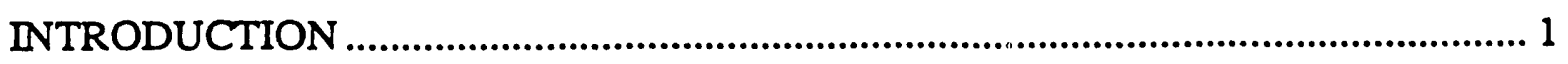

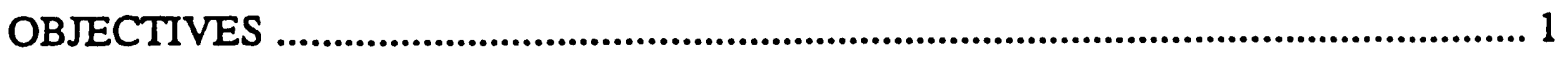

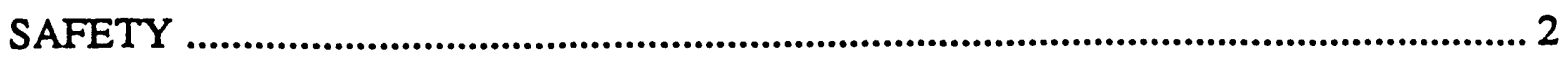

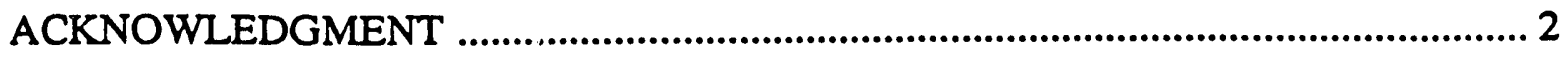

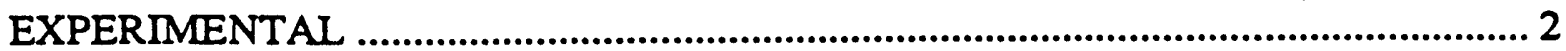

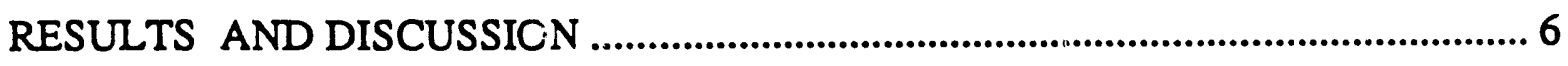

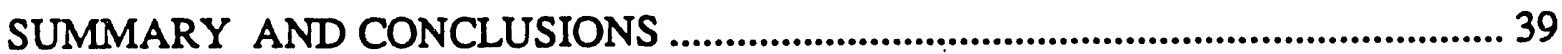

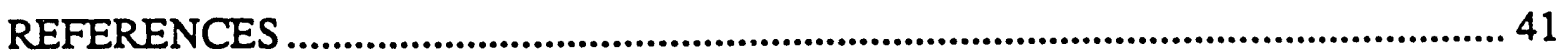




\section{LIST OF TABLES}

1. Rate Expressions for S3-85 Data Base

2. Rate Expressions for S3-86 Data Base .................................................... 28

A-1. Composition of Syngas Mixtures

A-2. BASF S3-85 Catalyst Data Base

A-3. BASF S3-86 Catalyst Data Base

B-1. Model S3-T2 Fit to all 250 $\quad$ C Data for S3-85

B-2. Model XX14 Fit to all $250^{\circ} \mathrm{C}$ Data for S3-86

\section{LIST OF FIGURES}

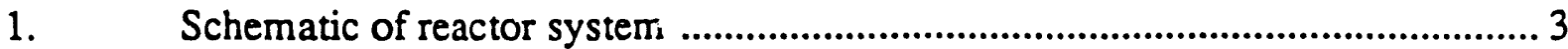

2. Parity plot for model S3-T2 for S3-85 .................................................. 12

3. Comparison of measured and predicted $\mathrm{CH}_{3} \mathrm{OH}$ rate vs. exit $\mathrm{CO}_{2} \ldots \ldots \ldots \ldots \ldots . . . . . .13$ concentration for Texaco gas at 5,000 GHSV

4. Comparison of measured and predicted $\mathrm{CH}_{3} \mathrm{OH}$ rate vs. exit $\mathrm{CO}_{2} \ldots \ldots \ldots \ldots . . . . . . .14$ concentration for Texaco gas at 10,000 GHSV

5. Comparison of measured and predicted $\mathrm{CH}_{3} \mathrm{OH}$ rate for $\mathrm{H}_{2} \mathrm{O}$ addition ............. 16 to $0 \%$ feed $\mathrm{CO}_{2}$ Texaco gas at $5,000 \mathrm{GHSV}$

6. Comparison of measured and predicted $\mathrm{CH}_{3} \mathrm{OH}$ rate for $\mathrm{H}_{2} \mathrm{O}$ addition ............. 17 to $0 \%$ feed $\mathrm{CO}_{2}$ Texaco gas at $10,000 \mathrm{GHSV}$

7. Comparison of measured and predicted $\mathrm{CH}_{3} \mathrm{OH}$ rate for $\mathrm{H}_{2} \mathrm{O}$ addition ............. 18 to $13 \%$ feed $\mathrm{CO}_{2}$ Texaco gas at $5,000 \mathrm{GHSV}$

8. Comparison of measured and predicted $\mathrm{CH}_{3} \mathrm{OH}$ rate for $\mathrm{H}_{2} \mathrm{O}$ addition ............ 19 to $13 \%$ feed $\mathrm{CO}_{2}$ Texaco gas at $10,000 \mathrm{GHSV}$

9. Comparison of measured and predicted $\mathrm{CH}_{3} \mathrm{OH}$ rate for $\mathrm{H}_{2} \mathrm{O}$ addition ............ 20 to Shell gas at 5,000 GHSV

10. Comparison of measured and predicted $\mathrm{CH}_{3} \mathrm{OH}$ rate for $\mathrm{H}_{2} \mathrm{O}$ addition .............2 21 to Shell gas at $10,000 \mathrm{GHSV}$

11. $\mathrm{CH}_{3} \mathrm{OH}$ rate vs. GHSV for S3-86 using Great Plains gas $\left(0.5 \%\right.$ feed $\left.\mathrm{CO}_{2}\right) \ldots . . .23$ at 5.27 $\mathrm{MPa}$ and $250^{\circ} \mathrm{C}$

12. $\mathrm{CH}_{3} \mathrm{OH}$ rate vs. GHSV for S3-86 using Great Plains gas $\left(5.0 \%\right.$ feed $\left.\mathrm{CO}_{2}\right) \ldots . . .24$ at $5.27 \mathrm{MPa}$ and $250^{\circ} \mathrm{C}$

13. $\mathrm{CH}_{3} \mathrm{OH}$ rate vs. GHSV for S3-86 using Great Plains gas $\left(5.0 \%\right.$ feed $\left.\mathrm{CO}_{2}\right) \ldots . . .25$ at $7.34 \mathrm{MPa}$ and $250^{\circ} \mathrm{C}$

14. $\mathrm{CH}_{3} \mathrm{OH}$ rate vs. temperature for S3-86 using Great Plains gas ......................... 26 $\left(5.0 \%\right.$ feed $\mathrm{CO}_{2}$ ) at $7.34 \mathrm{MPa}, 250^{\circ} \mathrm{C}$, and $10,000 \mathrm{GHSV}$

15. Parity plot for model XX14 for S3-86 data base ............................................ 29

16. Comparison of measured and predicted $\mathrm{CH}_{3} \mathrm{OH}$ rate vs. GHSV ..................... 31 for Texaco gas at $5.27 \mathrm{MPa}$

17. Comparison of measured and predicted $\mathrm{CH}_{3} \mathrm{OH}$ rate vs. GHSV ..................... 32 for Texaco gas at $9.75 \mathrm{MPa}$ 


\section{LIST OF FIGURES \\ (continuad)}

18. Comparison of measured and predicted $\mathrm{CH}_{3} \mathrm{OH}$ rate vs. GHSV ...................... 33 for Dow gas at $5.27 \mathrm{MPa}$

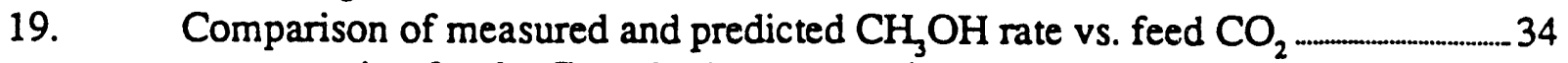
concentration for the Great Plains gas matrix at 5.27 MPa

20. Comparison of measured and predicted $\mathrm{CH}_{3} \mathrm{OH}$ rate vs. GHSV ..................... 35 for Great Plains gas $\left(0.5 \%\right.$ feed $\left.\mathrm{CO}_{2}\right)$ at $5.27 \mathrm{MPa}$

21. Comparison of measured and predicted $\mathrm{CH}_{3} \mathrm{OH}$ rate vs. GHSV 36 for Great Plains gas $\left(5.0 \%\right.$ feed $\mathrm{CO}_{2}$ ) at $5.27 \mathrm{MPa}$

22. Comparison of measured and predicted $\mathrm{CH}_{3} \mathrm{OH}$ rate vs. GHSV 37 for Great Plains gas (5.0\% feed $\mathrm{CO}_{2}$ ) at $7.34 \mathrm{MPa}$ 


\begin{abstract}
In support of the DOE-sponsored Liquid Phase Methanol research and development program (Contract No. DE-AC22-87PC90005), rate expressions for methanol synthesis from syngas in a slurry reactor have been developed. These rate models, which express methanol rate as a function of gas phase fugacities, were fit to the $250^{\circ} \mathrm{C}$ laboratory experimental data bases for two BASF methanol synthesis catalysts, S3-85 and S3-86. In addition, the S3-86 experimental data base was expanded by obtaining data on the Great Plains syngas feed. The best fit rate expressions identified for each catalyst differ in mathematical form, but were both derived from a reaction mechanism that assumes that $\mathrm{CO}$ and $\mathrm{CO}_{2}$ are hydrogenated in parallel on separate sites on the surface of the catalyst. Model S3-T2, the best model identified for S3-85, yielded an average prediction error per experimental observation of $12.9 \%$, while the average error for model XX14, the best model for S386 , was $15.3 \%$. Agreement between experimentally observed trends and model predictions is generally good, though some deficiencies of the models have been identified.
\end{abstract}




\section{INTRODUCTION}

The Liquid Phase Methanol (LPMEOH) process is an efficient method of producing methanol from coal-derived synthesis gas. In the LPMEOH reactor, the methanol synthesis catalyst, in a powder form, is suspended in an inert liquid medium. Because of the superior heat transfer characteristics of this slurry medium, the highly exothermic and equilibrium-limited methanol synthesis reaction can be run under essentially isothermal conditions. This enables the use of unshifted feed gases which contain high levels of $\mathrm{CO}$ and the achievement of a high per-pass conversion.

Successful application and optimization of the LPMEOH process requires a method of predicting methanol synthesis rate as a function of reaction conditions. A key requirement is the development of an accurate kinetic model, i.e., a mathematical expression of the intrinsic methanol synthesis rate as a function of pressure, temperature, and gas composition. A rate expression derived from fundamental considerations of the elementary steps of the reaction mechanism is desirable, because such an expression is likely to be applicable over a wide range of reaction conditions.

Historically, methanol synthesis from syngas has been one of the most studied reactions, as indicated by the extensive literature. Numerous reaction schemes and rate expressions have been developed to describe the methanol rate for a variety of reaction conditions. Most associated experimental measurements of rate have involved synthesis in packed bed reactors with high $\mathrm{H}_{2} / \mathrm{CO}$ feed. Many of the proposed rate expressions lack important features, such as the influence of $\mathrm{CO}_{2}$ and the watergas shift reaction. Some of these rate models are also quite complicated and difficult to use.

The primary goal of this work was to develop a simple, fundamental rate model for slurry-phase methanol synthesis from coal-derived syngas. Development of an accurate model will assist in successful scale up and commercial implementation of the LPMEOH process.

\section{OBJECTIVES}

The objectives of the present work can be divided into three parts. The first objective was to develop. a best-fit model for the older methanol synthesis catalyst (BASF S3-85) data base. At the time that this work commenced (June 1989), the BASF S3-85 data base contained many rate measurements accumulated over a few years. The newer catalyst (BASF S3-86) data base, at that time, contained only a few observations and did not include a broad range of conditions. Thus, a second objective of this work was to expand the BASF S3-86 data base to include more rate observations over a broader range of conditions. Finally, after expansion of the BASF S3-86 data base, the third objective was to develop a rate expression to describe this data base. This would include the application of rate expressions developed for the BASF S3-85 catalyst, as well as new models. 


\section{SAFETY}

The major safety concems in the experimental part of this study were the flammability of $\mathrm{H}_{2}$ and the toxicity and flammability of $\mathrm{CO}$, both of which are present in syngas. The primary measures taken to minimize the consequences of an unexpected release of these gases were: the apparatus was housed in a continuously ventilated walk-in hood, the atmosphere in the hood and the laboratory area was continuously monitored by flammable gas and $\mathrm{CO}$ detectors, and the flammable gas and $\mathrm{CO}$ detectors were interfaced to an automatic gas flow shutdown system.

\section{ACKNOWLEDGMENT}

The author would like to thank the following people who are largely responsible for obtaining the experimental data that comprises the data bases used in the modelling: T. A. Dahl, R. C. Blum, S. E. Gaul, B .L. Bhatt, T. H. Hsiung, and J. J. Lewnard.

\section{EXPERIMENTAL}

\section{Materials:}

The catalysts used for these experiments were BASF S3-85-44 and BASF S3-86-43 (previously designated F21/0E75-44 and F21/0E75-43), respectively. Hereinafter, BASF S3-85-44 and BASF S3-86-43 will be referred to as S3-85 and S3-86, respectively. Both catalysts are commercial $\mathrm{Cu} /$ $\mathrm{ZnO} / \mathrm{Al}_{2} \mathrm{O}_{3}$ methanol synthesis cataiysts which differ in the relative proportions of $\mathrm{Cu}, \mathrm{ZnO}$, and $\mathrm{Al}_{2} \mathrm{O}_{3}$. S3-85 is the older catalyst; $\mathrm{S3-86}$ replaced S3-85 as the preferred catalyst for the process because it has shown a higher methanol synthesis rate for $\mathrm{CO}$-rich syngas. The slurrying liquid used was either Witco 70 or Penreco Drakeol 10, both of which are white mineral oils.

Premixed gases, supplied from cylinders or a tube trailer, were obtained from Air Products Specialty Gases. Table A-1 of Appendix A shows the nominal compositions for the syngas mixtures. The gas compositions were chosen to simulate the bulk syngas product from various coal gasifiers, including Shell, Texaco, and Dow. In addition, two high $\mathrm{H}_{2} / \mathrm{CO}$ gas mixtures were used. One mixture simulated the shifted syngas from the Great Plains gasification facility. The composition of the other high $\mathrm{H}_{2} / \mathrm{CO}$ mixture, designated "balanced" gas, was such that $\mathrm{H}_{2} /\left(\mathrm{CO}+1.5 \mathrm{CO}_{2}\right)=2$, thereby having hydrogen and carbon oxides present in stoichiometric proportions for methanol synthesis from $\mathrm{CO}$ and $\mathrm{CO}_{2}$. Also, additional syngas mixtures were used, the compositions of which simulated the removal or addition of $\mathrm{CO}_{2}$ from the basic syngas matrices shown in Table A-1. In some experiments using the $\mathrm{S} 3-85$ catalyst, $\mathrm{H}_{2} \mathrm{O}$ was added to the feed. The trace components usually present in actual coal gasifier product streams, e.g. sulfur compounds, were not present in these gas mixtures.

\section{Experimental Apparatuses:}

The data which comprise the data bases were obtained using three experimental apparatuses. A flow schematic for a typical apparatus is shown in Figure 1. The reactors used were stirred autoclaves, manufactured by Autoclave Engineers, with internal volumes of $50 \mathrm{cc}, 300 \mathrm{cc}$, or $1000 \mathrm{cc}$. Feed gas from cylinders or a tube trailer was compressed by a gas booster pump. Gas flow rate to the reactor was controlled by an electronic mass flow controller. The vapor product stream was passed through 


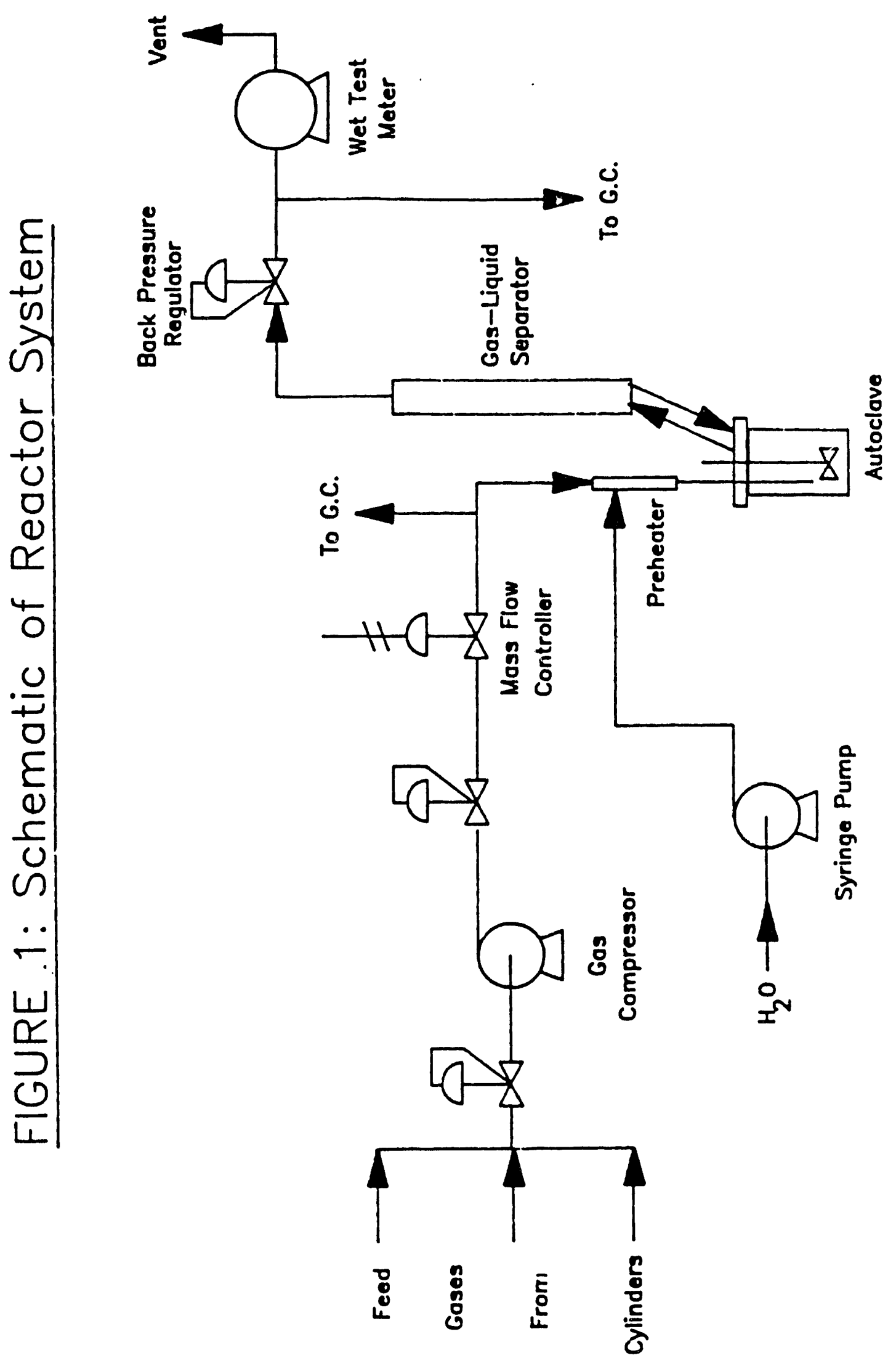


a gas-liquid separator to remove entrained and vaporized oil from the reactor. The gas-liquid separator, the heat-traced lines downstream of the reactor, and the line to the gas chromatograph were maintained at a temperature sufficient to prevent the condensation of product $\mathrm{CH}_{3} \mathrm{OH}$. Reactor pressure was regulated by means of a back pressure regulator and product gas flow rate was measured using a wet test meter.

For some of the experiments, $\mathrm{H}_{2} \mathrm{O}$ was added to the feed as steam. This was done using a syringe pump which injected liquid $\mathrm{H}_{2} \mathrm{O}$ to a feed preheater located immediately upstream of the reactor inlet. The feed preheater, an electrically-heated vessel packed with brass machine screws, vaporized the injected liquid $\mathrm{H}_{2} \mathrm{O}$ into the feed gas stream.

The influence of mass transfer on the measured methanol rate was shown to be negligible by observing the effect of stirrer speed on the rate for each reactor. The results of these measurements indicated that, for all three reactor sizes, mass transfer influence was negligible for stirrer speeds greater than or equal to $1200 \mathrm{rpm}$. A stirrer speed of at least $1200 \mathrm{rpm}$ was used for all of the data in the data bases. Since mass transfer limitations are negligible, the autoclave reactors are regarded as continuous stirred tank reactors (CSTRs). Thus, the gas phase composition in the reactor, which is equal to the effluent gas composition, determines the rate of methanol synthesis. In fitting the experimental data, the observed methanol rates were regressed on the reactor effluent fugacities calculated from effluent concentrations.

Feed and product gas compositions were measured on-line by a GC equipped with thermal conductivity detectors. Since the GC columns used did not perform well for $\mathrm{H}_{2} \mathrm{O}$ at low concentrations, accurate quantitative analysis for $\mathrm{H}_{2} \mathrm{O}$ was not possible. Thus, reactor effluent water concentrations are not, unfortunately, included in the data base. Water concentrations were calculated by assuming that the water-gas shift reaction was at equilibrium, as will be discussed later.

\section{Data Bases:}

Tables A-2 and A-3 of Appendix A are summaries of the laboratory autoclave tata bases used in the model development for the S3-85 and S3-86 catalysts, respectively. Brief study of the limited range of reaction conditions in these data bases elucidates the fact that the experiments were not chosen for the sole purpose of developing a rate model. In fact, most of the data wer-obtained using practical conditions of temperature, pressure, flow rate, and gas composition. Practical conditions span a somewhat limited range of conditions, making it more difficult to adequately test the validity of a model. Of course, a model which accurately describes all practical conditions is obviously very useful.

For the S3-85 catalyst, the majority of the experiments were done using the Texaco gas matrix. Limited data for "balanced" gas and Shell eas are also included. The overwhelming majority of this data was obtained using a reaction temperature of $250^{\circ} \mathrm{C}$ and reaction pressure of $52.02 \mathrm{~atm}$ (750 psig). Thus, the S3-85 data base is somewhat limited in scope. Most of the Texaco gas data was obtained during the study of the effects of $\mathrm{CO}_{2}$ in Texaco gas, Subtask 3.2 of the current DOE contract. Much of this data was obtained using a gas-hourly space velocity (GHSV) of 5,000 or 10,000 std.lit./kg-hr. The rightmost column of Table $\mathrm{A}-2$ indicates the feed $\mathrm{CO}_{2}$ and/or $\mathrm{H}_{2} \mathrm{O}$ levels for experiments in which these levels were varied from the basic syngas matrix. In total, the $\$ 3-85$ data base consists of 128 observations at 84 different conditions. The portion of the data base which 
includes runs at $250^{\circ} \mathrm{C}$ consists of 112 observations at 69 different conditions of feed gas composition and GHSV.

In contrast to the $\$ 3-85$ data base, the $\$ 3-86$ data base spans a considerably broader range of conditions and is not as concentrated on the Texaco gas matrix. Table A-3 shows that the experimental runs are fairly evenly divided among the Texaco, Dow, and Great Plains gas matrices. Broader ranges of GHSV and pressure are also a feature of the S3-86 data base. The inclusion of extensive runs on Great Plains gas, including the effect of feed $\mathrm{CO}_{2}$, enables the fitting and testing of models at $\mathrm{H}_{2}$-rich feed conditions. However, in contrast to the S3-85 data base, the S3-86 data base does not include any runs in which $\mathrm{H}_{2} \mathrm{O}$ was added to the feed, nor does it include any data on the very CO-rich Shell gas. In total, the S3-86 data base consists of 85 observations at 57 different conditions. The portion of the data base which includes runs at $250^{\circ} \mathrm{C}$ consists of 61 observations at 52 different conditions of feed gas composition, pressure, and GHSV.

\section{Calculations:}

To enable the developed rate models to be applicable over the broadest range of reaction conditions possible, gas phase fugacities were used in the rate expressions instead of partial pressures. This required the conversion of measured reactor effluent mole fractions and reactor total pressure to fugacities for each experimental run. To do this for each data base, the relevant data were assembled into a PC-based ASCI file. The necessary data for each run for this conversion to fugacity included the temperature, total pressure, outlet mole fractions of $\mathrm{H}_{2}, \mathrm{CO}, \mathrm{CO}_{2}, \mathrm{CH}_{3} \mathrm{OH}$, and inerts $\left(\mathrm{CH}_{4}+\mathrm{N}_{2}\right)$, and methanol rate. These data were transferred serially to a file on the Air Products mainframe computer. There the data were used by a Fortran program that calculated normalized mole fractions, $\mathrm{H}_{2} \mathrm{O}$ concentration by water-gas shift equilibrium, and, finally, fugacity coefficients and fugacities. The determination of fugacities was done using an Air Products proprietary subroutine which uses the modified Redlich-Kwong equation of state with experimentally determined parameter values. The resulting fugacities were serially downloaded from the mainframe to an ASCI format file on the PC.

For each data base a file was assembled which contained, for each run, the observation number, measured methanol rate, data weight factor, and fugacities of $\mathrm{H}_{2}, \mathrm{CO}, \mathrm{CO}_{2}$, and $\mathrm{CH}_{3} \mathrm{OH}$. The data weight factor is an input to the non-linear regression package and was used to assign relative importance to the square of the residual calculated for each observation. If the data weight factor is 1.0 for all observations, each is weighted equally. Assigning a value of less than 1.0 puts less significance on that observation for the regression. Data weight factors of less than 1.0 were used in the S3-85 data base for runs using Texaco gas at $250^{\circ} \mathrm{C}$ and 5,000 and 10,000 GHSV, because these conditions were repeated many times experimentally.

A non-linear, least squares regression routine in SAS was used for the data regressions. An example SAS program listing is shown in Appendix B. SAS was run on a Compaq Deskpro 286 equipped with a math coprocessor. The data files containing the fugacities for each data base were converted into SAS datasets and used as input to the regression routine. Either the Marquardt or modired Gauss-Newton iterative methods were used in minimizing the residual sum of squares. The residual sum of squares, or sum of the squares of the errors (SSE), is defined as:

$$
\text { SSE }=*_{i}\left(\text { predicted rate }_{i}-\text { measured rate }\right)^{2} \text {. }
$$


For each regression, specification of initial parameter estimates and the partial derivative of the rate expression with respect to each parameter were required. The version of SAS used (version 6.03) was quite interactive and allowed for real-time observation of the convergence process. This way the iterations could be stopped if the search was headed toward unrealistic values of the parameters or got "bogged down". Convergence time was a function of the quality of the initial parameter estimates, but, for fairly good guesses, a typical 6-parameter rate expression required 5-10 minutes to converge. The results of the regression were transferred to a spreadsheet where plots that compare measured and predicted results were generated.

\section{RESULTS AND DISCUSSION}

\section{Basis for Modeling:}

In the development of rate expressions, emphasis was on those derived from assumed sequences of elementary steps, rather than empirical mathematical expressions. The assumed reaction mechanisms were meant to be consistent with published aspects of the chemisorption of the reacting species, observations of surface intermediates, and isotopic tracer studies. Also, investigations of the effect of reaction cunditions on experimentally measured methanol rate from the published literature and from work done in Air Products laboratory, was used as additional guidance in developing rate expressions.

Previous published work provides some guidance in terms of probable reaction mechanisms. However, much controversy exists in the literature regarding the source of carbon, whether $\mathrm{CO}$ or $\mathrm{CO}_{2}$, in methanol synthesis from $\mathrm{CO} / \mathrm{CO}_{2} / \mathrm{H}_{2}$ mixtures. Some authors have speculated that methanol is formed largely from $\mathrm{CO}$, while the primary role of $\mathrm{CO}_{2}$ is to maintain the catalyst in the most active state ${ }^{(12)}$. Other authors believe that the primary carbonaceous reactant is $\mathrm{CO}_{2}^{(3-6)}$. For example, workers at ICI have recently presented some rather compelling experimental evidence that methanol is formed directly from $\mathrm{CO}_{2}{ }^{(5,6)}$, at least under the reaction conditions used in their studies. Indeed, other invesugators believe that both $\mathrm{CO}$ and $\mathrm{CO}_{2}$ hydrogenation are kinetically important in methanol synthesis ${ }^{(-11)}$. Though universal agreement does not exist regarding the primary carbon source, general agreement exists that the presence of some $\mathrm{CO}_{2}$ is necessary to achieve high methanol synthesis rate. In addition, the water-gas shift reaction is important under methanol synthesis conditions and frequently complicates the interpretation of experimental results.

Noteworthy is the fact that many of the studies referred to above involved methanol synthesis from $\mathrm{H}_{2}$-rich syngas, i.e., syngas representative of that obtained from steam-methane reforming (SMR). The syngas obtained from the gasification of coal is typically much richer in carbon oxides, especially $\mathrm{CO}$. Thus, the relative importance of $\mathrm{CO}$ and $\mathrm{CO}_{2}$ as carbon sources may be different for coal-derived, CO-rich gas than that for SMR-derived syngas.

In view of the above, the present work is focused on rate expressions derived from reaction mechanisms in which methanol is formed from both $\mathrm{CO}$ and $\mathrm{CO}_{2}$ hydrogenation. This generality will allow the data fit to decide which route allows for a better description of the experimental data. However, a cautionary note is required here. The validation of a reaction mechanism by means of best fit rate expressions is tenuous, at best. In other words, if a rate model fits the data best, this alone does not provide sufficient evidence that th'; model is accurate. This is true largely because 
vastly different reaction mechanisms may yield very similar rate expressions. Other corroborating experimental and, perhaps, theoretical evidence is required to adequately validate a reaction mechanism.

Assuming that methanol is produced from $\mathrm{CO}$ and $\mathrm{CO}_{2}$ hydrogenation, the relevant stoichiometric equations are:

$$
\begin{aligned}
& \mathrm{CO}+2 \mathrm{H}_{2} \Longleftrightarrow===\mathrm{CH}_{3} \mathrm{OH} \\
& \mathrm{CO}_{2}+3 \mathrm{H}_{2} \Longleftrightarrow==\Rightarrow \mathrm{CH}_{3} \mathrm{OH}+\mathrm{H}_{2} \mathrm{O}
\end{aligned}
$$

Occurring along with these reactions is the water-gas shift (WGS) reaction:

$$
\mathrm{CO}+\mathrm{H}_{2} \mathrm{O}==\Rightarrow \mathrm{CO}_{2}+\mathrm{H}_{2}
$$

Note that only two of these three equations [1-3] are algebraically independent because each can be written as a linear combination of the other two.

In the present work, the development of rate expressions from assumed sequences of surface reaction steps has been done using standard Langmuir-Hinshelwood kinetics, probably the most commonly used technique because of its relative simplicity. A number of simplifying assumptions are intrinsic in analysis by the Langmuir-Hinshelwood method in order to make the derivation mathematically tractable and produce an explicit, analytic expression for the rate. As a review, some of the assumptions inherent in this technique are:

(1) The reactants, intermediates, and products adsorb on discrete, energetically homogeneous sites on the surface of the catalyst.

(2) Chemisorption is confined to a monolayer.

(3) The fractional coverage by reaction intermediates is negligible relative to the coverage by reactants and products.

(4) One step in the reaction pathway is the rate-determining step (RDS).

(5) Steps in the reaction pathway which are not rate limiting are at equilibrium.

The Langmuir-Hinshelwood treatment generally produces a fractional rate expression in terms of the partial pressures or fugacities of the reactants and products. The numerator has a forward and a reverse reaction term, while the denominator consists of a sum of adsorption terms for the reactants and products. The assumption of a particular RDS influences the form of the numerator. The denominator is dictated entirely by the chemisorption of the reactants and products and is not influenced by the RDS, provided the adsorption of a reactant or desorption of a product is not the RDS. 
As mentioned earlier, the majority of the experimental observations in the S3-85 and S3-86 data bases were done using a reaction temperature of $250^{\circ} \mathrm{C}$. In fact, relatively few runs were done at temperatures other than $250^{\circ} \mathrm{C}$, especially for the $S 3-85$ data base. In view of this, the work here was confined to the development of rate expressions for methanol synthesis at $250^{\circ} \mathrm{C}$. However, as will be apparent in the derivation of the models, each parameter is typically a product of rate and adsorption equilibrium constants, both of which are exponential functions of temperature. Thus, a rate expression explicit in temperature would have twice the number of parameters as the isothermal one. The determination of the additional parameters for the non-isothermal rate expressions had to be left to future work.

Ranking of the quality of the rate expressions was done by considering two basic criteria. Firstly, the sum of the squares of the residuals was used to judge the quality of the fit. Secondly, the rate expressions were judged in their accuracy in describing experimentally observed trends, for example, the effect on the methanol rate of gas-hourly space velocity (GHSV), feed $\mathrm{CO}_{2}$ content, etc.

The results will be presented in three parts. First, the development and testing of rate expressions for the S3-85 data base will be discussed. Second, experimental results which expanded the data base for S3-86, consisting largely of additional runs for the $\mathrm{H}_{2}$-rich Great Plains gas matrix, will be presented. Third, and perhaps most importantly, modeling of the S3-86 data base will be discussed. As mentioned previously, the S3-86 data base is distributed more equitably over a broader range of gas composition, gas-hourly space velocity, and total pressure than the S3-85 data base. Thus, the S3-86 data base provides a much more demanding test of a general model. In fact, rate expressions which best fit the S3-85 data base are not the best for the S3-86 data base.

\section{Modeling of S3-85 Catalyst Data Base:}

Rate expressions were derived primarily by using variations of the basic reaction mechanism of Graaf et al. ${ }^{(9)}$. Graaf et al. have assumed that $\mathrm{CO}$ and $\mathrm{CO}_{2}$ are hydrogenated in parallel on the surface. Hydrogenation of each takes place by simple, stepwise addition of hydrogen atoms, formed by the dissociative adsorption of $\mathrm{H}_{2}$, until gaseous product $\mathrm{CH}_{3} \mathrm{OH}$ is produced. Graaf et al. have also assirmed that there are two types of sites: $\mathrm{CO}$ and $\mathrm{CO}_{2}$ adsorb competitively on site 1 (denoted s1), while $\mathrm{H}_{2}$ and $\mathrm{H}_{2} \mathrm{O}$ adsorb competitively on site 2 (denoted $\mathrm{s} 2$ ). The adsorption of product $\mathrm{CH}_{3} \mathrm{OH}$ is assumed to be negligible. So, the first steps in this mechanism are the adsorption of $\mathrm{CO}$, $\mathrm{CO}_{2}$, and $\mathrm{H}_{2}$ :

$$
\begin{aligned}
& \mathrm{CO}(\mathrm{g})+\mathrm{sl}=\mathrm{CO}-\mathrm{s} 1 \\
& \mathrm{CO}_{2}(\mathrm{~g})+\mathrm{s} 1=\mathrm{CO}_{2}-\mathrm{s} 1 \\
& \mathrm{H}_{2}(\mathrm{~g})+\mathrm{s} 2=2 \mathrm{H}-\mathrm{s} 2
\end{aligned}
$$

Methanol is produced from $\mathrm{CO}$ by stepwise hydrogenation:

$$
\begin{aligned}
& \mathrm{CO}-\mathrm{s} 1+\mathrm{H}-\mathrm{s} 2=\mathrm{HCO}-\mathrm{s} 1+\mathrm{s} 2 \\
& \mathrm{HCO}-\mathrm{s} 1+\mathrm{H}-\mathrm{s} 2=\mathrm{H}_{2} \mathrm{CO}-\mathrm{s} 1+\mathrm{s} 2 \\
& \mathrm{H}_{2} \mathrm{CO}-\mathrm{s} 1+\mathrm{H}-\mathrm{s} 2=\mathrm{H}_{3} \mathrm{CO}-\mathrm{s} 1+\mathrm{s} 2 \\
& \mathrm{H}_{3} \mathrm{CO}-\mathrm{s} 1+\mathrm{H}-\mathrm{s} 2=\mathrm{CH}_{3} \mathrm{OH}(\mathrm{g})+\mathrm{s} 1+\mathrm{s} 2
\end{aligned}
$$


In parallel, methanol is also produced from $\mathrm{CO} 2$, by stepwise hydrogenation:

$$
\begin{aligned}
& \mathrm{CO}_{2}-\mathrm{s} 1+\mathrm{H}-\mathrm{s} 2=\mathrm{HCO}_{2}-\mathrm{s} 1+\mathrm{s} 2 \\
& \mathrm{HCO}_{2}-\mathrm{s} 1+\mathrm{H}-\mathrm{s} 2=\mathrm{H}_{2} \mathrm{CO}_{2}-\mathrm{s} 1+\mathrm{s} 2 \\
& \mathrm{H}_{2} \mathrm{CO}_{2}-\mathrm{s} 1+\mathrm{H}-\mathrm{s} 2=\mathrm{H}_{3} \mathrm{CO}_{2}-\mathrm{s} 1+\mathrm{s} 2 \\
& \mathrm{H}_{3} \mathrm{CO} 2-\mathrm{s} 1+\mathrm{H}-\mathrm{s} 2=\mathrm{H}_{2} \mathrm{CO}-\mathrm{s} 1+\mathrm{H}_{2} \mathrm{O}-\mathrm{s} 2 \\
& \\
& \mathrm{H}_{2} \mathrm{CO}-\mathrm{s} 1+\mathrm{H}-\mathrm{s} 2=\mathrm{H}_{3} \mathrm{CO}-\mathrm{s} 1+\mathrm{s} 2 \\
& \mathrm{H}_{3} \mathrm{CO}-\mathrm{s} 1+\mathrm{H}-\mathrm{s} 2=\mathrm{CH}_{3} \mathrm{OH}(\mathrm{g})+\mathrm{s} 1+\mathrm{s} 2 \\
& \mathrm{H}_{2} \mathrm{O}-\mathrm{s} 2=\mathrm{H}_{2} \mathrm{O}(\mathrm{g})+\mathrm{s} 2
\end{aligned}
$$

Graaf et al. have also considered the kinetics of the water-gas shift reaction. As mentioned earlier, for the present work, lack of experimental measurements of exit water concentration made regression on the rate of water formation impossible. Instead, the water-gas shift reaction was assumed to be at equilibrium in the present work and the water concentration was calculated using this assumption.

Graaf et al. derived Langmuir-Hinshelwood rate expressions for methanol synthesis from this mechanism (9). The hydrogeration of $\mathrm{CO}$ and $\mathrm{CO}_{2}$ were assumed to occur independently but in parallel, even though some of the elementary reactions are the same. Thus, $\mathrm{CO}$ aild $\mathrm{CO}_{2}$ hydrogenation each yield a term in the rate expression, but share the same denominator. The numerator terms, or "driving force" groups, for each term depend on the choice of RDS. The assumed $\mathrm{RDS}$ and corresponding driving force group appearing in the numerator of the rate expression for $\mathrm{CO}$ and $\mathrm{CO}_{2}$ hydrogenation are:

$\underline{\mathrm{RDS}}$

CO Hvdrogenation

$\underline{\mathrm{RDS}}$

\section{Driving Force Group}$$
\mathrm{f}_{\mathrm{CO}} \mathrm{f}_{\mathrm{HL}}^{1 / 2}-\mathrm{f}_{\mathrm{CHOOH}} /\left(\mathrm{K}_{1} \mathrm{f}_{\mathrm{HZ}}{ }^{3 / 2}\right)
$$$$
\mathrm{fCO}_{\mathrm{HO}}-\mathrm{f}_{\mathrm{CHOH}} /\left(\mathrm{K}_{1} \mathrm{f}_{\mathrm{HO}}\right)
$$$$
\mathrm{f}_{\mathrm{CO}} \mathrm{f}_{\mathrm{HZ}}^{3 / 2}-f_{\mathrm{OH} O \mathrm{OH}} /\left(\mathrm{K}_{1} \mathrm{f}_{\mathrm{HO}}{ }^{1 / 2}\right)
$$

$$
\mathrm{f}_{\mathrm{CO}} \mathrm{f}_{\mathrm{HL}^{2}}{ }^{2}-\mathrm{f}_{\mathrm{CHOH}} /\left(\mathrm{K}_{1}\right) \text {. }
$$

$\mathrm{CO} 2$ Hydrogenation Driving Force Group

$$
\mathrm{f}_{\mathrm{CO}^{2} \mathrm{f}_{\mathrm{H} 2}}{ }^{1 / 2}-\mathrm{f}_{\mathrm{CH} 3 \mathrm{OH}} \mathrm{f}_{\mathrm{H} 2 \mathrm{O}} /\left(\mathrm{K}_{2} \mathrm{f}_{\mathrm{H} 2}{ }^{5 / 2}\right)
$$$$
\mathrm{f}_{\mathrm{CO} 2} \mathrm{f}_{\mathrm{HL}}-\mathrm{f}_{\mathrm{CHOOH}} \mathrm{f}_{\mathrm{HO}} d\left(\mathrm{~K}_{2} \mathrm{f}_{\mathrm{HL}}{ }^{2}\right)
$$

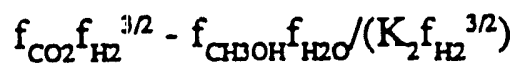$$
f_{\mathrm{CO}_{2}} \mathrm{f}_{\mathrm{H}_{2}}{ }^{2}-f_{\mathrm{CH} 3 \mathrm{OH}} f_{\mathrm{H} 2} /\left(\mathrm{K}_{2} \mathrm{f}_{\mathrm{H} 2}\right)
$$ 


$$
\begin{aligned}
& \mathrm{f}_{\mathrm{CO} 2} \mathrm{f}_{\mathrm{HL}}{ }^{5 / 2} / \mathrm{f}_{\mathrm{HLO}}-\mathrm{f}_{\mathrm{CHOH}} /\left(\mathrm{K}_{2} \mathrm{f}_{\mathrm{HZ}}{ }^{1 / 2}\right) \\
& \mathrm{f}_{\mathrm{CO} 2} \mathrm{f}_{\mathrm{HL}}{ }^{3 / \mathrm{f}_{\mathrm{HDO}}}-\mathrm{f}_{\mathrm{CHOOH}} / \mathrm{K}_{2}
\end{aligned}
$$

Here, $\mathrm{K}_{1}$ and $\mathrm{K}_{2}$ are the equilibrium constants for reactions [1] and [2], respectively. The denominator, or adsorption terms, for the rate expressions are $\left(1+\mathrm{K}_{\mathrm{co}} \mathrm{f}_{\mathrm{cO}}+\mathrm{K}_{\mathrm{CO}_{2}} \mathrm{f}_{\mathrm{CO}_{2}}\right)$ for site $\mathrm{s} 1$ and $\left(1+\mathrm{K}_{\mathrm{FD}}^{1 / 2} \mathrm{f}_{\mathrm{H} 2}^{1 / 2}+\mathrm{K}_{\mathrm{FDO}} \mathrm{f}_{\mathrm{HDO}}\right)$ for site $\mathrm{s} 2$. These terms are a product in the denominator of the rate expression since each possible RDS involves partic pation of $\mathrm{s} 1$ and $\mathrm{s} 2$.

Rate expressions from the mechanism of Graaf et al. were fit to the $S 3.85250^{\circ} \mathrm{C}$ data base. Before fitting the data base, the expression $f_{\mathrm{H} 20}=f_{\cos } f_{\mathrm{Hz}} /\left(\mathrm{K}_{\mathrm{wGS}} \mathrm{f}_{\mathrm{CO}}\right)$ was used to eliminate $f_{\mathrm{H} 2 \mathrm{O}}$ in the rate expressions to reflect the assumption of equilibrium for the water-gas shift reaction. Use was also made of the fact that $\mathrm{K}_{2}=\mathrm{K}_{1} / \mathrm{KwCS}$.

The best fit for the Graaf et al. mechanism was obtained for the rate expression derived assuining that step [9] for $\mathrm{CO}$ hydrogenation and step [12] for $\mathrm{CO}_{2}$ hydrogenation are the $\mathrm{RDSs}$ for methanol synthesis. In addition, the regressions showed that two parameters could be eliminated with negligible effect on the data fit because $\mathrm{K}_{\mathrm{CO}} \mathrm{f}_{\mathrm{cO}}+\mathrm{K}_{\mathrm{CO} 2} \mathrm{f}_{\mathrm{cO} 2} \gg 1$ and $\mathrm{K}_{\mathrm{Hz}}^{1 / 2} \mathrm{f}_{\mathrm{H} 2}{ }^{1 / 2}+\mathrm{K}_{\mathrm{H} 20} \mathrm{f}_{\mathrm{H} 2 \mathrm{O}} \gg 1$ in the denominator, that is, vacant sites are negligible. Thus, the number of adjustable parameters in each rate expression was reduced to four. This model, designated A3-C2, is shown in the first line of Table 1. Model A3-C2, with the besi-fit parameters shown in Table 1, has a residual sum of squares of $1,170 \mathrm{gmol} / \mathrm{kg}-\mathrm{hr}$, which corresponds to an average absolute error of $13.8 \% \mathrm{per}$ observation. The absolute error for an observation is defined as the absolute value of $100 \%$ (predicted rate - measured rate)/(measured rate).

Also shown in Table 1 is another model, S3-T2, which fits the data base slightly better than model A3-C2. Model S3-T2 was derived from the same basic mechanism as A3-C2, with some important differences. Instead of $\mathrm{CO}$ and $\mathrm{CO}_{2}$ adsorbing on the same site, each adsorbs on separate sites. In addition, $\mathrm{H}_{2}$ adsorbs dissociatively on each of these sites. Stepwise hydrogenation occurs on each site through the same intermediates as model A3-C2. Model S3-T2 yields a residual sum of squares of $1,030 \mathrm{gmol} / \mathrm{kg}-\mathrm{hr}$, corresponding to an average absolute error of $12.9 \%$.

For comparison, also shown in Table 1 is model W1, previously proposed as a viable rate expression. As can be seen, model W1 results in a much worse data fit than either A3-C2 or S3-T2, with a residual sum of squares of $5,697 \mathrm{gmol} / \mathrm{kg}$-hr and average absolute error per observation of $31.2 \%$. The lack of fit is not surprising since model $\mathrm{W} 1$ has no $\mathrm{CO}_{2}$ dependence.

Model S3-T2 was the best model found for the S3-85 data base. A compilation of the reactor exit concentrations and calculated fugacities of $\mathrm{H}_{2}, \mathrm{CO}, \mathrm{CO}_{2}$, and $\mathrm{CH}_{3} \mathrm{OH}$, the measured rate, the predicted rate, the residual, and the prediction enror is shown in Table B-1 of P-ppendix B.

The following are some comparisons between measured and predicted methanol rates for model S3T2. Note that the predicted rates are based on fugacities calculated from the measured reactor exit gas composition and total pressure for each run. A parity plot for this model is shown in Figure 2. Scatter about the $45^{\circ}$ line is fairly uniform. Shown in Figures 3-10 are comparisons between measured and predicted rate trends. Figures 3 and 4 show the effect of $\mathrm{CO}_{2}$ concentration in the Texaco gas matrix at 5,000 GHSV and 10,000 GHSV, respectively. Good agreement between 


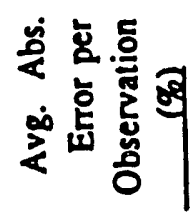

$\stackrel{\infty}{\check{2}}$

ิㅡำ

$\stackrel{ }{\pi}$

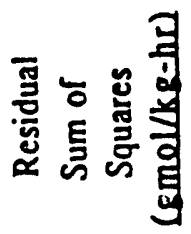

$\supseteqq$

용

ธิธ

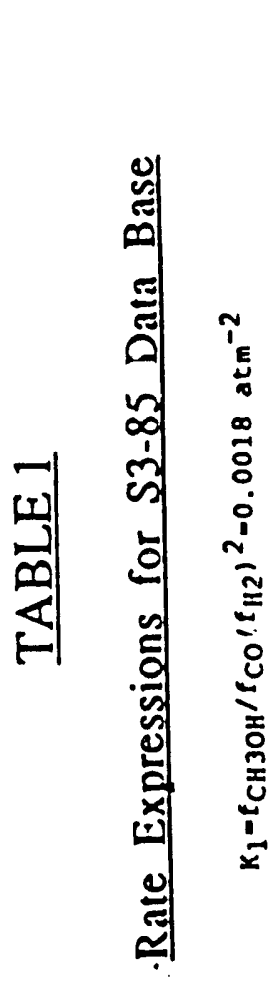

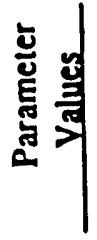
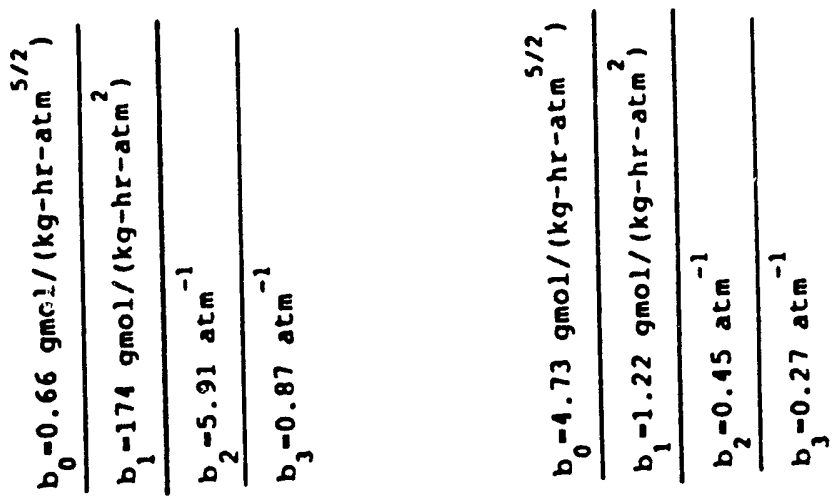

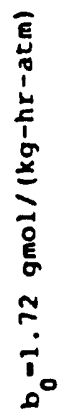
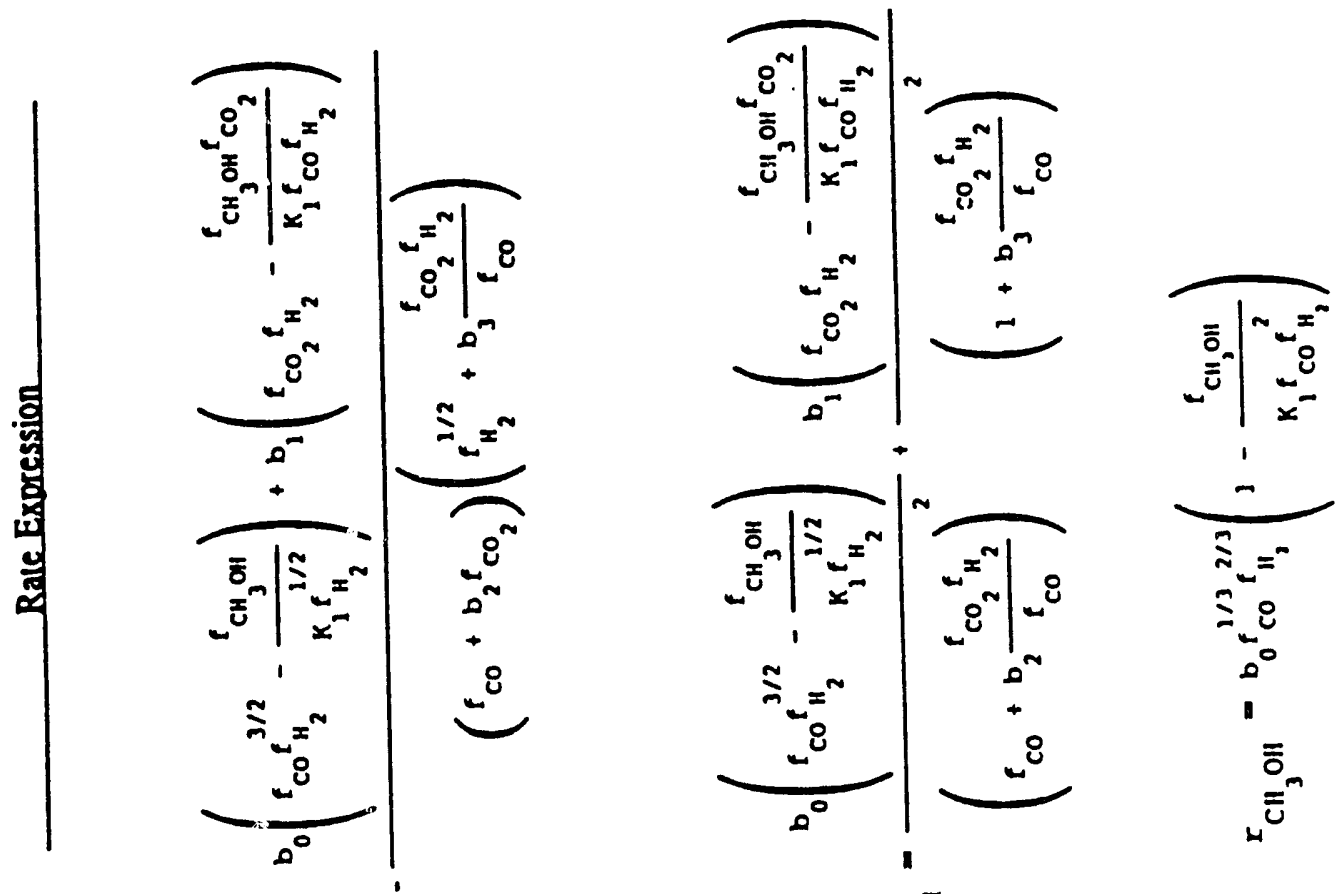

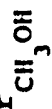
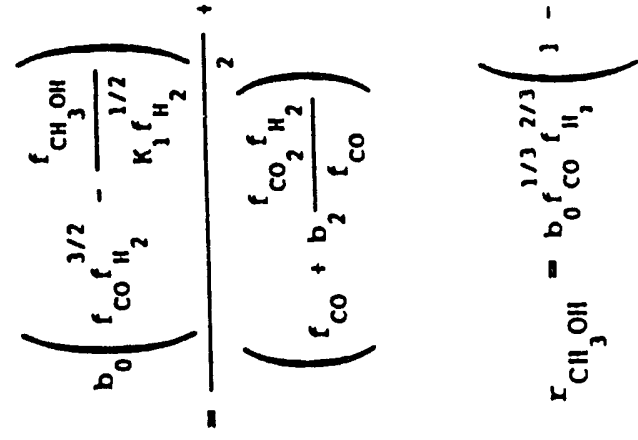

喜逻

ฐ

톰 


\section{PARITY PLOT}

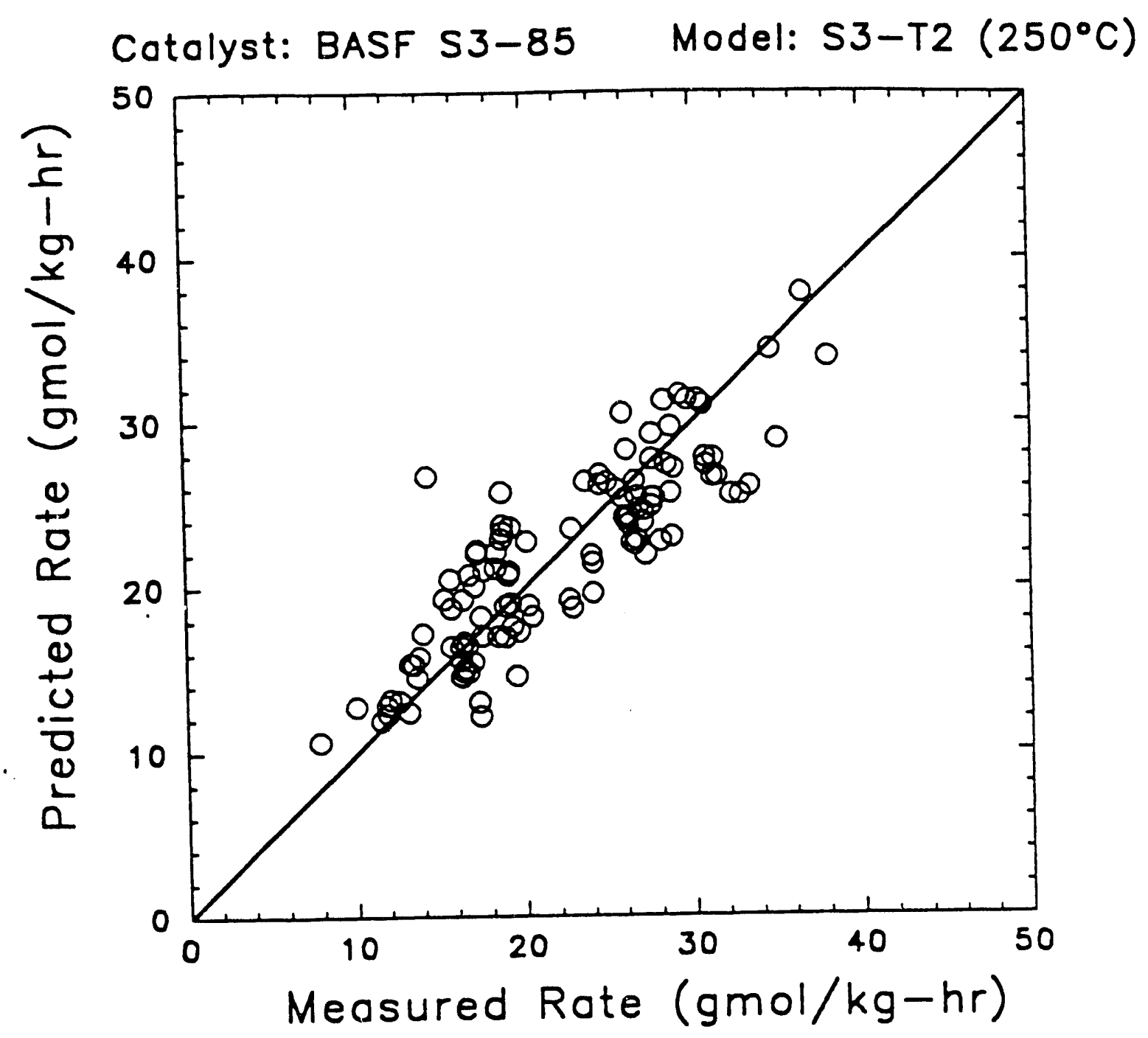


Rate vs. Exit $\mathrm{CO}_{2}$ Concentration Texaco Gas, 5.27MPo, 5,000 GHSV Catalyst: BASF S3-85 Model: S3-T2 $\left(250^{\circ} \mathrm{C}\right)$

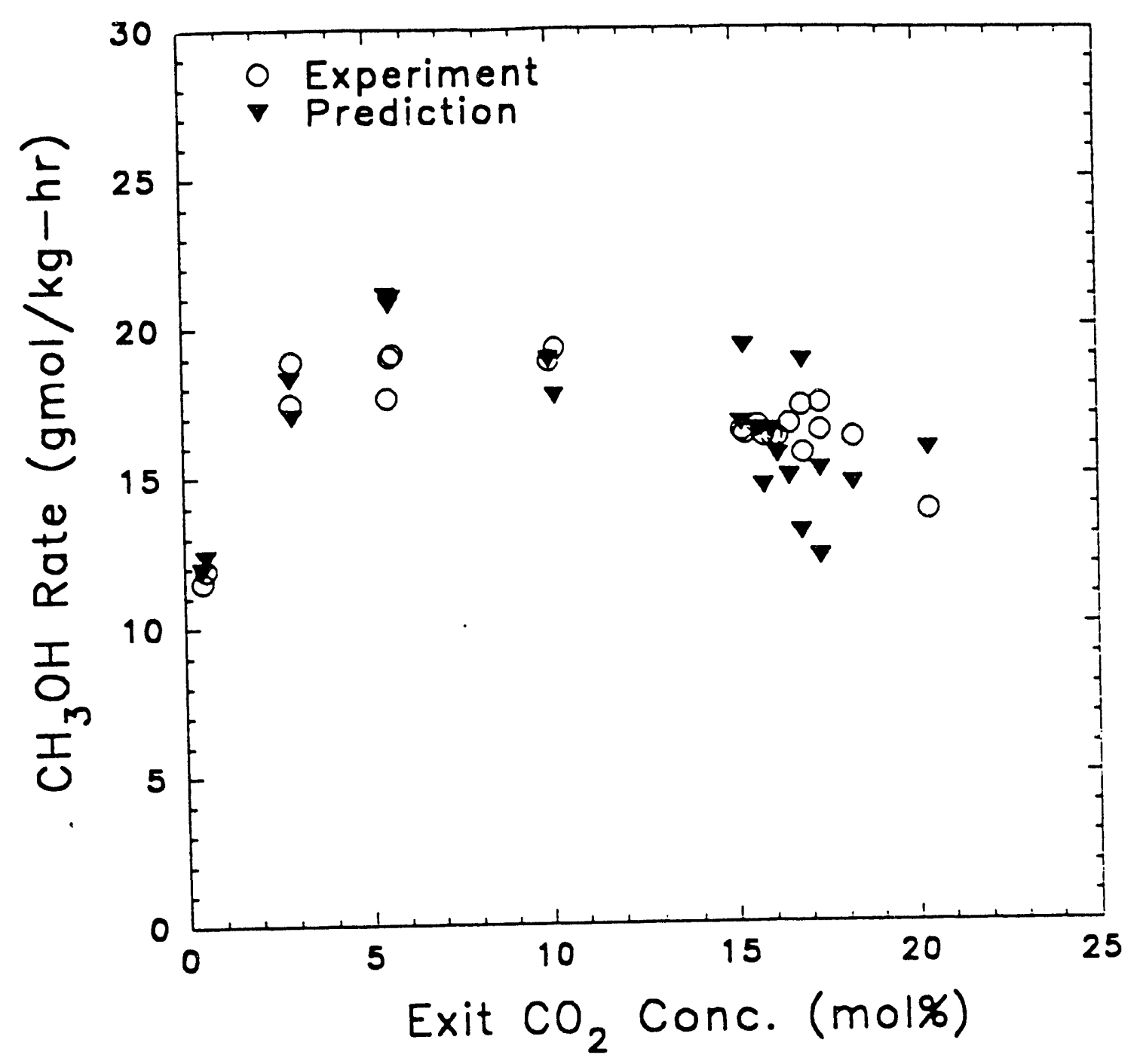




\section{EIGURE 4}

Rate vs. Exit $\mathrm{CO}_{2}$ Concentration Texaco Gos, 5.27MPo, 10,000 GHSV Cotalyst: BASF S3-85 Model: S3-T2 $\left(250^{\circ} \mathrm{C}\right)$

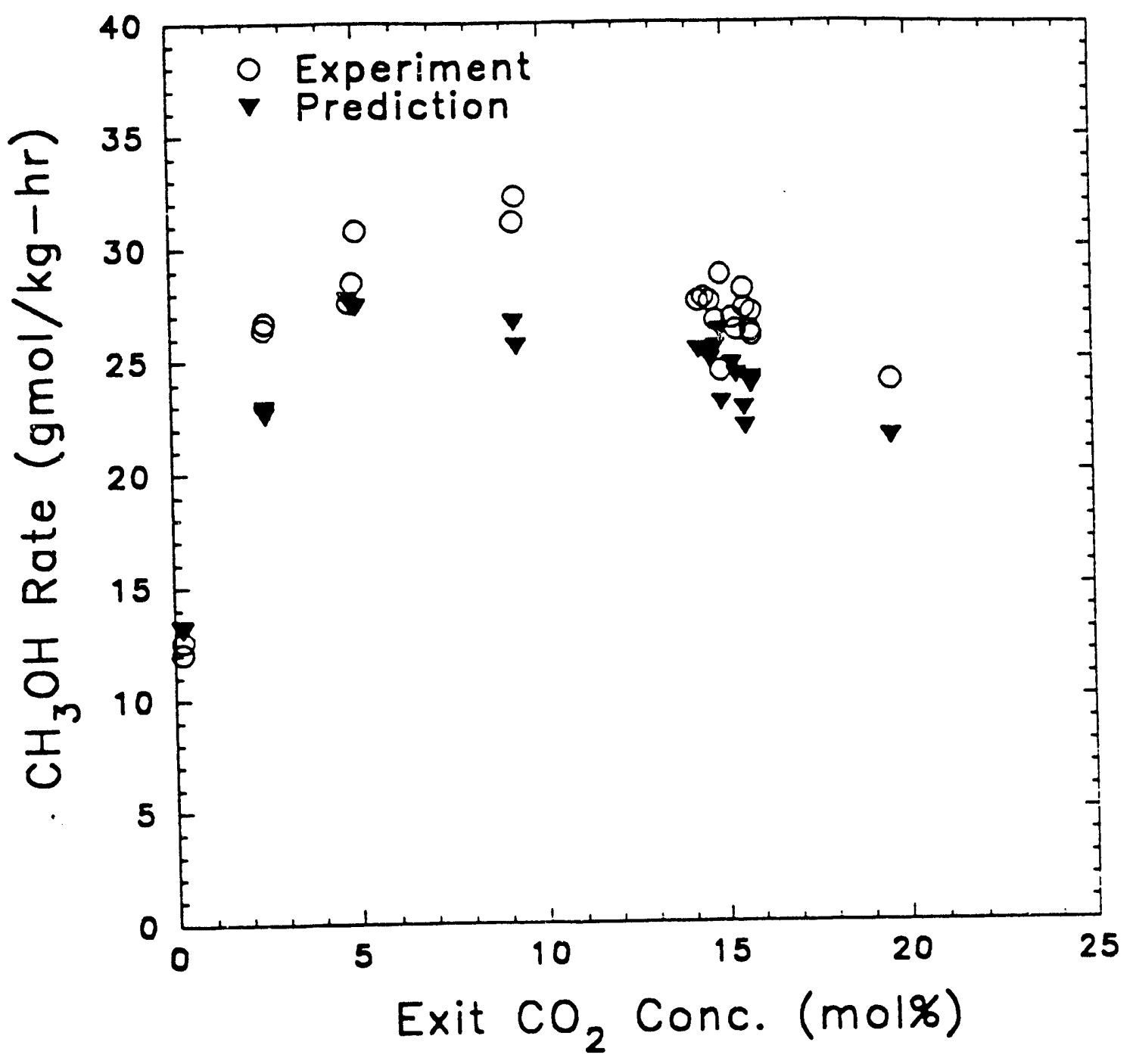


measured and predicted is observed; as expected from the form of the rate trpression, the model quite adequately predicts the trend. Figures 5 and 6 show measured and predicted rates for $\mathrm{H}_{2} \mathrm{O}$ feed addition to Texaco gas with 0 mol\% feed $\mathrm{CO}_{2}$ at 5,000 GHSV and 10,000 GHSV, respectively. At 5,000 GHSV, it appears that the predicted increase in rate with $\mathrm{H}_{2} \mathrm{O}$ addition is steeper than that measured. Figures 7 and 8 show measured and predicted rates for $\mathrm{H}_{2} \mathrm{O}$ addition to Texaco gas with $13 \mathrm{~mol} \% \mathrm{CO}_{2}$. At 10,000 GHSV, the model predicts a slight increase in rate with $\mathrm{H}_{2} \mathrm{O}$ addition, while the experimental results indicate the opposite. Measured and predicted rates for $\mathrm{H}_{2} \mathrm{O}$ addition to the Shell gas matrix at 5,000 GHSV and 10,000 GHSV are shown in Figures 9 and 10, respectively. Again, at 10,000 GHSV, the model predicts a steeper rise in rate with increased feed $\mathrm{H} 2 \mathrm{O}$ concentration. The rate is somewhat overpredicted at 5,000 GHSV across the range of feed $\mathrm{H} 2 \mathrm{O}$ concentration.

Some important points regarding characteristics of the data base which affect the quality of the fit for model S3-T2 are worth mentioning. First, the approximate measurement accuracy and reproducibility for a particular observation is approximately $5 \%$. Thus, a model is not expected to have a prediction accuracy greater than this. Second, the data base consists of data obtained for various times on stream and reaction histories. Some deactivation of the catalyst was observed during the typical time on stream (generally a few hundred hours). Typically, the catalyst would deactivate by $5 \%$ before being taken off line. No attempt was made to correct the data for deactivation, nor was there any attempt to account for deactivation in the model. Finally, the rate expression S3-T2, because of its mathematical form, is particularly sensitive to errors in gas composition measurements (fugacities). This can be understood by considering the "driving force" terms in the numerator of the rate expression. Each driving force term consists of a forward and reverse reaction term. For a large fraction of the different reaction conditions in the data base, the methanol synthesis reaction is fairly close to equilibrium. Typically, the difference between the forward and reverse terms is ccinparable in magnitude to each of the terms. Thus, small gas composition measurement error, particularly with $\mathrm{H}_{2}$, may cause larger amplitude errors in the rate predictions.

With the above points taken into account, a large fraction of the average absolute prediction error of $12.9 \%$ for model S3-T2 can be attributed to the characteristics of the data base. However, it is important to note that some trends, including the effect of feed $\mathrm{H}_{2} \mathrm{O}$ addition, are not accurately predicted. This probably means that the model needs improvement and is an oversimplification of reality. Certainly the basic Langmuir-Hinshelwood treatment is intrinsically a simplification. Another possible deficiency of the model is the assumption of water-gas shift equilibrium. Though the S3-85 methanol catalyst is very effective in catalyzing the water-gas shift reaction, the possibility exists that even a small deviation from equilibrium may have a large effect on the methanol rate. In fact, the lack of accuracy in predicting the effect of feed $\mathrm{H}_{2} \mathrm{O}$ addition may very well be attributed to this. Further work in model development may yield a better rate expression for methanol synthesis on S3-85.

\section{Expansion of the Data Base for S3-86:}

In order to expand the S3-86 data base, while also obtaining important data on simulated Great Plains gas, the effect of GHSV on $\mathrm{CH}_{3} \mathrm{OH}$ rate was measured for the $\mathrm{H}_{2}$-rich Great Plains gas matrix with $0.5 \mathrm{~mol} \%$ and $5 \mathrm{~mol} \%$ feed $\mathrm{CO}_{2}$. The intent was to scan as broad a range of GHSV as practical 
FIGURE 5

Rate vs. Feed $\mathrm{H}_{2} \mathrm{O}$ Concentration Texaco Gas with 0 mol\% Feed $\mathrm{CO}_{2}, 5.27 \mathrm{MPo}, 5,000$ GHSV Cotalyst: BASF S3-85 Model: S3-T2 $\left(250^{\circ} \mathrm{C}\right)$

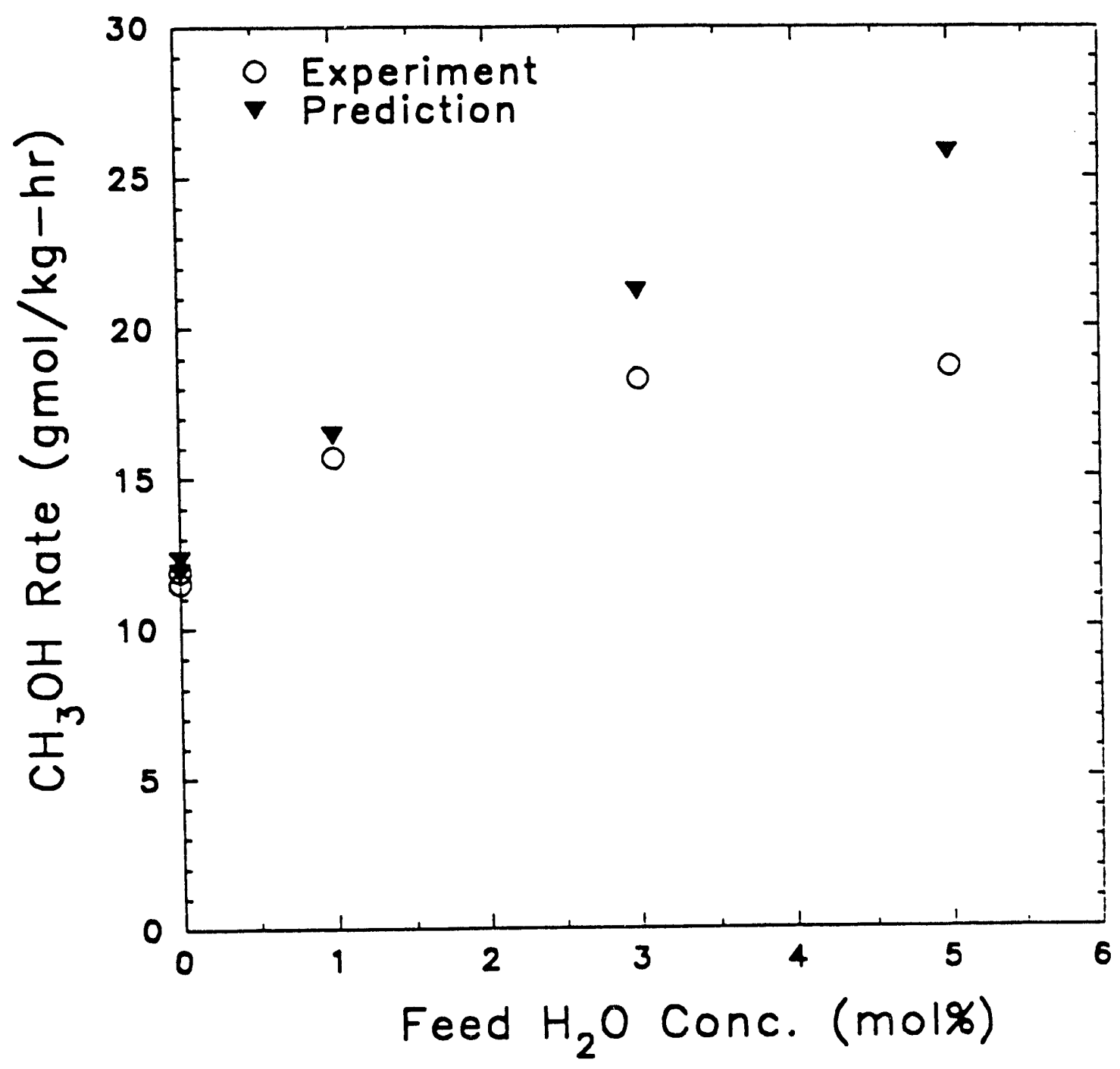




\section{FIGURE 6}

Rate vs. Feed $\mathrm{H}_{2} \mathrm{O}$ Concentration Texaco Gas with 0 mol\% Feed $\mathrm{CO}_{2}, 5.27 \mathrm{MPa}, 10,000$ GHSV Cotalyst: BASF S3-85 Model: S3-T2 $\left(250^{\circ} \mathrm{C}\right)$

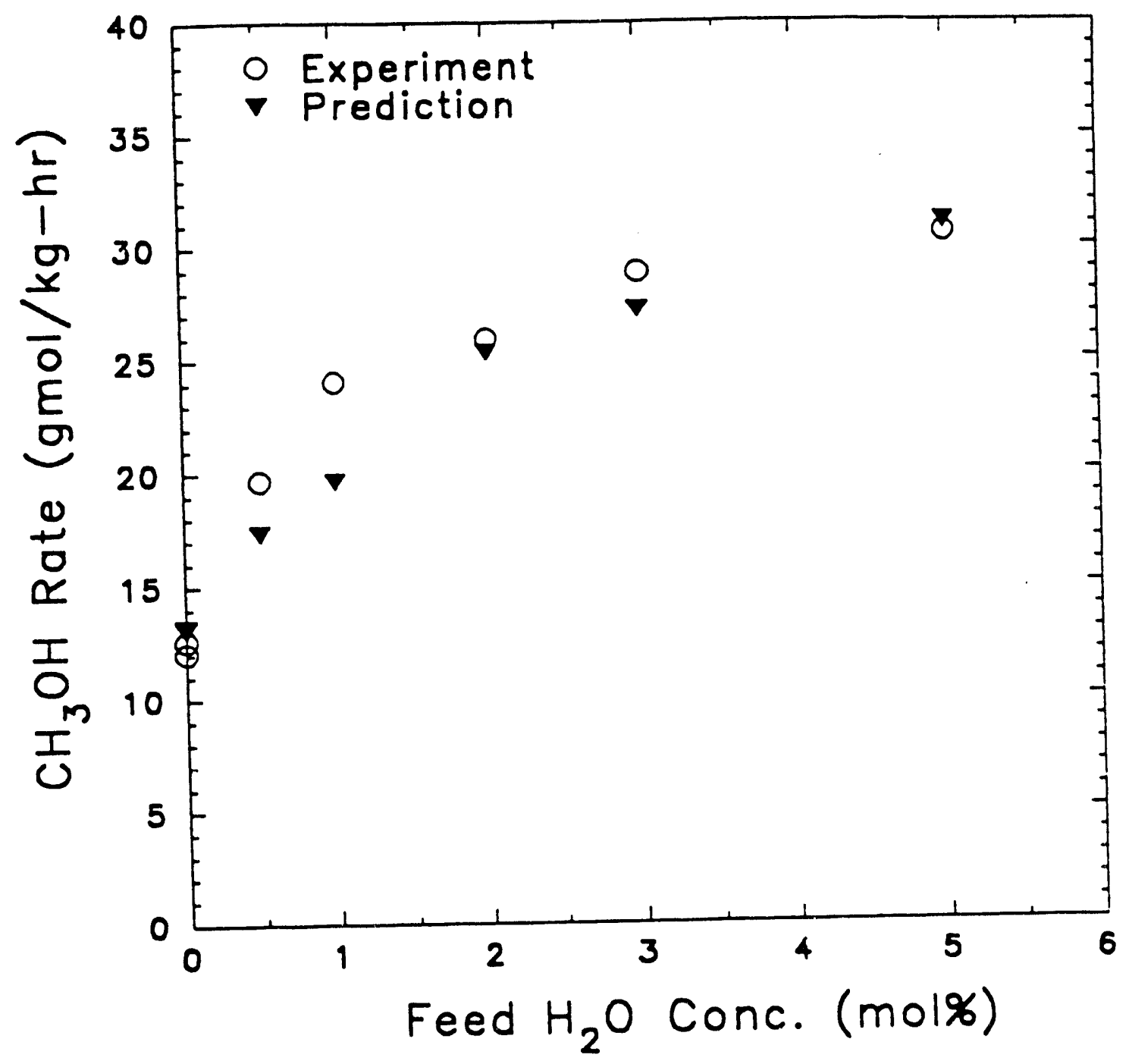




\section{FIGURE ?}

Rate vs. Feed $\mathrm{H}_{2} \mathrm{O}$ Concentration Texaco Gos with 13 molo Feed $\mathrm{CO}_{2}, 5.27 \mathrm{MPa}, 5,000 \mathrm{GHSV}$ Cotolyst: BASF S3-85 Model: S3-T2 (250 $\mathrm{C}$ )

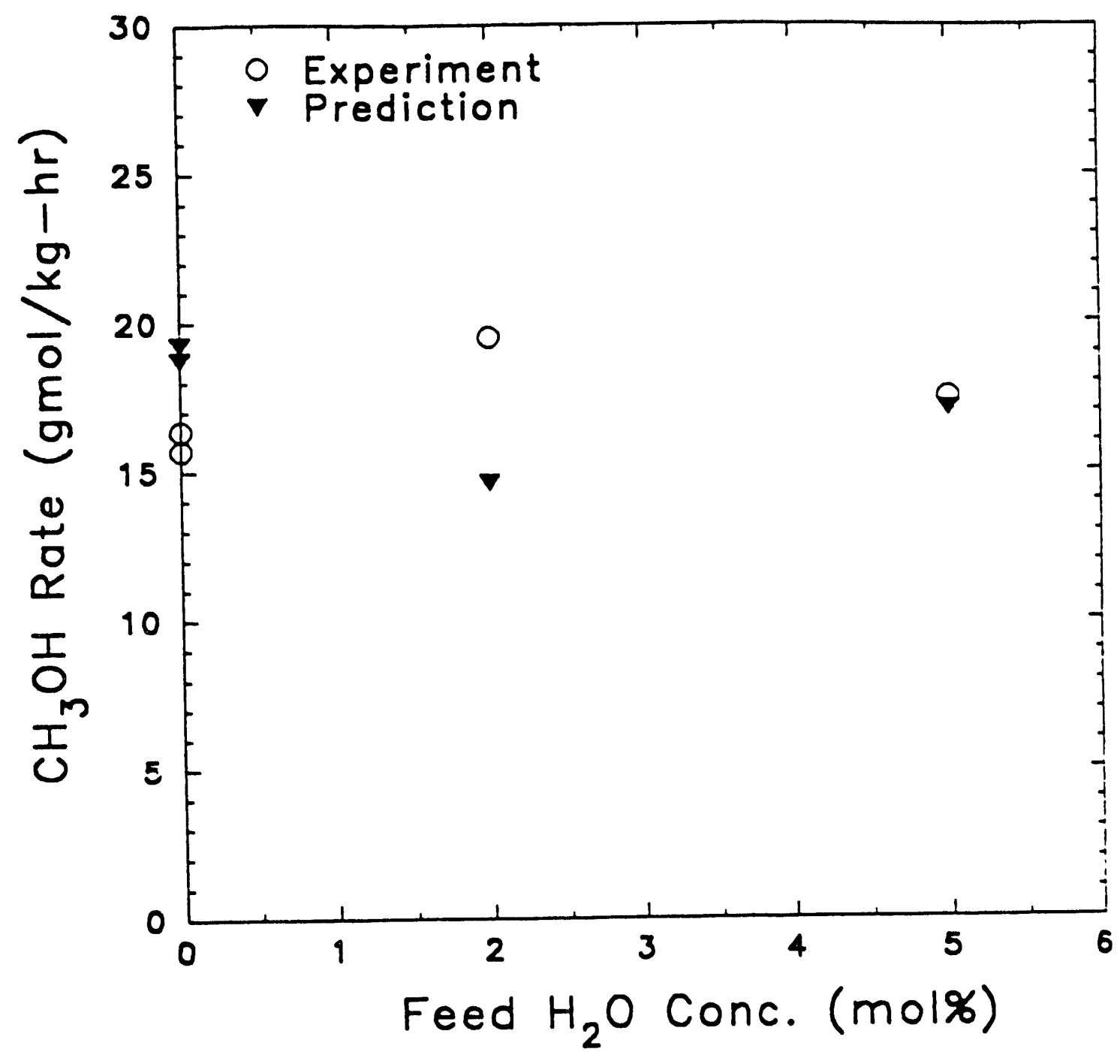


EIGURE 8

Rate vs. Feed $\mathrm{H}_{2} \mathrm{O}$ Concentration

Texoco Gos with 13 molx feed $\mathrm{CO}_{2}, 5.27 \mathrm{MPo}, 10,000$ GHSV Catalyst: BASF S3-85 Model: S3-T2 $\left(250^{\circ} \mathrm{C}\right)$

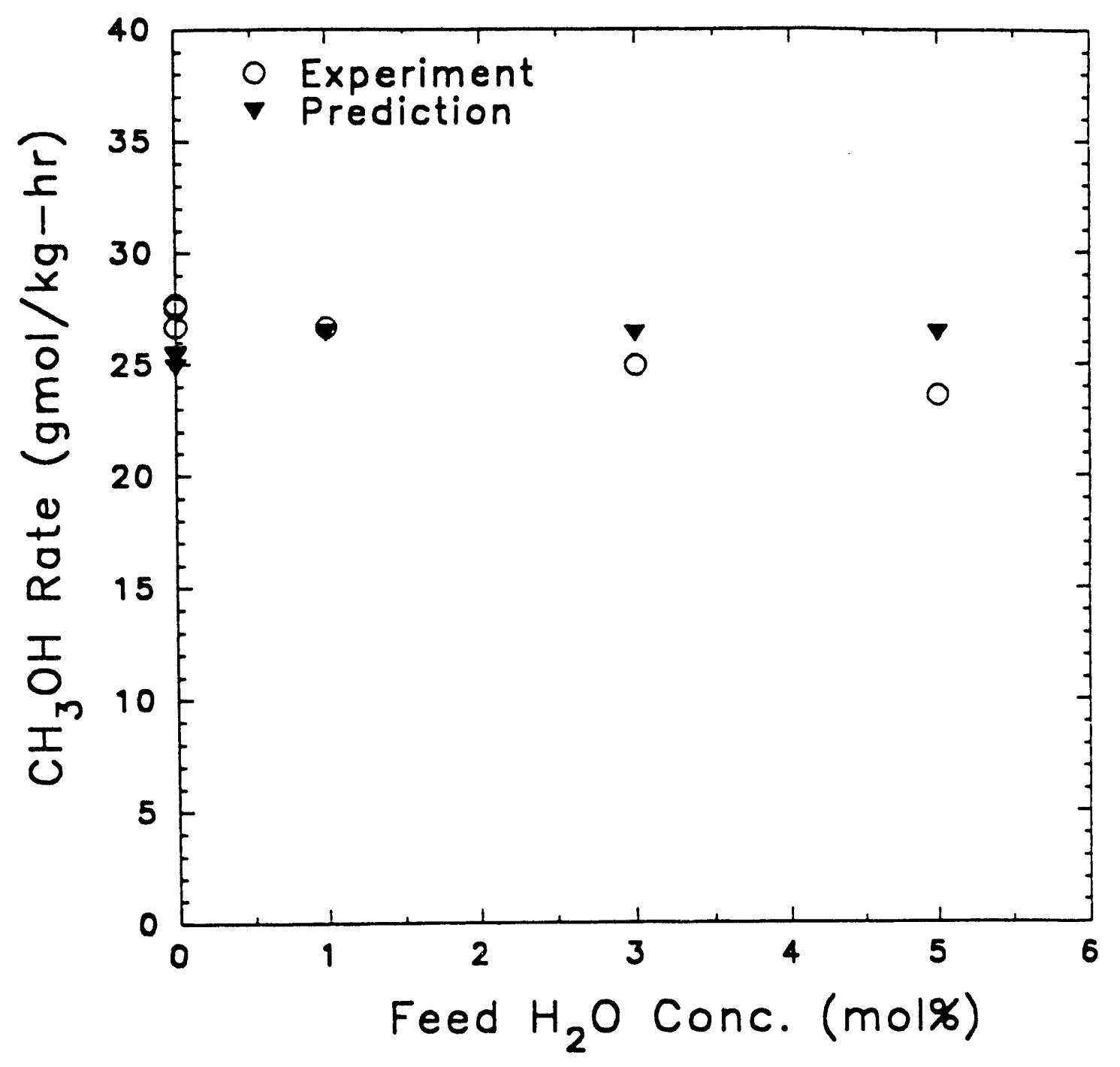


EIGURE 9

Rate vs. Feed $\mathrm{H}_{2} \mathrm{O}$ Concentration Shell Gos 5.27MPo, 5,000 GHSV Catalyst: BASF S3-85 Model: S3-T2 $\left(250^{\circ} \mathrm{C}\right)$

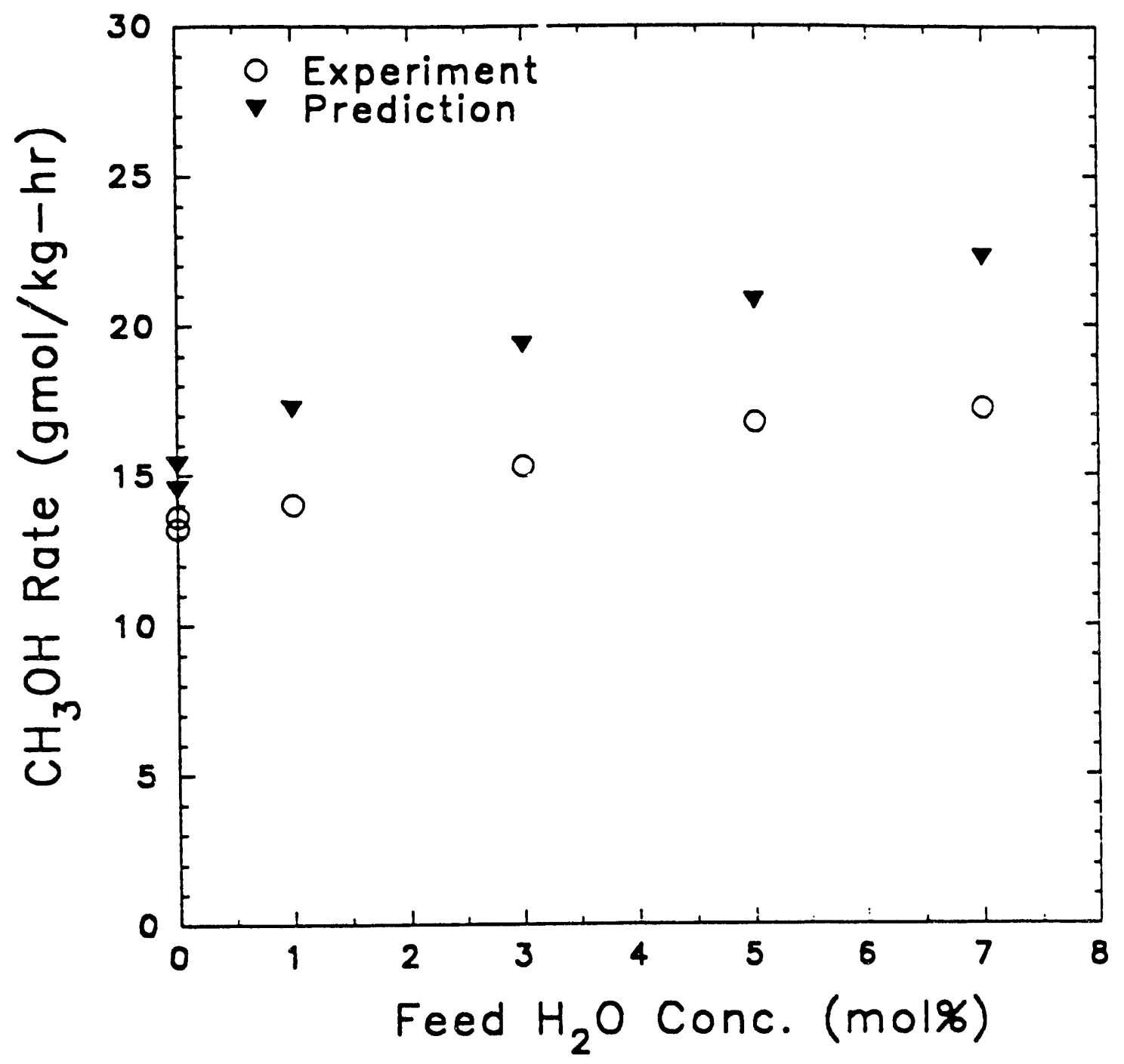




\section{EIGURE 10}

Rate vs. Feed $\mathrm{H}_{2} \mathrm{O}$ Concentration Shell Gas 5.27MPa, 10,000 GHSV Catalyst: BASF S3-85 Model: S3-T2 $\left(250^{\circ} \mathrm{C}\right)$

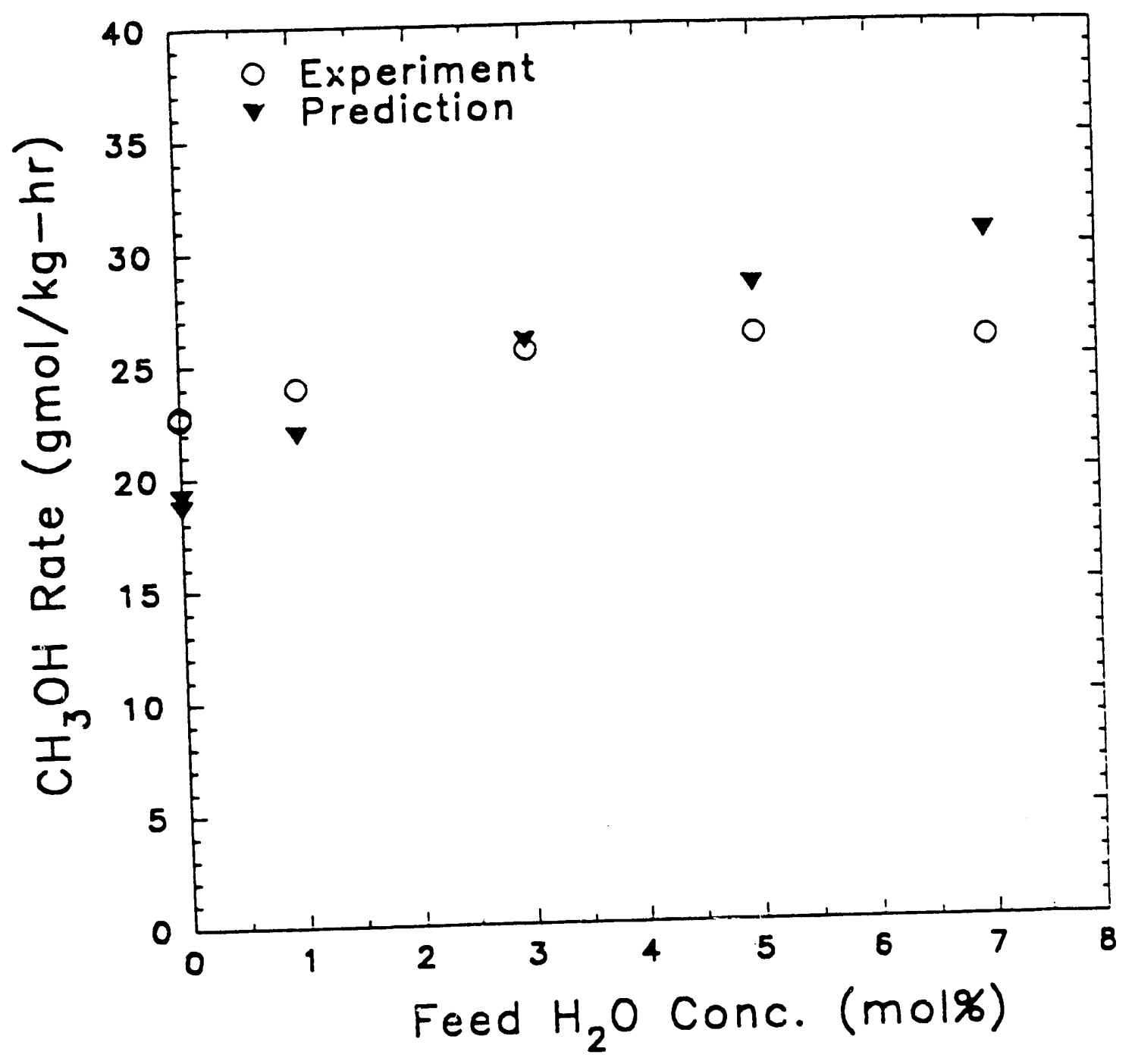


in order to provide design data, while at the same time obtaining broad range data that would be a critical test for a reaction model.

Figure 11 shows the effect of GHSV on methanol rate at $5.27 \mathrm{MPa}$ and $250^{\circ} \mathrm{C}$ for Great Plains gas with $0.5 \mathrm{~mol} \%$ feed $\mathrm{CO}_{2}$, that is, no $\mathrm{CO}_{2}$ addition or removal. The rate was measured at gas-hourly space velocities ranging from 5,000 to $25,000 \mathrm{std}$. lit./kg-hr. The methanol rate increased from 18 to $38 \mathrm{gmol} / \mathrm{kg}$ - $\mathrm{hr}$ across this range of GHSV. Comparison with data obtained for Texaco gas at the same conditions indicates that the methanol rate is approximately the same at 5,000 GHSV. However, at higher GHSV, rates observed for Texaco gas are higher. At 10,000 GHSV, the rate for Texaco gas is 32 gmol/kg-hr, while the corresponding rate for Great Plains gas is $25 \mathrm{gmol} / \mathrm{kg}-\mathrm{hr}$. Figure 12 shows $\mathrm{CH}_{3} \mathrm{OH}$ rate at $5.27 \mathrm{MPa}$ and $250^{\circ} \mathrm{C}$ as a function of GHSV for Great Plains gas with $\mathrm{CO}_{2}$ added to the feed at a level of $5 \mathrm{~mol} \%$. Comparison with data of Figure 11 for $0.5 \mathrm{~mol} \%$ feed $\mathrm{CO}_{2}$ indicates that $\mathrm{CO}_{2}$ addition dramatically increases the methanol rate across the GHSV range. For example, at $10,000 \mathrm{GHSV}$, the $\mathrm{CH}_{3} \mathrm{OH}$ rate is $62 \%$ higher for $5 \mathrm{~mol} \%$ feed $\mathrm{CO}_{2}$.

Figure 13 shows the effect of GHSV for the 5 mol\% feed $\mathrm{CO}_{2}$ Great Plains gas at a higher reaction pressure, $7.34 \mathrm{MPa}$ (1050 psig). Comparison with Figure 12 shows that higher reaction pressure increases the $\mathrm{CH}_{3} \mathrm{OH}$ rate across the range of GHSV. At $10,000 \mathrm{GHSV}$, the measured $\mathrm{CH}_{3} \mathrm{OH}$ rate at $7.34 \mathrm{MPa}$ is $48.5 \mathrm{gmol} / \mathrm{kg}-\mathrm{hr}$ compared to $38.2 \mathrm{gmol} / \mathrm{kg}-\mathrm{hr}$, an increase of $27 \%$.

The effect of reaction temperature for the $5 \mathrm{~mol} \% \mathrm{CO}_{2}$ Great Plains gas at $7.34 \mathrm{MPa}$ was explored using a GHSV of 10,000 std.lit./kg-hr. Figure 14 shows results obtained for $235^{\circ} \mathrm{C}$ and $255^{\circ} \mathrm{C}$, in addition to the $250^{\circ} \mathrm{C}$ data. The methanol rates measured at $235^{\circ} \mathrm{C}$ and $255^{\circ} \mathrm{C}$ are both lower than that observed at $250^{\circ} \mathrm{C}$.

The data from Figures 11-13 were entered into the S3-86 data base to be used in the model development. The $235^{\circ} \mathrm{C}$ and $255^{\circ} \mathrm{C}$ data points were entered into the data base but were not used in the model development since the data fits were confined to the $250^{\circ} \mathrm{C}$ data, as mentioned earlier.

\section{Modeling of S3-86 Catalyst Data Base:}

Some of the more accurate rate expressions developed for the S3-85 data base were fit to the S3-86 data base. The best-fit parameters were determined using the same technique as that for the S3-85 data base. However, the rate expressions which provided the best fit for the S3-85 data base, yielded poor fits for the S3-86 data base. For example, Models A3-C2 and S3-T2, previously identified in Table 1 in the discussion of the results for S3-85, gave poor fits of the S3-86 data base. The best-fit residual sums of squares for Models A3-C2 and S3-T2 were 7,923 gmol/kg-hr and $6,603 \mathrm{gmol} / \mathrm{kg}-\mathrm{hr}$, respectively. Corresponding to these residual sums of squares are average absolute errors per observation of $34.3 \%$ for model A3-C2 and $26.3 \%$ for model S3-T2. Recall that models A3-C2 and S3-T2 yielded average errors per observation of $13.8 \%$ and $12.9 \%$, respectively, for the S3-85 data base. The reason for the poorer fit for the S3-86 data base is probably because the breadth of the S3-86 data base provides a much more discriminating test of the general validity of the model. These rate expressions may provide a good representation of a limited "CO-rich" data base, such as that of $\$ 3-85$, but are quite deficient for the broader $\$ 3-86$ data base, which includes extensive data for $\mathrm{H}_{2}$-rich Great Plains gas.

To find a better model, a variety of other derived rate expressions were investigated for the S3-86 data base. Many of these rate expressions were similar to those investigated for the S3-85 data base. 
$\mathrm{CH}_{3} \mathrm{OH}$ Rate vs. GHSV

Great Plains Gas $\left(0.5 \mathrm{~mol} \mathrm{CO}_{2}\right), 5.27 \mathrm{MPa}, 250^{\circ} \mathrm{C}$ Cotalyst: BASF S3-86

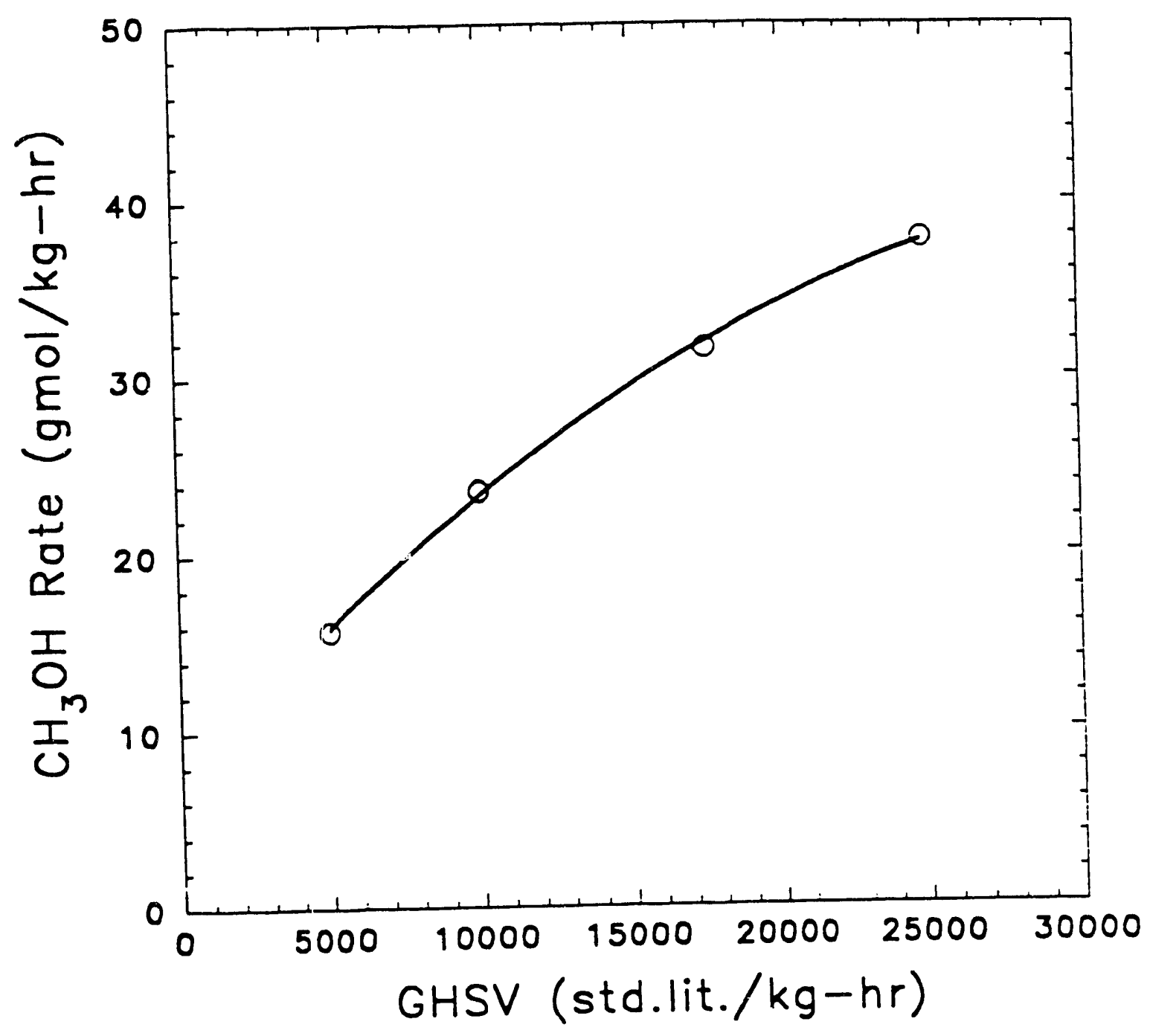




\section{$\mathrm{CH}_{3} \mathrm{OH}$ Rate vs. GHSV}

Great Plains Gas $\left(5.0\right.$ molx $\left.\mathrm{CO}_{2}\right), 5.27 \mathrm{MPo}, 250^{\circ} \mathrm{C}$ Catalyst: BASF S3-86

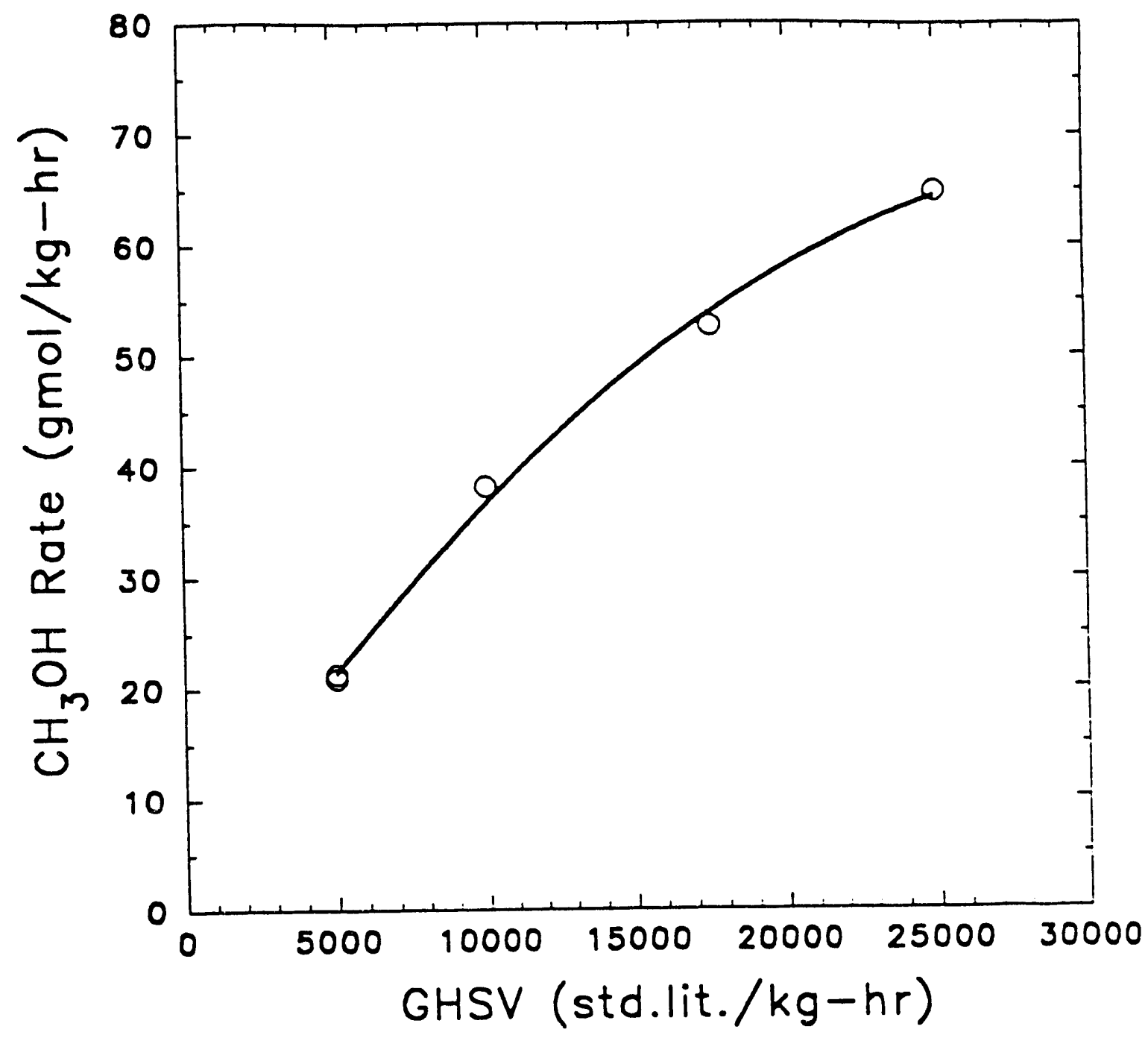




\section{$\mathrm{CH}_{3} \mathrm{OH}$ Rate vs. GHSV}

Great Plains Gas $\left(5.0 \mathrm{~mol} \% \mathrm{CO}_{2}\right), 7.34 \mathrm{MPa}, 250^{\circ} \mathrm{C}$ Cotalyst: BASF S3-86

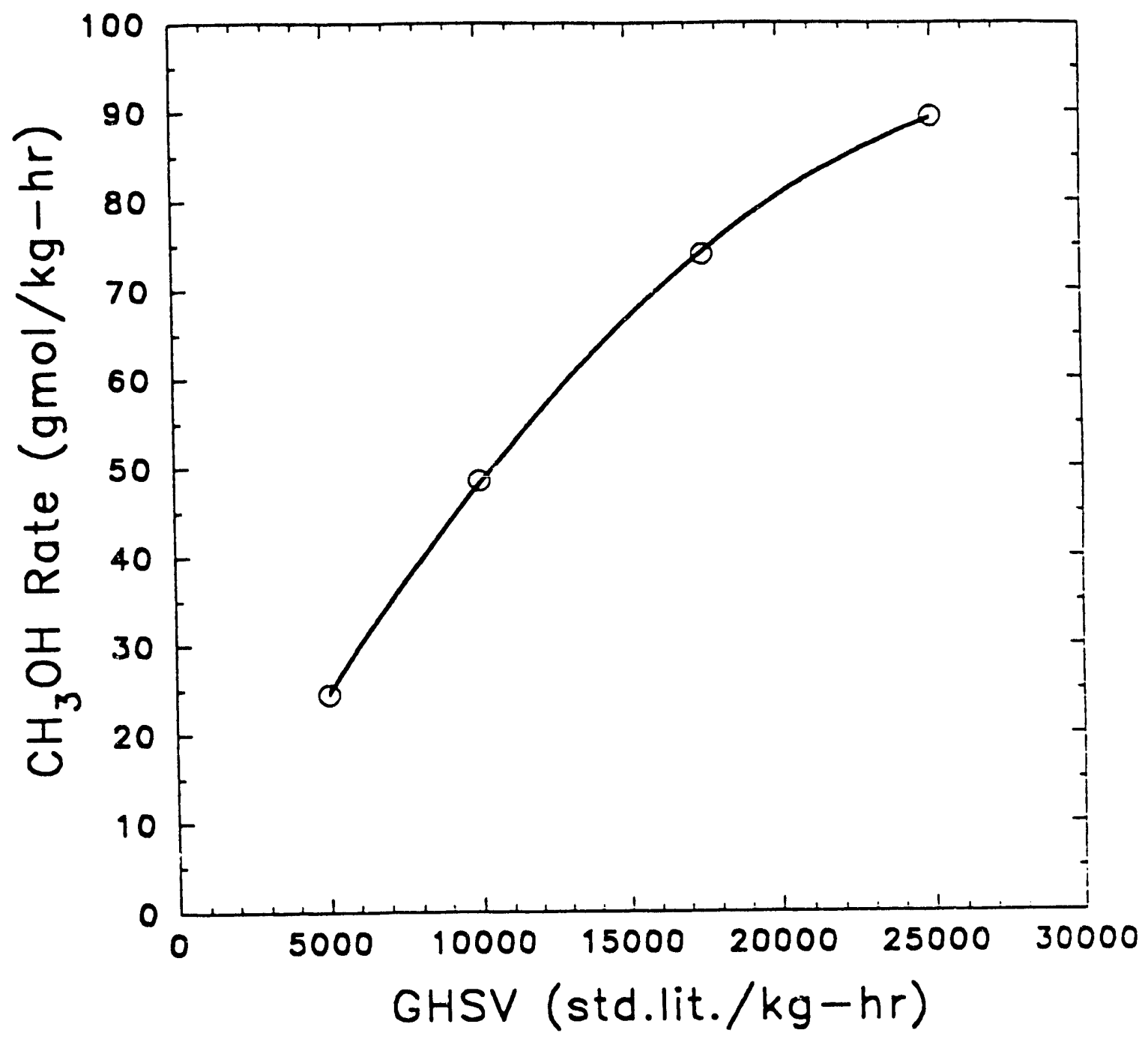




\section{EIGURE 14}

$\mathrm{CH}_{3} \mathrm{OH}$ Rate vs. Temperature Great Plains Gas (5.0 mol\% $\left.\mathrm{CO}_{2}\right), 7.34 \mathrm{MPa}, 10,000 \mathrm{GHSV}$ Cotolyst: BASF S3-86

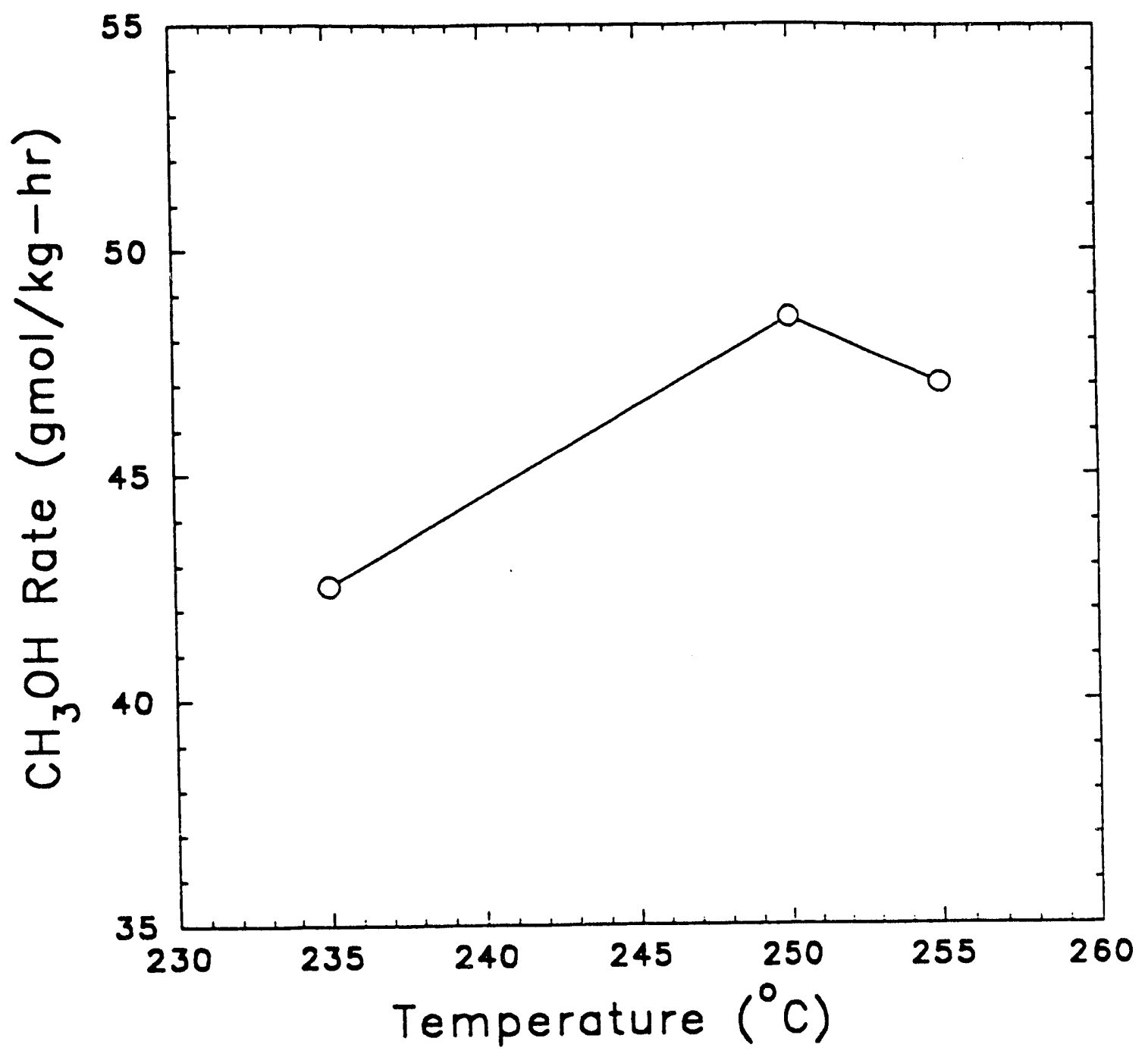


For example, rate expressions were derived from the mechanism of Graaf et al. ${ }^{(9)}$, like model A3$C 2$, but with different RDSs and assumptions regarding the dominant adsorbed species. Also, rate expressions derived assuming that $\mathrm{CO}$ and $\mathrm{CO}_{2}$ are stepwise hydrogenated on separate sites (like model S3-T2) were fit to the data, also with a variety of different assumptions regarding the RDSs and adsorption characteristics. Noteworthy is the fact that, in general, rate expressions derived assuming that $\mathrm{CO}$ and $\mathrm{CO}_{2}$ are hydrogenated on separate sites fit the data base better than those derived assuming that $\mathrm{CO}_{2}$ and $\mathrm{CO}_{2}$ are hydrogenated on the same site. However, this fact by itself does not provide sufficient evidence that the actual mechanism involves $\mathrm{CO}$ and $\mathrm{CO}_{2}$ hydrogenation on separate sites. The reason for the better fits may be purely a result of the particular mathematical form of the rate expressions.

Another noteworthy reaction mechanism that was considered involves the formation of formate, a species known to exist on operating methanol synthesis catalysts, from the surface reaction of adsorbed $\mathrm{CO}$ and $-\mathrm{OH}$. The formate intermediate then undergoes hydrogenation to $\mathrm{CH}_{3} \mathrm{OH}$ in a series of steps. The - $\mathrm{OH}$ intermediate is either present on the $\mathrm{ZnO}$ surface or formed from the hydrogenation of $-\mathrm{O}$ from $\mathrm{CO}_{2}$ dissociation. Langmuir-Hinshelwood rate expressions derived from this mechanism are quite similar in form to those obtained from the above mentioned mechanisms. Rate expressions derived from this mechanism did not fit the data base as well as the best model identified, which is discussed below.

The best model found in this work, designated XX14 and shown in Table 2, was derived from same basic mechanism as that used in the derivation of model S3-T2 for S3-85. Recall that model S3-T2 was derived from a mechanism which assumes that $\mathrm{CO}$ and $\mathrm{CO}_{2}$ are hydrogenated in parallel on separate sites. However, model XX14 has different rate determining steps and different adsorption characteristics than model S3-T2 for S3-85. The different RDSs result in different numerators in the Langmuir-Hinshelwood rate expression, while the different adsorption characteristics result in unique denominators. Specifically, for model XX14, the addition of the first hydrogen atom is the $\mathrm{RDS}$ for $\mathrm{CO}$ hydrogenation and the addition of the fourth hydrogen atom is the RDS for $\mathrm{CO}_{2}$ hydrogenation. The adsorption is assumed to be such that the most abundant species on the site that $\mathrm{CO}$ is hydrogenated are $\mathrm{CH}_{3} \mathrm{OH}, \mathrm{H}_{2} \mathrm{O}$, and vacancies, while the site on which $\mathrm{CO}_{2}$ is hydrogenated is assumed to be dominated by $\mathrm{CH}_{3} \mathrm{OH}, \mathrm{CO}_{2}$, and vacancies. The result of these assumptions is the six paramerer model shown in Table 2 . The best-fit residual sum of squares is 2,083 , corresponding to an average absolute error per observation of $15.3 \%$.

Also, shown in Table 2 for comparison are the results of fitting the S3-86 data base to rate expressions from the literature. However, note that these rate expressions were cast in terms of fugacities and the assumption of water-gas shift equilibrium was incorporated as required. The parameters in these rate expressions were made adjustable and were determined by the fit. The three rate expressions shown in Table 2 were selected from the literature because they specifically take into account the effect of $\mathrm{CO}_{2}$. The model designated $\mathrm{KL}$ is an adaptation of that of Klier et al. (2), model DJ is due to Dybjaer (12), and model RK is from the recent work of Rinker et al (11). As can be seen, none of these literature rate expressions fit the S3-86 data base as well as model XX14. Model DJ, from Dybjaer et al, yielded the best fit from these rate expressions, with a residual sum of squares of 4,583 gmol/kg-hr and an average absolute error per observation of $25 \%$.

For model XX14, a compilation of the reactor exit concentrations and calculated fugacities of $\mathrm{H}_{2}$, $\mathrm{CO}, \mathrm{CO}_{2}$, and $\mathrm{CH}_{3} \mathrm{OH}$, the measured rate, the predicted rate, the residual, and the prediction error is shown in Table B-2 of Appendix B. Figure 15 shows a parity plot, predicted ys. measured $\mathrm{CH}_{3} \mathrm{OH}$ 


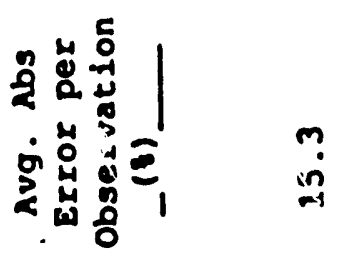

$\stackrel{\sim}{\sim}$

$\stackrel{n}{n}$

o.

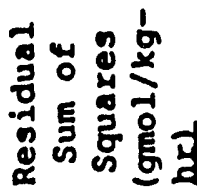

$\stackrel{m}{\infty}$

$\stackrel{0}{6}$

on

(1)

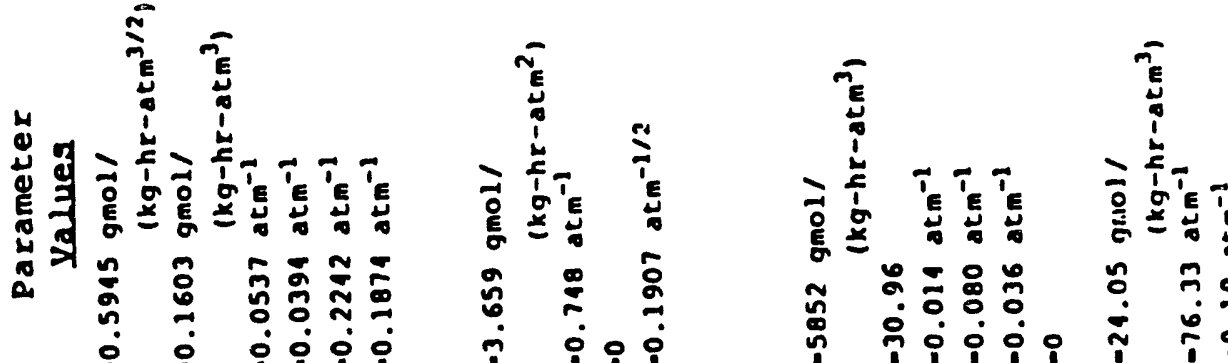
i i

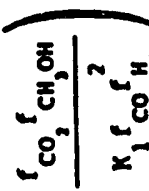

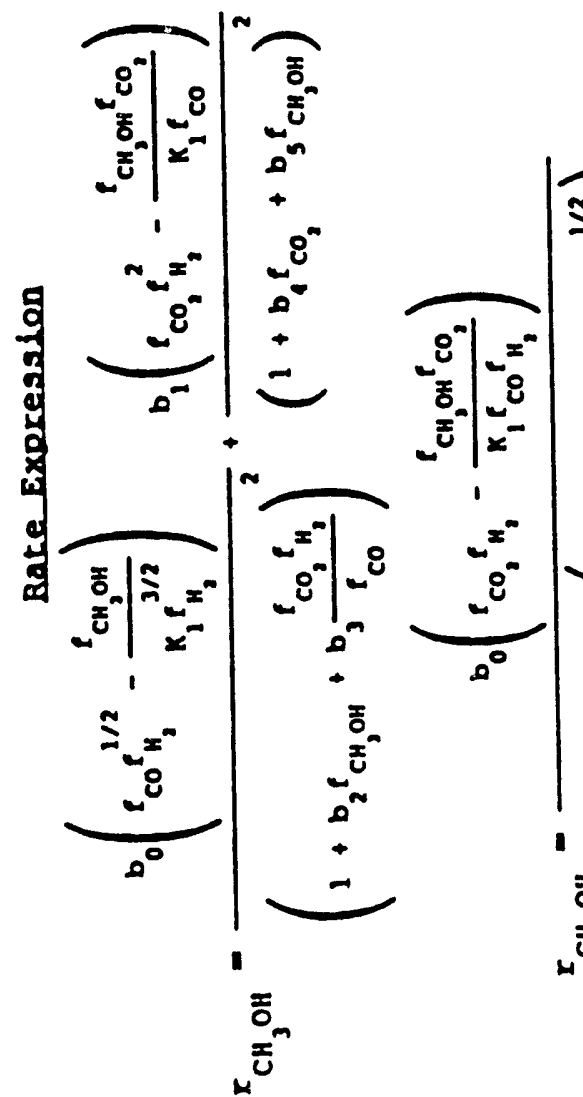

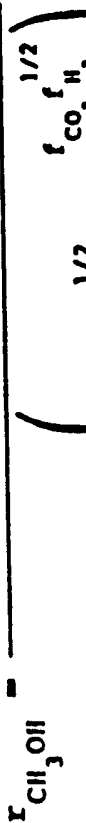

홀릴 $\frac{-}{x}$
3

$\overrightarrow{\mathbf{x}}$

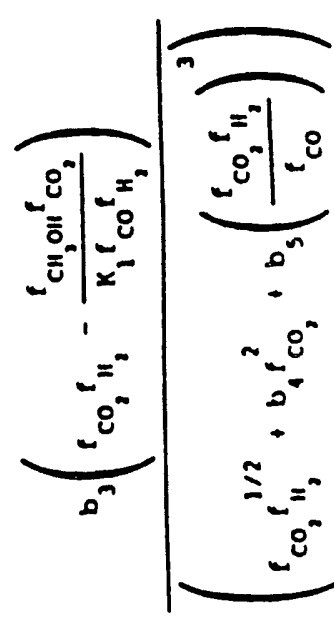

" 


\section{PARITY PLOT}

Cotolyst: BASF S3-86 Model: $x \times 14\left(250^{\circ} \mathrm{C}\right)$

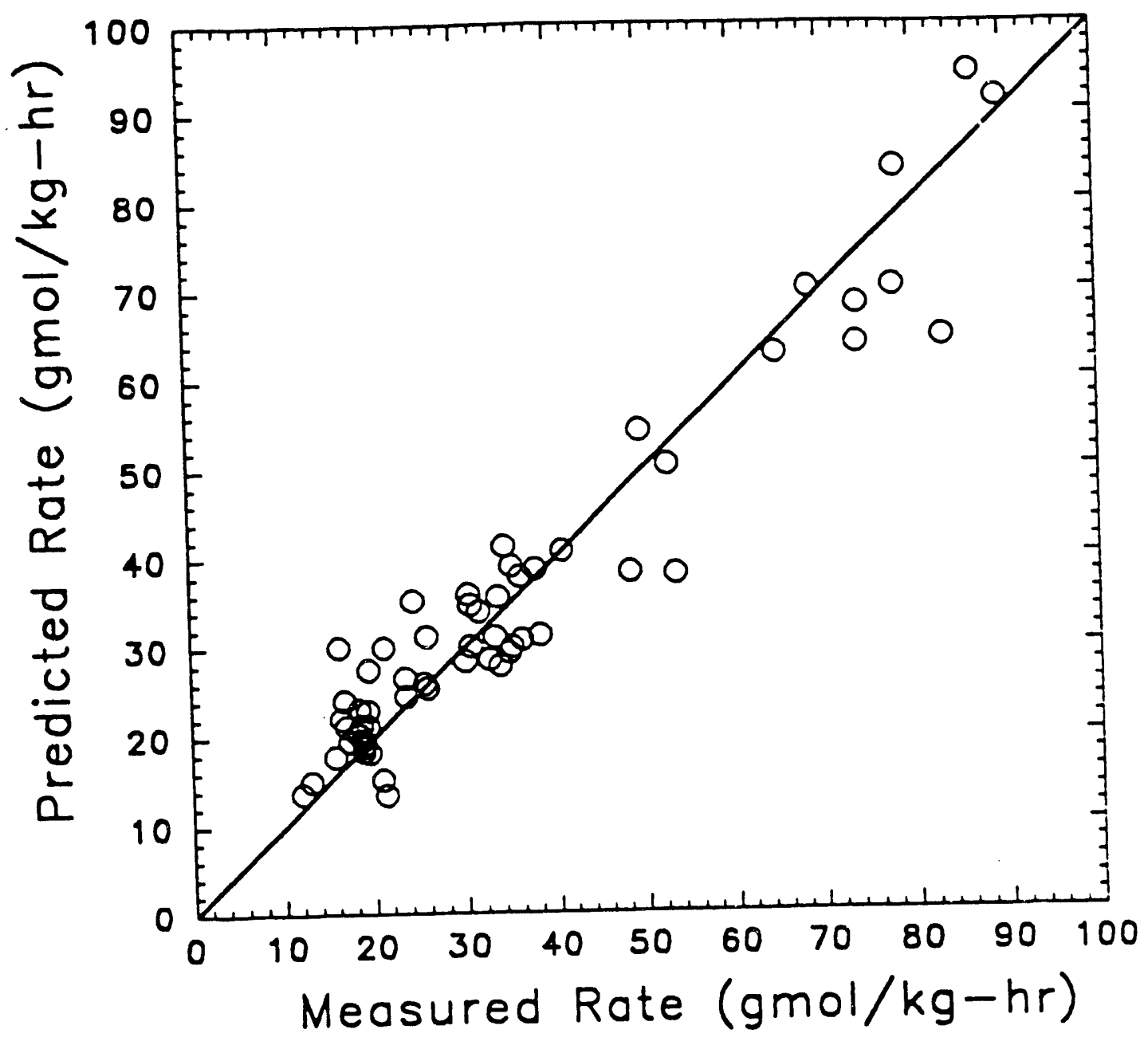


rate, for model XX14. The data are fairly evenly scattered about the $45^{\circ}$ line. However, there is a slight tendency for the model to overpredict the rate at low measured rates and underpredict the rate at the high measured rates. This results from the fact that the model tends to predict a weaker dependence of the rate on GHSV for the CO-rich gas matrices than that measured. This will be apparent in the discussion below of some of the other comparisons of measured and predicted rate.

Presented next are specific comparisons of measured trends and the corresponding predicted rates. Again, the predicted rates are based on fugacities calculated from the measured reactor exit gas composition and total pressure for each experimental observation.

Figure 16 shows, for model XX14, the measured effect of GHSV on $\mathrm{CH} 3 \mathrm{OH}$ rate and the corresponding predicted rates for Texaco gas at 5.27 MPa. The measured effect of GHSV is much steeper than that predicted by the model. Figure 17 shows the measured effect of GHSV and the corresponding predicted rates for Texaco gas at $9.75 \mathrm{MPa}$. For this pressure, there is good agreement between measured and predicted rate across the range of GHSV. The effect of GHSV on measured rate for Dow gas at $5.27 \mathrm{MPa}$, along with the model predictions, are shown in Figure 18. The predicted rates at low GHSV are generally slightly higher than the measured rates.

The effect of feed $\mathrm{CO}_{2}$ concentration on the measured rate for the Great Plains gas matrix at $5.27 \mathrm{MPa}$, along with corresponding predictions of model XX14, are shown in Figure 19. The measured rate increases dramatically with increasing $\mathrm{CO}_{2}$ concentration level at the low feed $\mathrm{CO}_{2}$ concentrations, but levels off at approximately $4-6 \mathrm{~mol} \%$ feed $\mathrm{CO}_{2}$. There are some deviations between measured and predicted rate, but the predicted trend is fairly accurate. Figure 20 shows the variation in rate with GHSV, both measured and predicted, for Great Plains gas with 0.5 mol\% feed $\mathrm{CO}_{2}$ at $5.27 \mathrm{MPa}$. Good agreement between measured and predicted rate exists across the range of GHSV. Figures 21 and 22 show the measured and predicted effect of GHSV for Great Plains gas with $5 \mathrm{~mol} \%$ feed $\mathrm{CO}_{2}$ at $5.27 \mathrm{MPa}$ and $7.34 \mathrm{MPa}$, respectively. Generally good agreement in the trend exists, but there are significant deviations between measured and predicted for some observations. The model tends to underpredict the rate, for all observations, at the lower pressure of 5.27 MPa (Figure 22).

Some additional points reg urding model XX14 are worth mentioning. As indicated earlier, the average absolute prediction error per observation for the entire $250^{\circ} \mathrm{C} \mathrm{S3-86}$ data base was determined to be $15.3 \%$. If the three runs with the highest error are not considered in calculating the average error, the accuracy improves to yield an average absolute error per observation of $13.1 \%$. This is comparable to the accuracy for S3-T2, the model developed for S3-85, which had an average absolute error per observation of $12.9 \%$. This accuracy is quite good considering the effects of experimental error, which were considered in the discussion of the S3-85 results. However, further work would probably yield a more accurate rate expression for the S3-86 data base.

Also, an interesting point to consider is the relative kinetic contribution of $\mathrm{CO}$ hydrogenation pathway and the $\mathrm{CO}_{2}$ hydrogenation pathway to the observed $\mathrm{CH}_{3} \mathrm{OH}$ rates. This can be determined by calculating the contribution of each term in the rate expression. Recall that rate expression XX14 is the sum of two terms (see Table 2). From the assumed reaction mechanism, the first term represents the $\mathrm{CH}_{3} \mathrm{OH}$ formed from $\mathrm{CO}$ hydrogenation, while the second term represents $\mathrm{CH}_{3} \mathrm{OH}$ formed from $\mathrm{CO}_{2}$. The magnitude of each of these terms was determined. For most of the experimental conditions in the data base, these two terms are approximately the same magnitude. 


\section{Rate vs. GHSV}

Texeco Gas, $5.27 \mathrm{MPO}$

Cotalyst: BASF S3-86 Model: $X \times 14\left(250^{\circ} \mathrm{C}\right)$

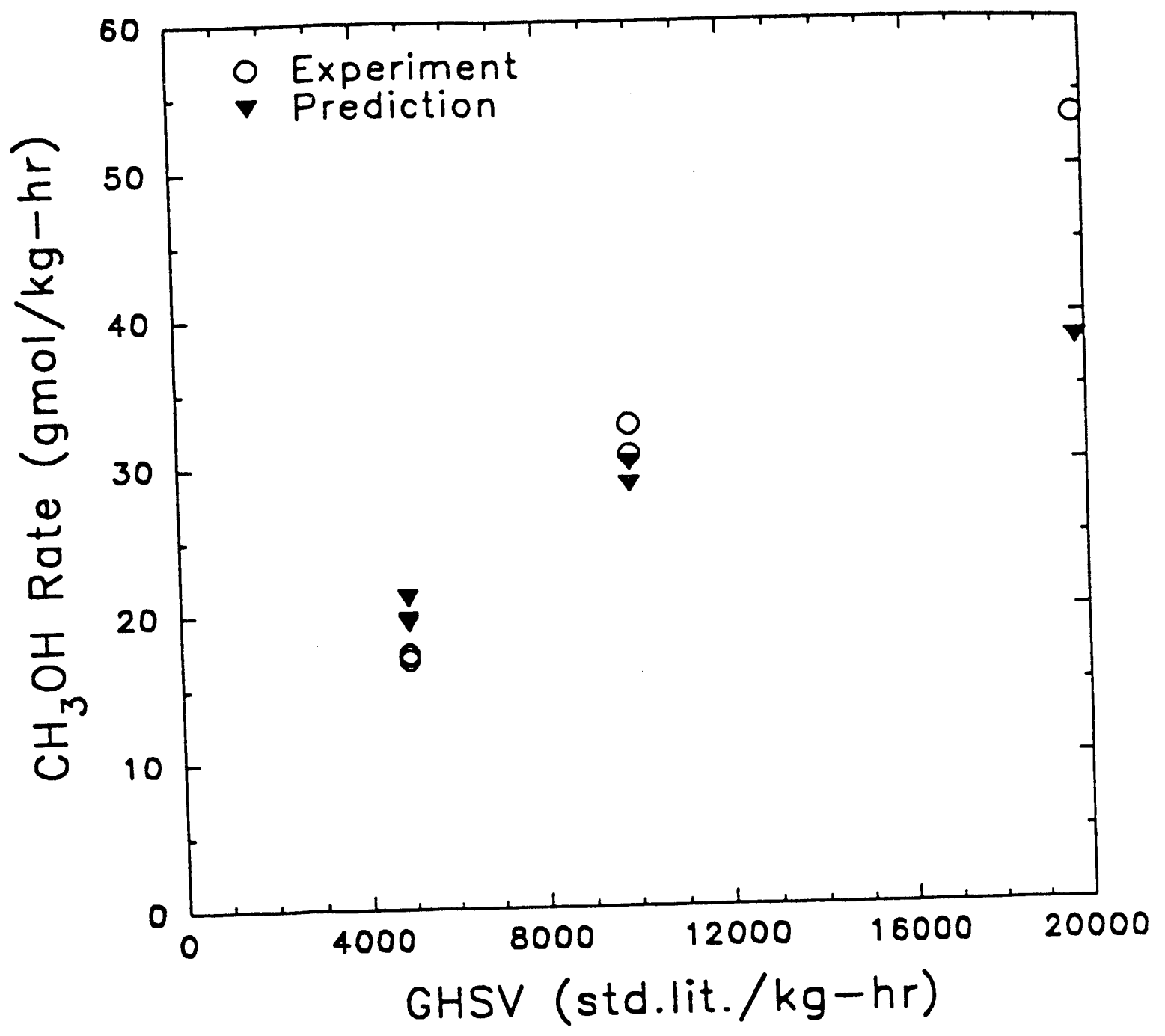


EIGURE 17

\section{Rate vs. GHSV \\ Texoco Gos, $9.75 \mathrm{MPo}$}

Cotalyst: BASF S3-86 Model: XX14 $\left(250^{\circ} \mathrm{C}\right)$

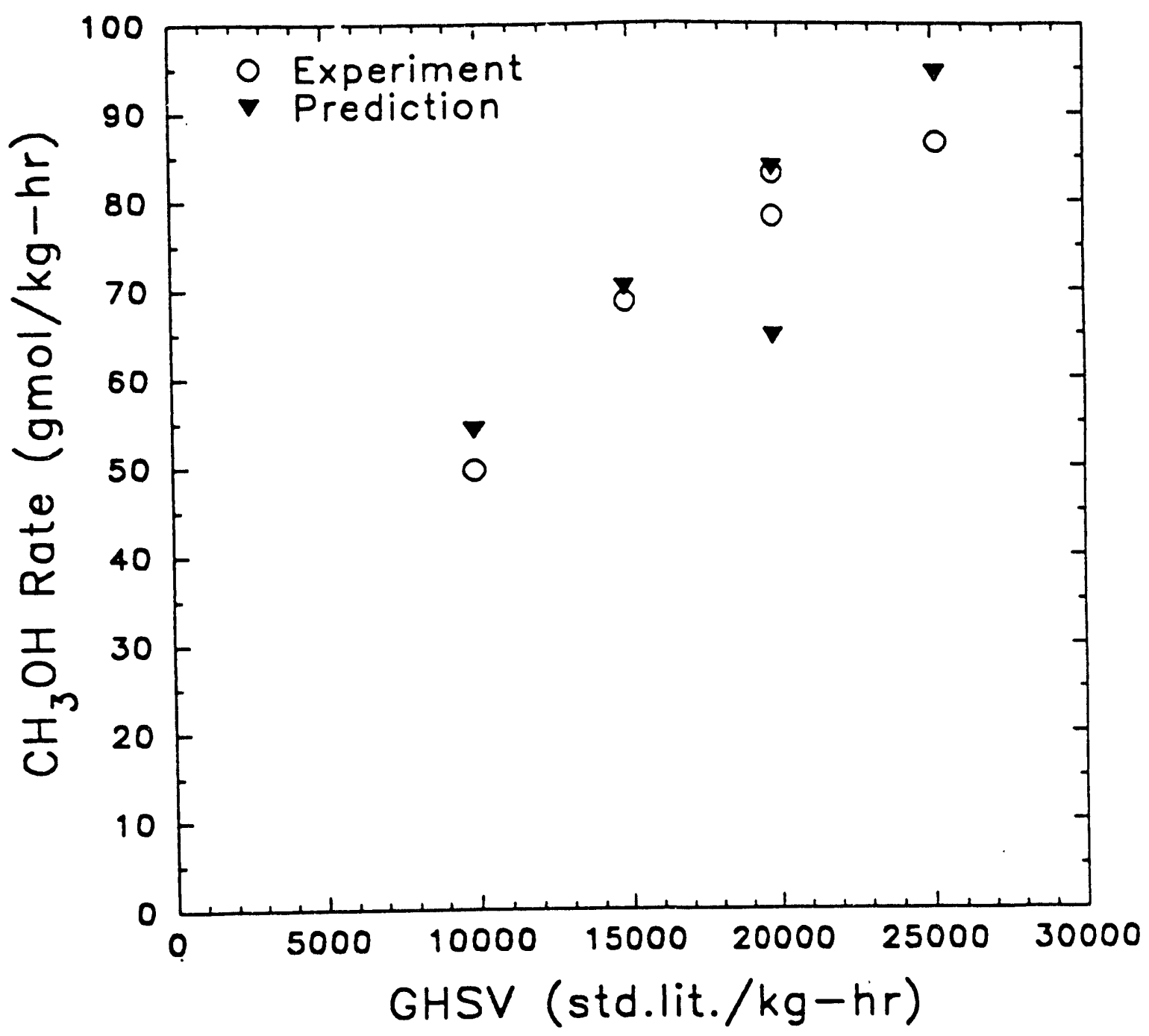


EIGURE 18

Rate vs. GHSV

Dow Gas, 5.27MPo

Cotolyst: BASF S3-86 Model: $X \times 14\left(250^{\circ} \mathrm{C}\right)$

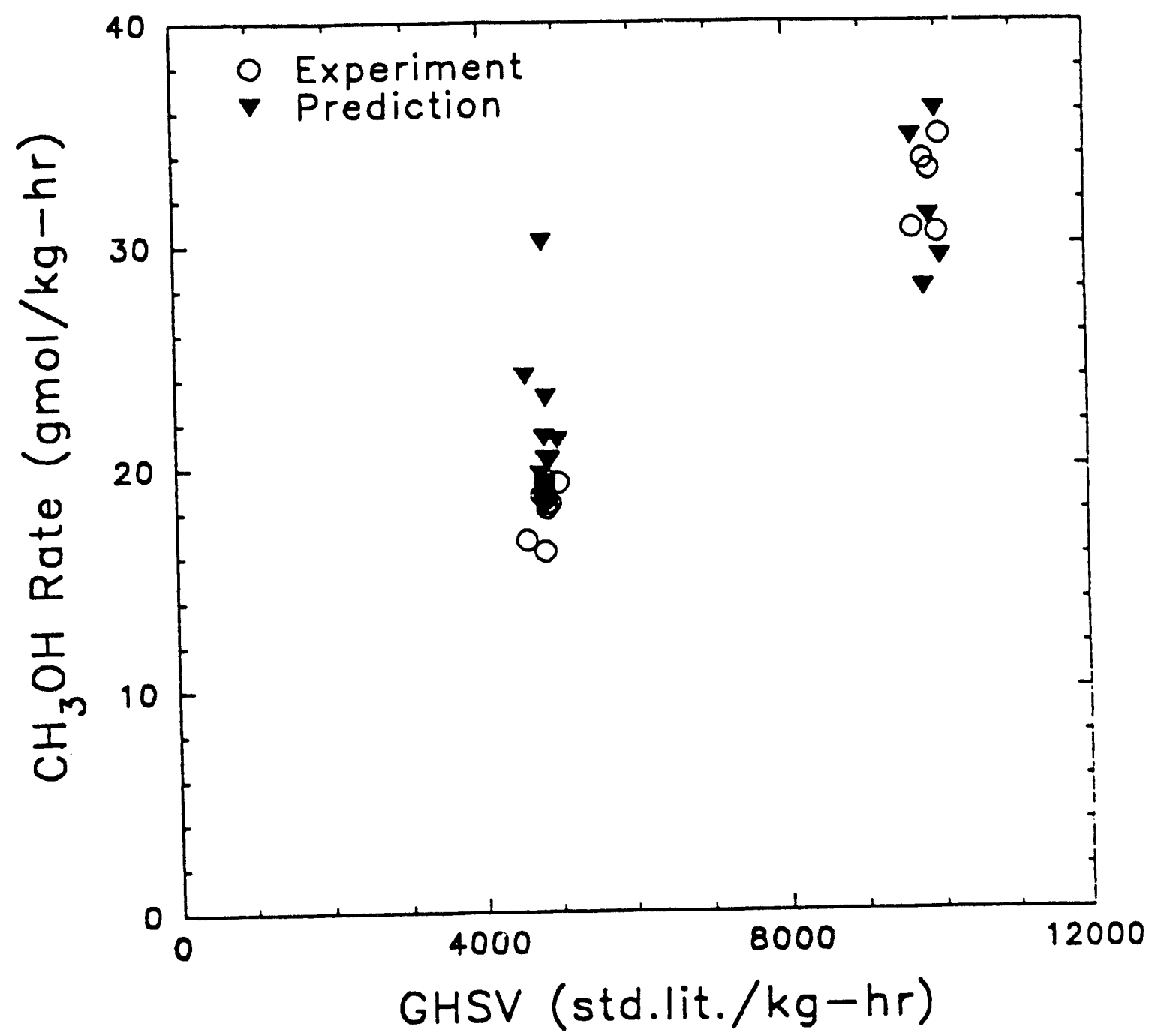


Rate vs. Feed $\mathrm{CO}_{2}$ Concentration Great Plains Gas, $5.27 \mathrm{MPa}$ Cotalyst: BASF S3-86 Model: $X \times 14\left(250^{\circ} \mathrm{C}\right)$

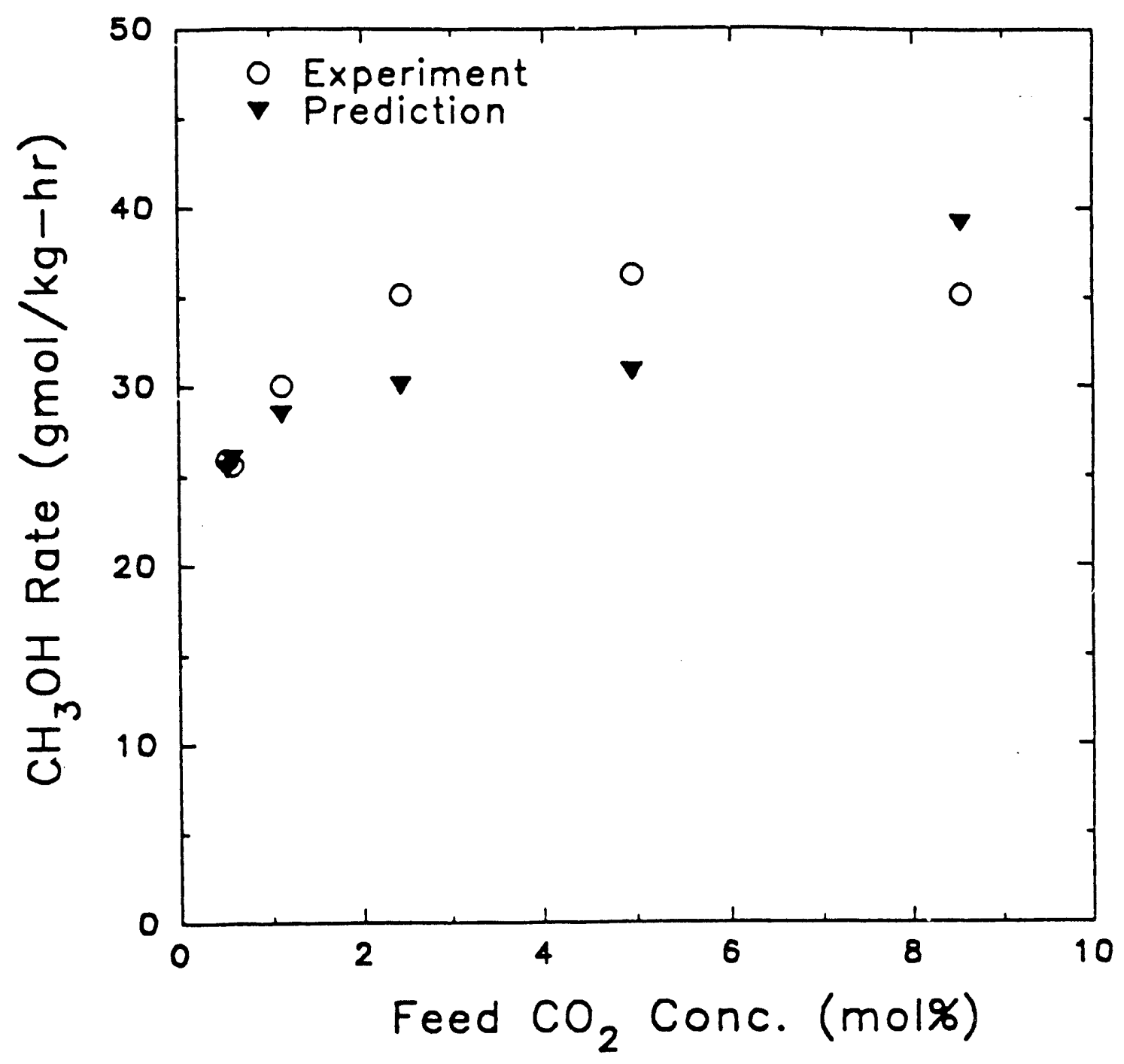


Rate vs. GHSV

Great Plains Gas $\left(0.5\right.$ mol\% $\left.\mathrm{CO}_{2}\right), 5.27 \mathrm{MPo}$ Catalyst: BASF S3-86 Model: $\times \times 14\left(250^{\circ} \mathrm{C}\right)$

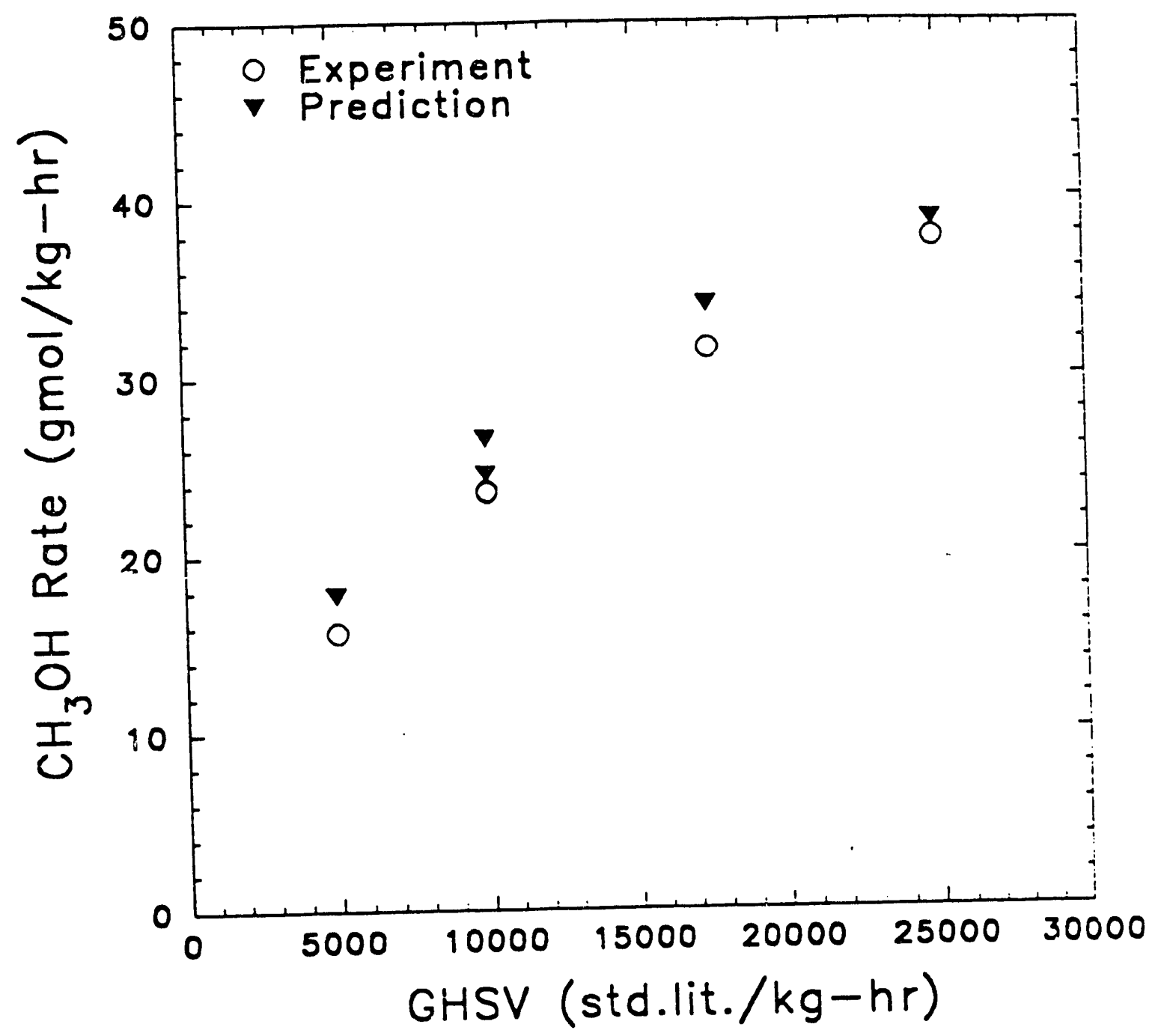


EIGURE 21

Rate vs. GHSV

Great Plains Gas ( 5.0 mol\% $\mathrm{CO}_{2}$ ), 5.27MPo

Cotolyst: BASF S3-86 Model: $X \times 14\left(250^{\circ} \mathrm{C}\right)$

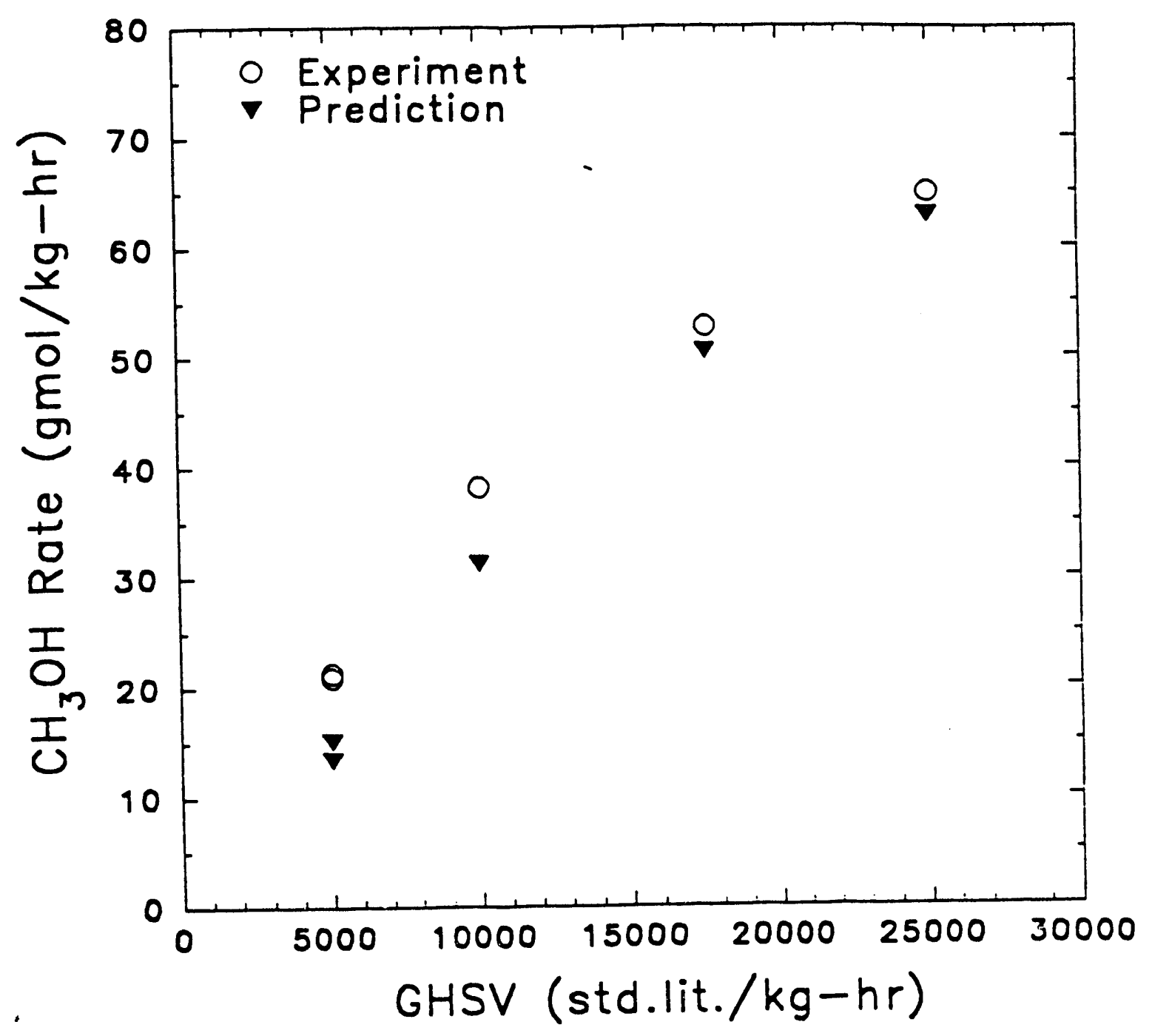


Rate vs. GHSV

Great Plains Gos (5.0 mol\% $\left.\mathrm{CO}_{2}\right), 7.34 \mathrm{MPa}$ Cotalyst: BASF S3-86 Model: $x \times 14\left(250^{\circ} \mathrm{C}\right)$

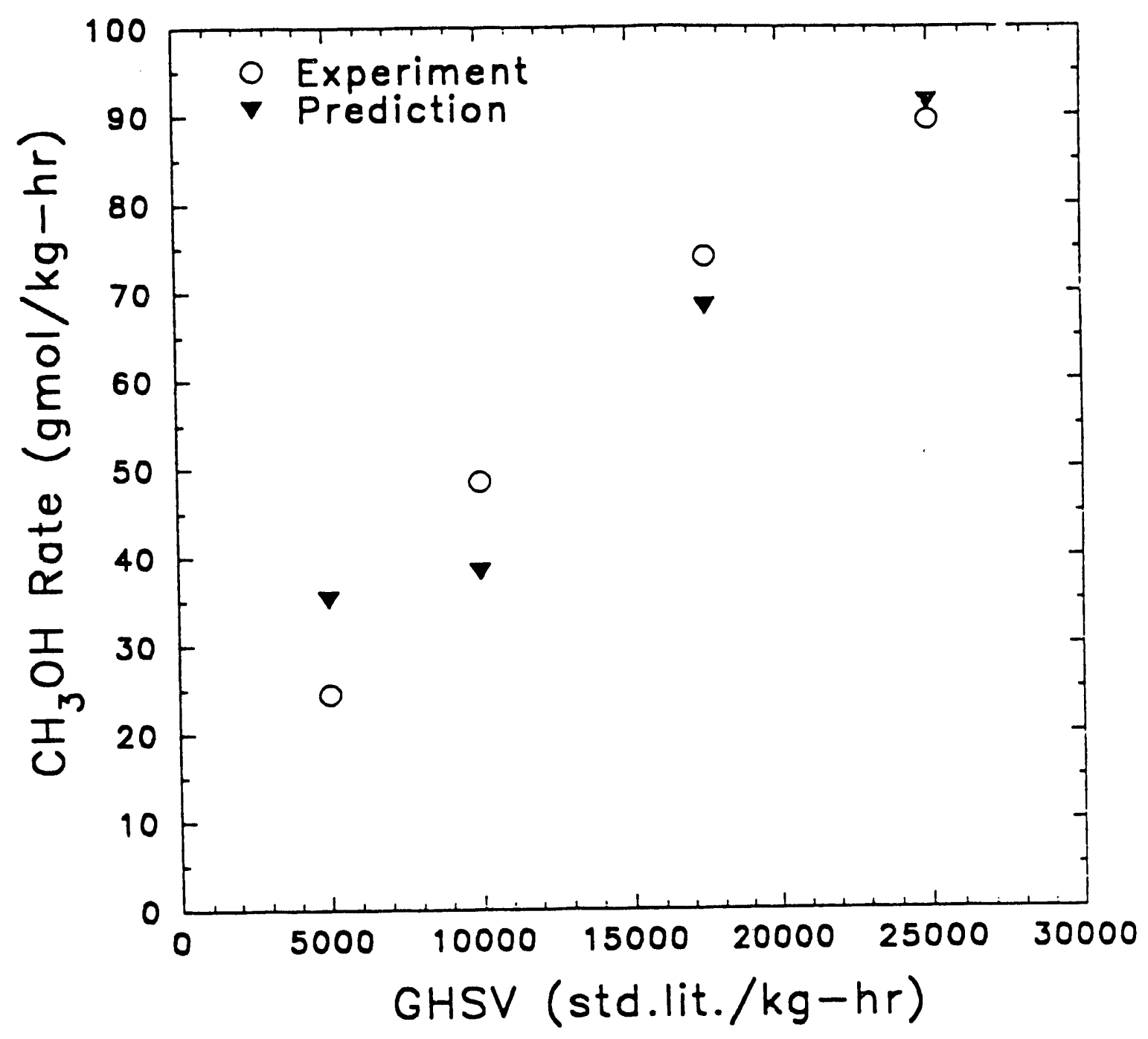


An exception to this is the runs on Great Plains gas with higher than 0.5 mol\% feed $\mathrm{CO}_{2}$. For these feed conditions, the $\mathrm{CO}_{2}$ hydrogenation term dominates and is typically an order of magnitude greater than the $\mathrm{CO}$ hydrogenation term.

A final point worth mentioning is that the application of model XX14 to the S3-85 data base unfortunately results in a very poor fit. The best fit of that data base yielded a residual sum of squares of 2,708 , corresponding to an average error per observation of $21.6 \%$. Furthermore, comparison of measured and predicted rate trends shows very poor agreement in general. The reason why model XX14 does such a poor job in fitting the S3-85 data base is not immediately clear. 


\section{SUMMARY AND CONCLUSIONS}

Fundamental rate expressions for methanol synthesis were developed to describe the BASF S3-85 and BASF S3-86 methanol catalyst experimental data bases. As part of this work, the BASF S3-86 experimental data base was also expanded with additional experimental measurements on the $\mathrm{H}_{2}$ rich Great Plains gas matrix. The principal results and conclusions of this work are:

1. Two data bases were constructed comprising all of the laboratory experimental measurements on the S3-85 and S3-86 catalysts. The S3-85 duta base is largely concentrated on CO-rich, Texaco feed gas with very limited ranges of pressure and gas-hourly space velocity (GHSV). By contrast, the S3-86 data base includes a much broader range of experimental conditions, including wider ranges of GHSV, pressure, and gas composition. Thus, the S3-86 data base is a more challenging test of a general rate model for methanol synthesis. Neither data base included extensive runs done at temperatures other than $250^{\circ} \mathrm{C}$. Therefore, rate expressions were developed for methanol synthesis at $250^{\circ} \mathrm{C}$.

2. The data bases for each catalyst were recast in terms of calculated fugacities of $\mathrm{H}_{2}, \mathrm{CO}, \mathrm{CO}_{2}$, and $\mathrm{CH}_{3} \mathrm{OH}$. The fugacity of product $\mathrm{H}_{2} \mathrm{O}$ was estimated by assuming water-gas shift equilibrium. The resulting $250^{\circ} \mathrm{C}$ data base for $S 3-85$ consisted of 112 observations at 69 different conditions, while the $250^{\circ} \mathrm{C} \mathrm{S3-86}$ data base consisted of 61 observations at 52 different conditions. PC SAS programs were developed to regress the observed methanol rates on the product fugacities and the best-fit models were detennined. Procedures were developed to transfer the SAS data to a spreadsheet program where comparisons of predicted and measured rate were generated.

3. A rate expression was developed for the $\$ 3-85$ data base using an assumed sequence of steps and Langmuir-Hinshelwood kinetics. This rate expression, designated model S3-T2, was derived from a mechanism in which $\mathrm{CO}$ and $\mathrm{CO}_{2}$ are hydrogenated in parallel on separate surface sites by stepwise addition of dissociatively adsorbed hydrogen. The derivation of model S3-T2 assumes that the rate determining steps are the addition of the third hydrogen atom to adsorbed $\mathrm{CO}$ and the addition of the second hydrogen atom to adsorbed $\mathrm{CO}_{2}$. The resulting 4-parameter rate expression is:

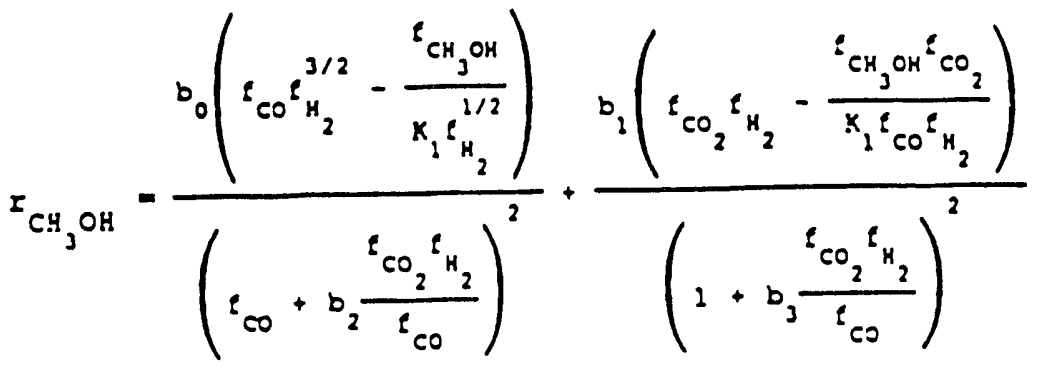

This model yieids an average absolute error per observation of $12.9 \%$. 
4. A rate expression was developed for the S3-86 data base. After screening a variety of mechanisms and combinations of rate-determining steps and adsorption characteristics, a model designated XX14 emerged as the best fit. Like model S3-T2 for S3-85, XX14 was also derived assuming that $\mathrm{CO}$ and $\mathrm{CO}_{2}$ are stepwise hydrogenated on separate surface sites. However, the rate-determining steps and adsorption characteristics are different than those for model S3-T2. The rate determining steps are the addition of the first hydrogen to adsorbed $\mathrm{CO}$ and the addition of the fourth hydrogen to adsorbed $\mathrm{CO}_{2}$. The resulting 6-parameter rate expression is:

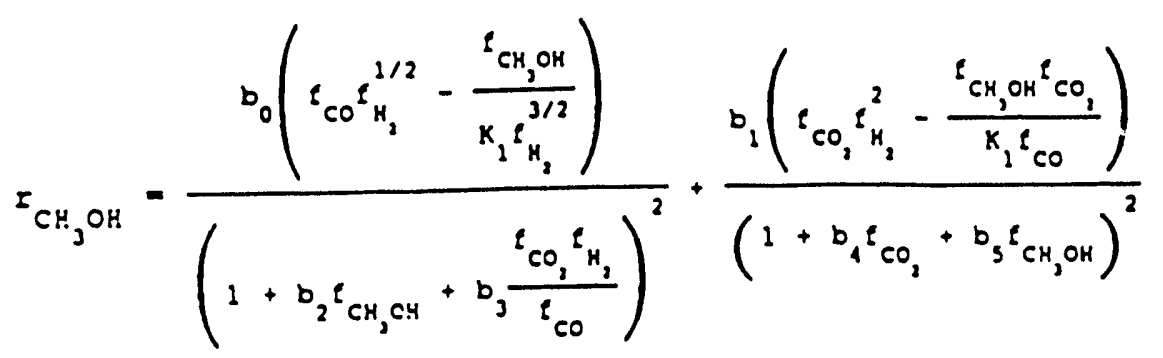

This model yields an average absolute error per observation of $15.3 \%$.

5. Three rate expressions obtained from the literature were also fit to the S3-86 data base for purposes of comparison. Model XX14 fit the data much better than any of these literature rate expressions.

6. The parameters in model XX14, the rate expression for $\$ 3-86$, were made adjustable and the model was fit to the S3-85 data base. The resulting fit was very poor, producing an average absolute error per observation of $21.5 \%$. The reason for the poor fit is not clear.

7. Investigations of various rate models for both data bases indicate that, in general, rate expressions derived from a mechanism in which $\mathrm{CO}$ and $\mathrm{CO}_{2}$ are hydrogenated in parallel on separate sites fit the data better than those derived assuming that $\mathrm{CO}$ and $\mathrm{CO}_{2}$ are hydrogenated on the same site.

8. Because of the mathematical form of rate expressions developed for each catalyst, the prediction accuracy is strongly influenced by the experimental accuracy in measuring reactor exit gas composition. For example, small deviations in the measured $\mathrm{H}_{2}$ concentration result in much larger deviations in predicted rate. Thus, measurement error contributed significantly to the calculated average prediction error.

9. The S3-86 data base was expanded with experimental runs on the Great Plains gas matrix. The effect of CHSV on the methanol rate was determined for Great Plains gas with 0.5 mol\% feed $\mathrm{CO}_{2}$ at $250^{\circ} \mathrm{C}$ and $5.27 \mathrm{MPa}(750 \mathrm{psig})$. In addition, methanol rate as a function of GHSV was measured for 5 mol\% feed $\mathrm{CO}_{2}$ at $250^{\circ} \mathrm{C}$ and pressures of $5.27 \mathrm{MPa}$ and $7.34 \mathrm{MPa}$. At fixed GHSV and $5.27 \mathrm{MPa}$, the methanol rate is much greater at the higher feed $\mathrm{CO}_{2}$ level. At fixed GHSV and $5 \mathrm{~mol} \%$ feed $\mathrm{CO}_{2}$, the methanol rate is greater at the higher pressure. 


\section{REFERENCES}

(1) Herman, R. G., Klier, K., Simmons, G. W., Finn, B. P., Bulko, J. B, and Kobylinski, T. P., J. Catal. 56, 407 (1979).

(2) Klier, K., Chatikavanij, V., Herman, R. G., and Simmons, G. W., J. Catal. 74, 343 (1982).

(3) Rozovskii, A. Ya., Kinet. Katal. 21, 97 (1980).

(4) Kuznetsov, V. D., Shub, F. S., and Temkin, M. I., Kinet. Katal 23, 932 (1982).

(5) Chinchen, G. C., Denny, P. J., Parker, D. G., Spencer, M. S., and Whan, D. A., Appl. Catal. 30,333 (1987).

(6) Chinchen, G. C., Mansfield, K. and Spencer, M. S., Chemtech, p. 692, November 1990.

(7) Liu, G., Willcox, D., Garland, M., and Kung, H. H., J. Catal. 96, 251 (1985).

(8) Takagawa, M. and Ohsugi, M., J. Catal. 107, 161 (1987).

(9) Graaf, G. H., Stamhuis, E. J., and Beenackers, A. A. C. M., Chem. Eng, Sci. 43, 3185 (1988).

(10) Graaf, G. H., Winkelman, J. G. M., Stamhuis, E. J., and Beenackers, A. A. C. M., Chem. Eng. Sci. 43, 2161 (1988).

(11) McNeil, M. A., Schack, C. J., and Rinker, R. A., Appl. Catal. 50, 265 (1989).

(12) Dybjaer, I., Paper presented at NATO conference on chemical reactor design and technology, 1985. (As referenced in Graaf et al. (9)). 
APPENDDX A 
TABLE A-1

\section{Syngas Mixtures}

Nominal Composition (mol\%)

Syngas Tyoe

Texaco

Shell

Dow

Great Plains

"Balanced"
H2

35

30

44

64.5

55 $\mathrm{co2}$

13

66

38

19

19

5
N2

1

1

2

0

21
$\mathrm{CH} 4$

0

0

c

16

0 


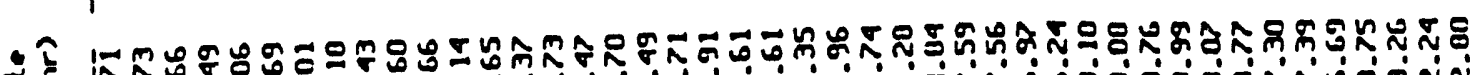

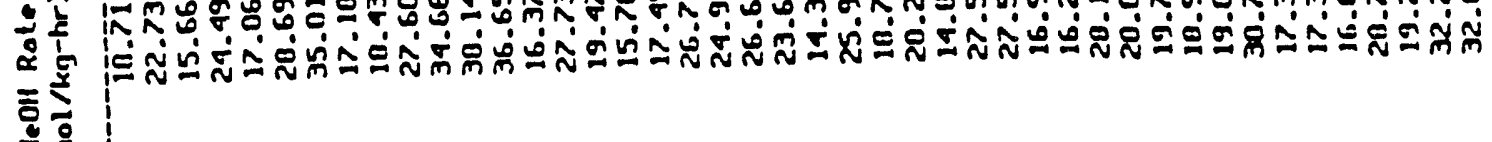

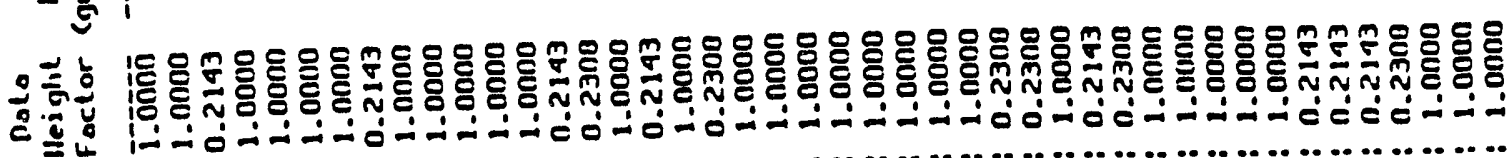

WHAMHAH in

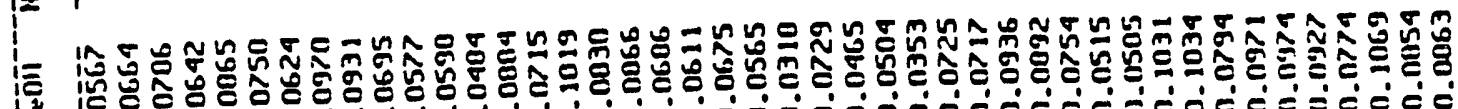

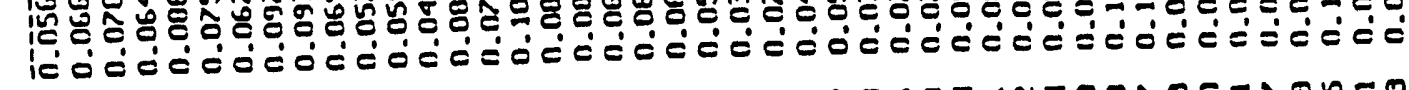

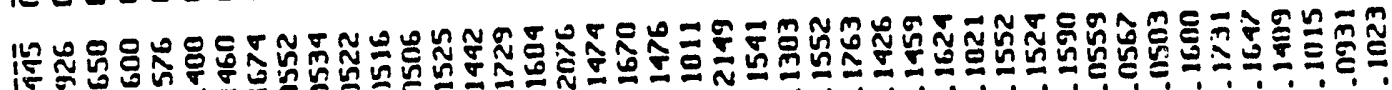
lín

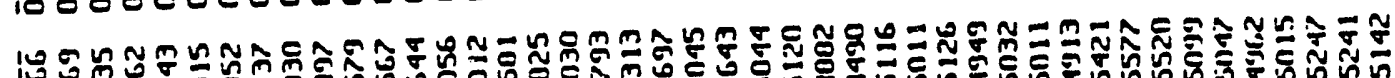

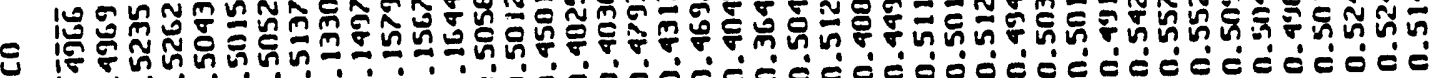

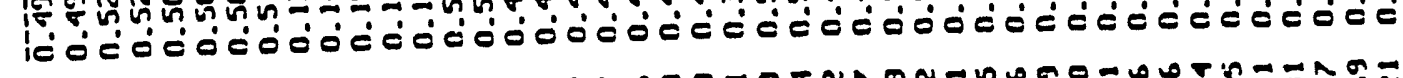

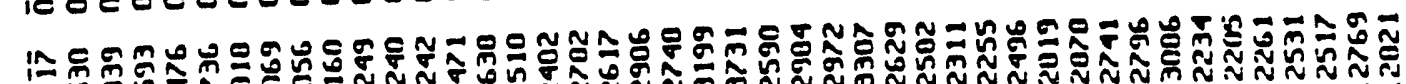

iN

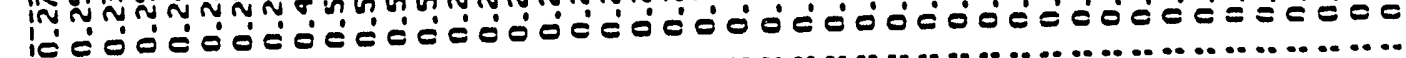

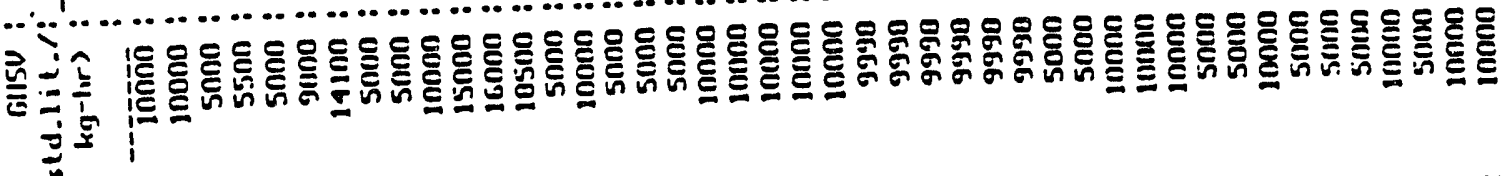

* ป .

16 象

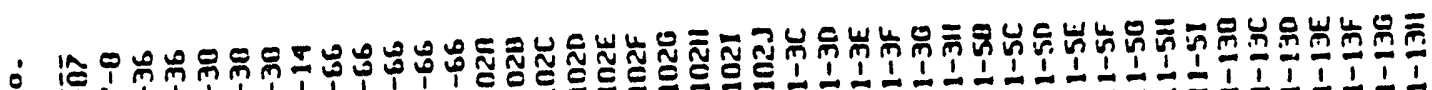

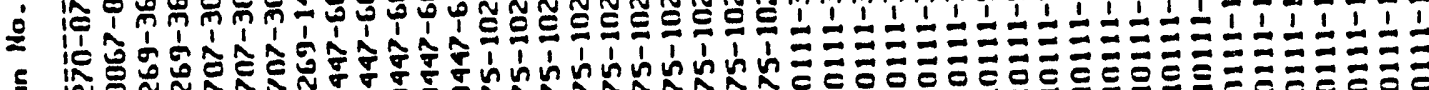

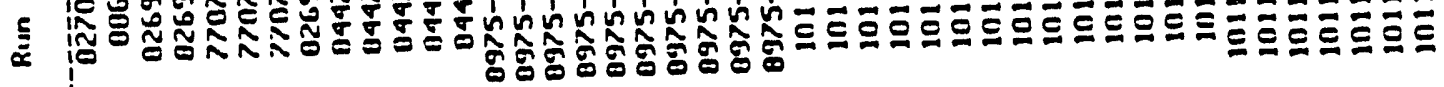

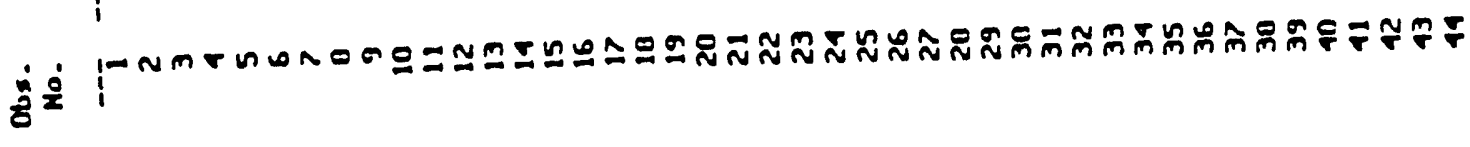




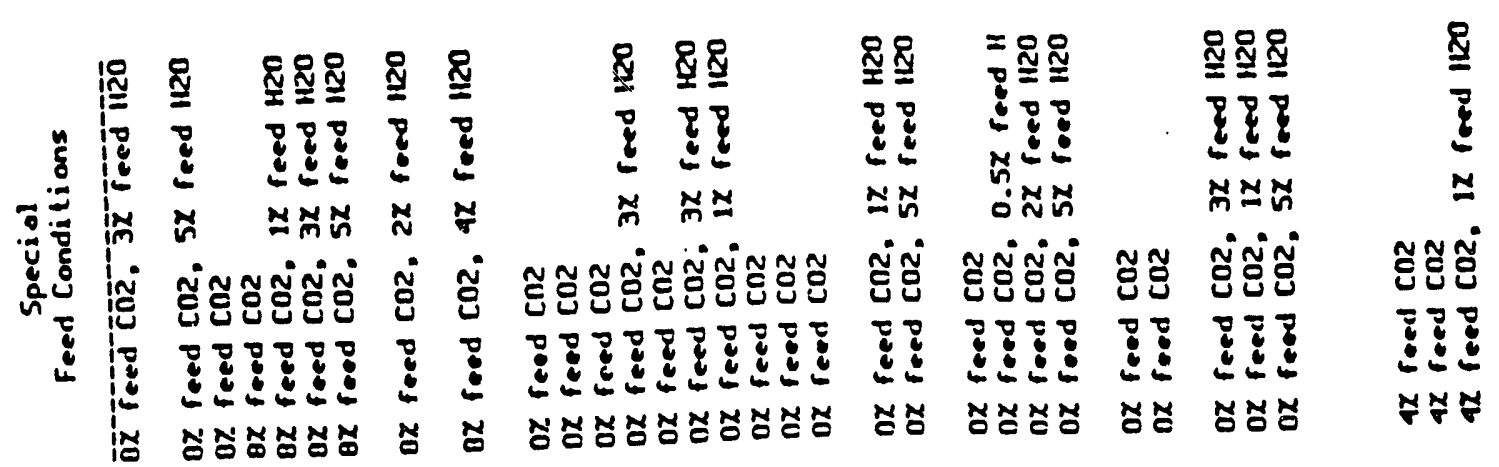
宏

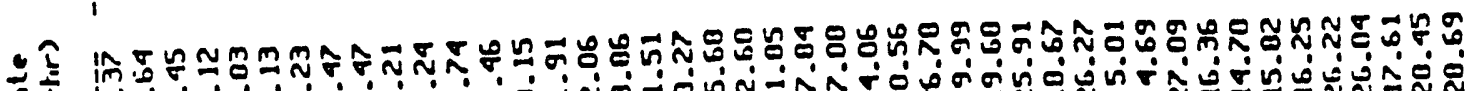

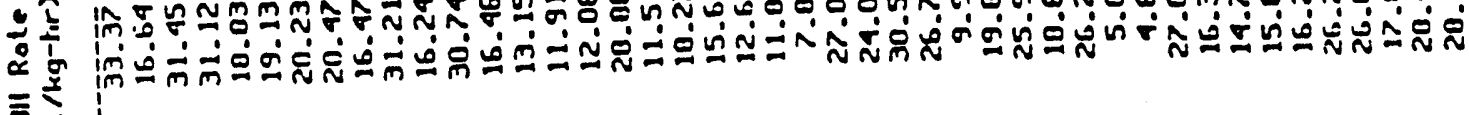
言要

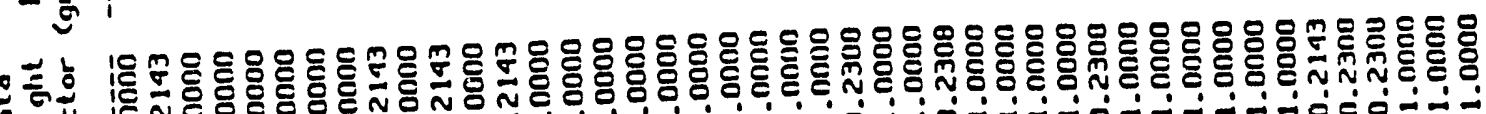
氙

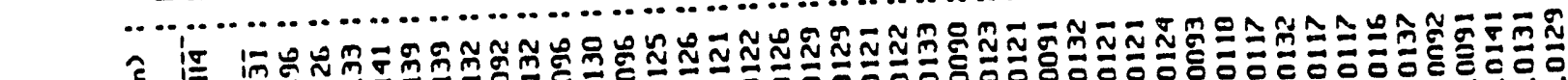

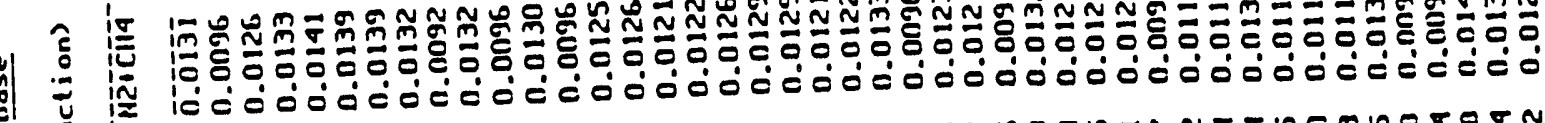

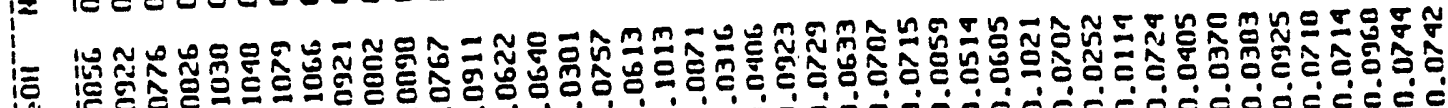

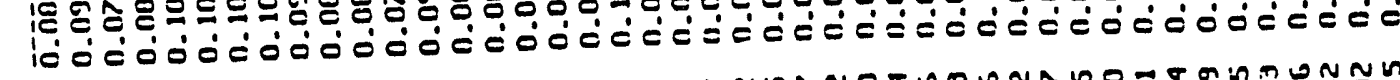

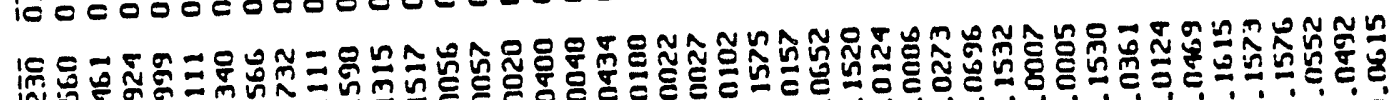

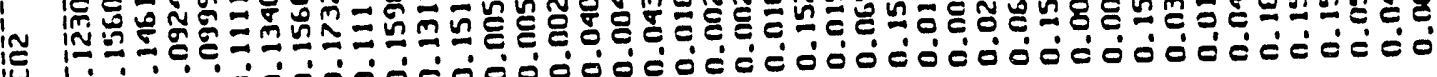

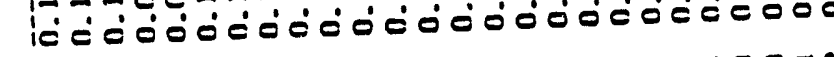

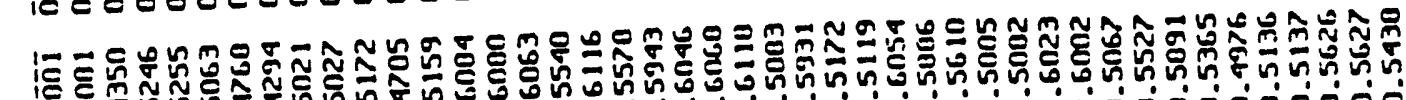

is 传

突

に茫 N

N

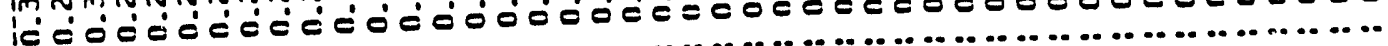

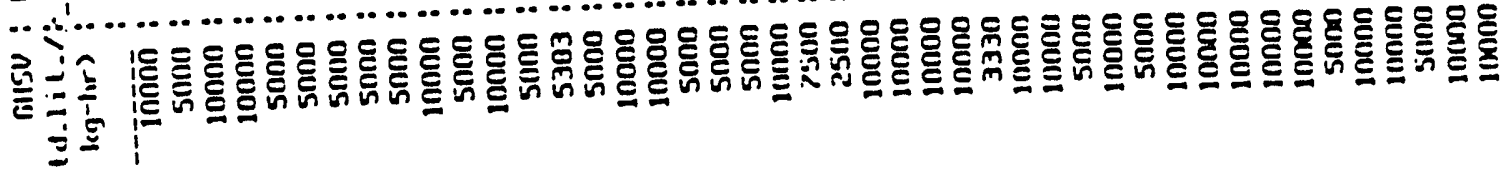

$\bar{n}$

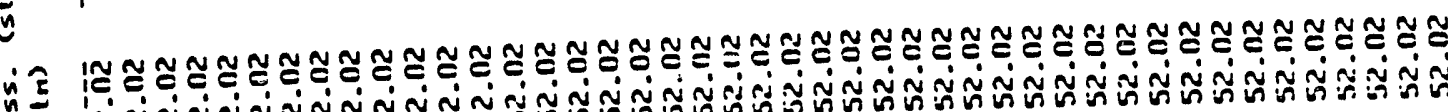
ะ

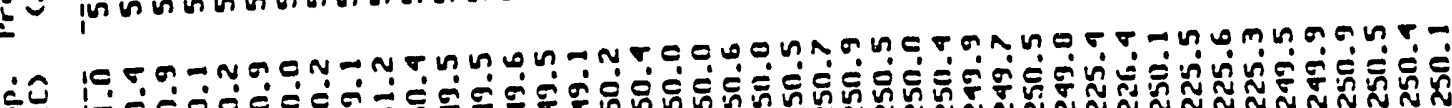
过

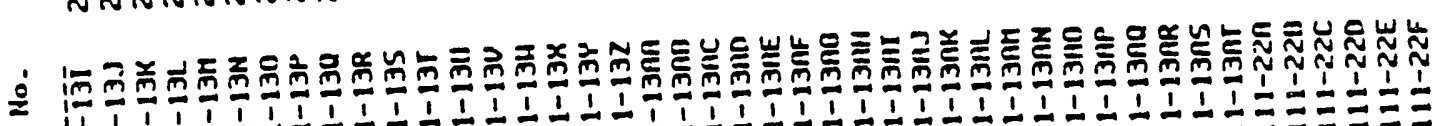

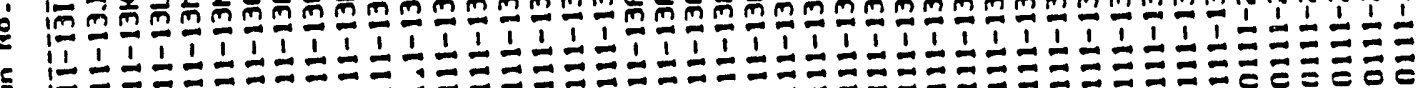

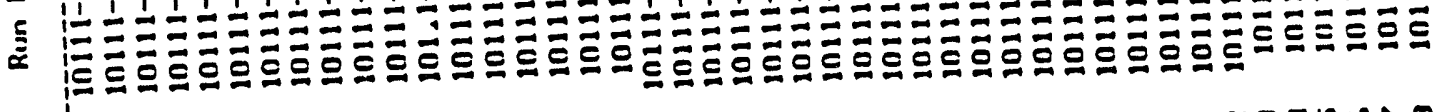

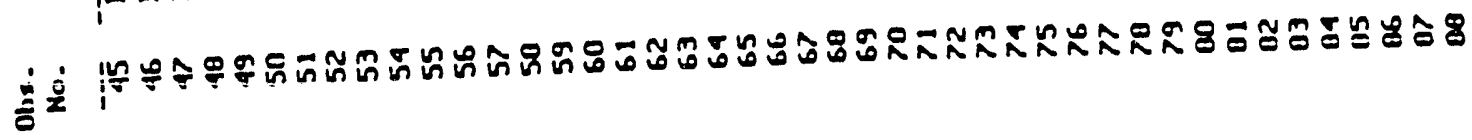




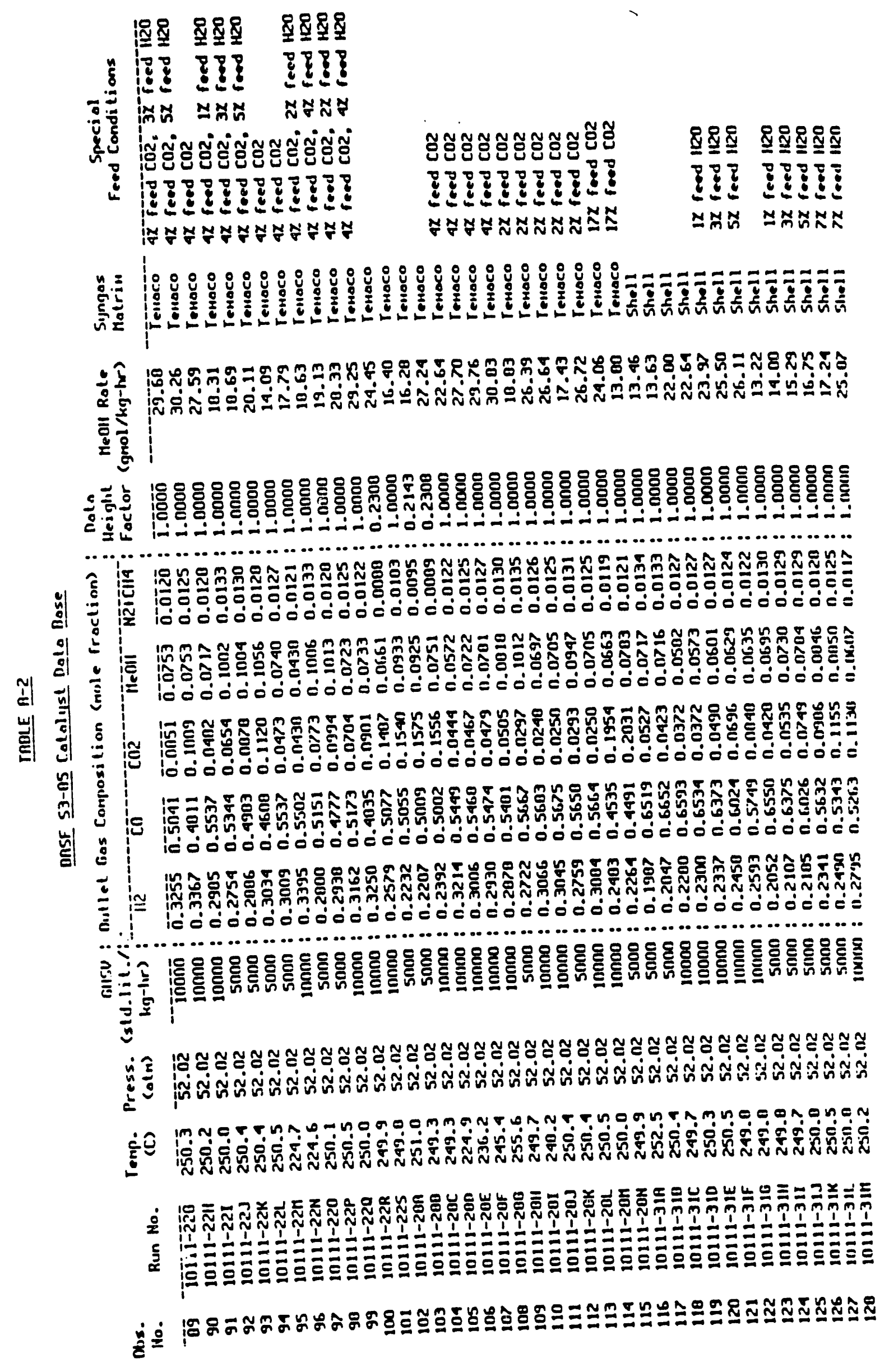


๖

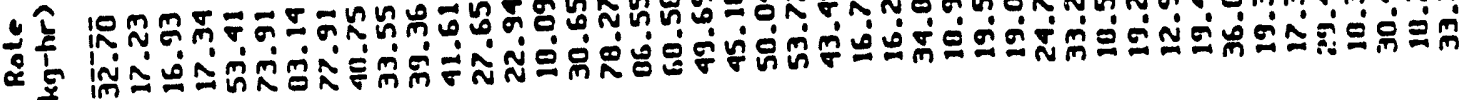

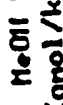

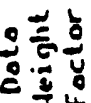

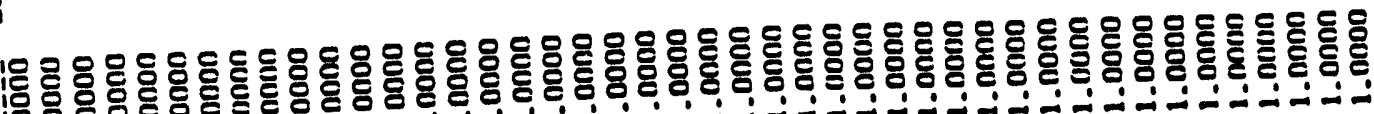

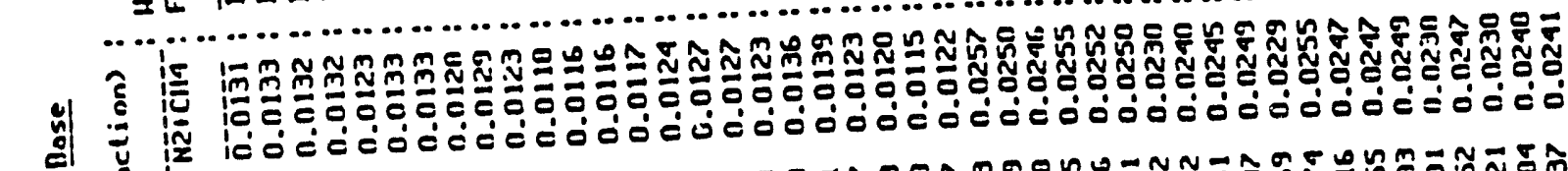

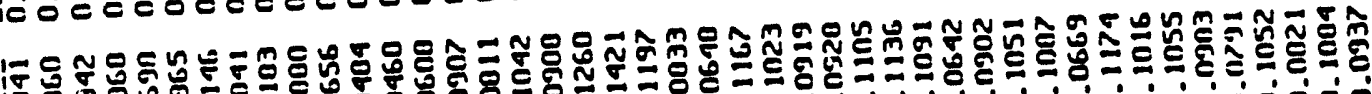

eç

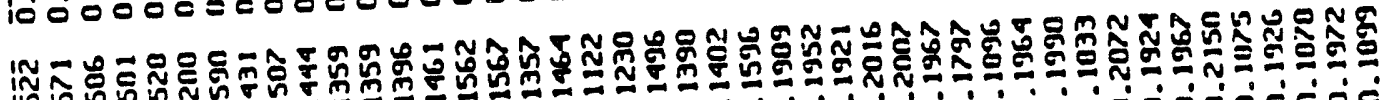

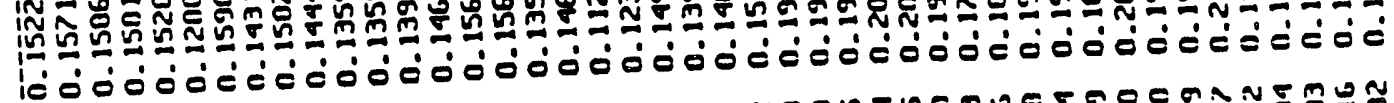

le

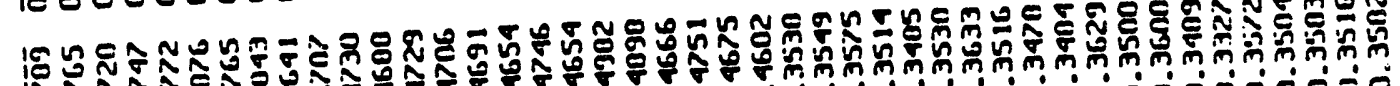

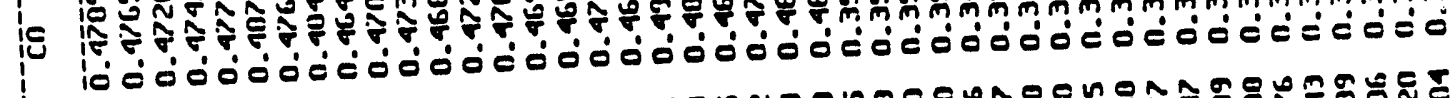

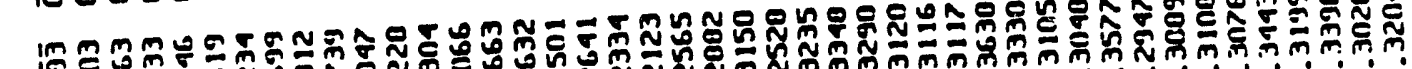

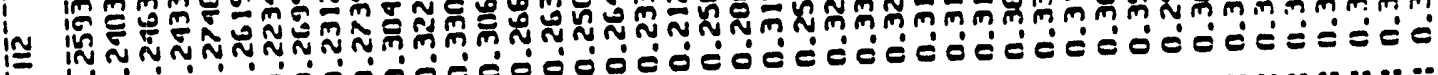

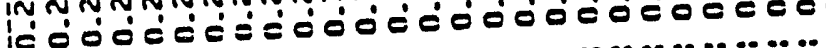

่ิธ

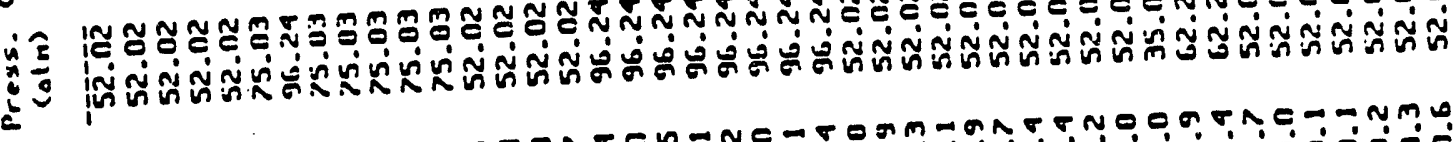

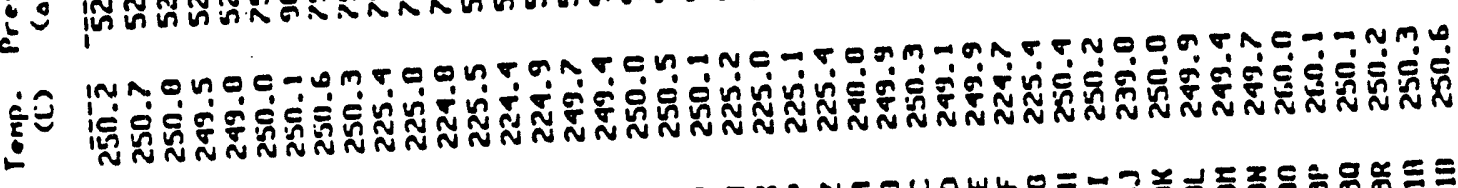

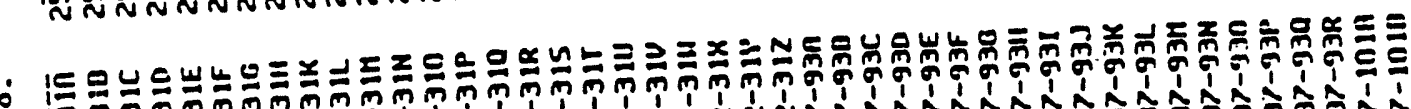

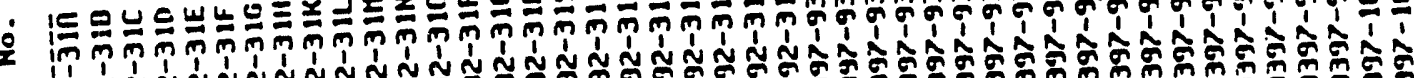

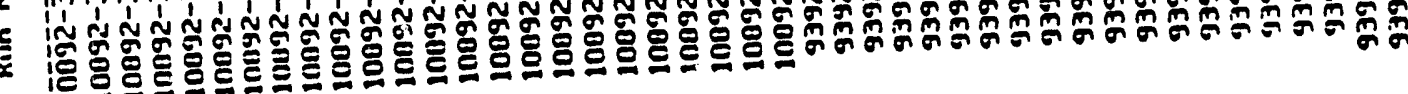

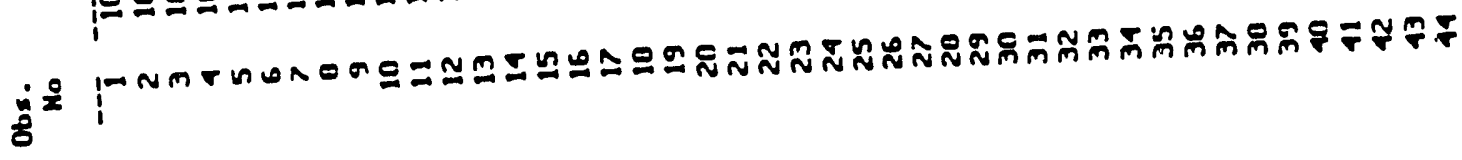




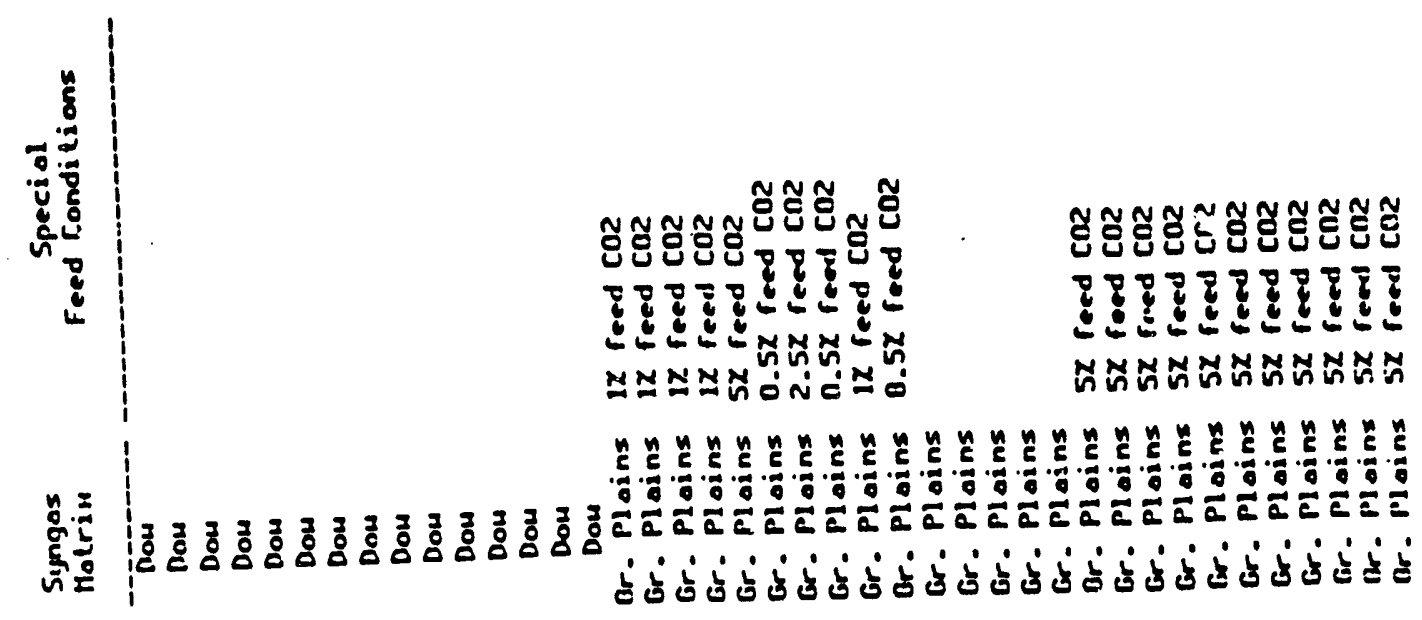

๖ ¿ 要总

象象

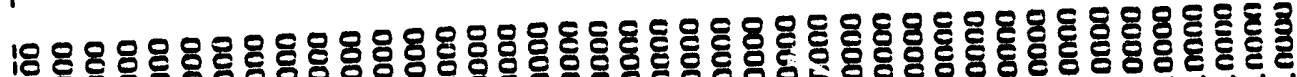
te 8 8

1) có

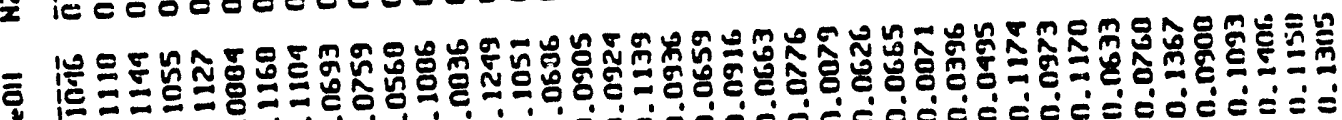

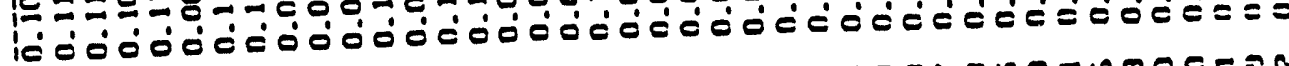

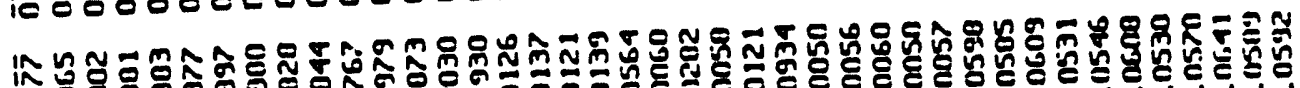

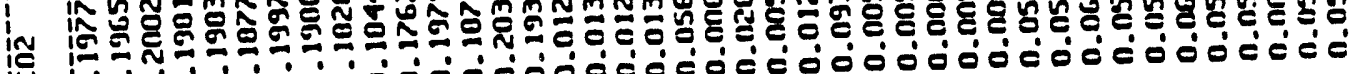

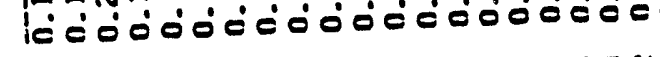

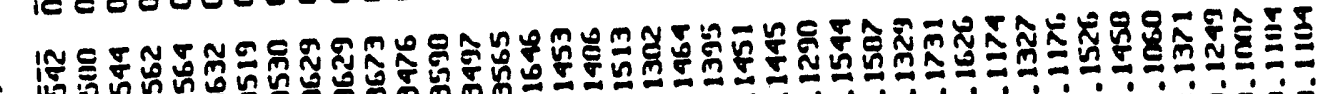

L

है।

8

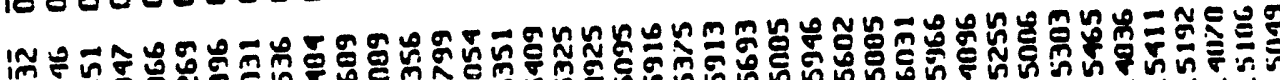

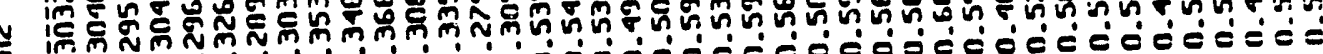

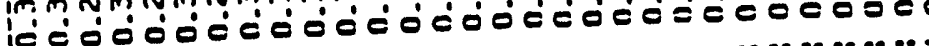

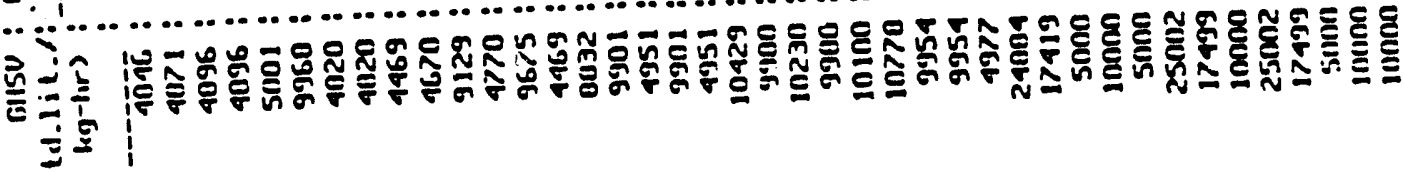

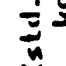

मิ

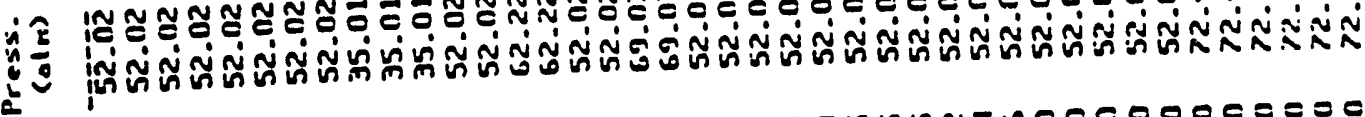

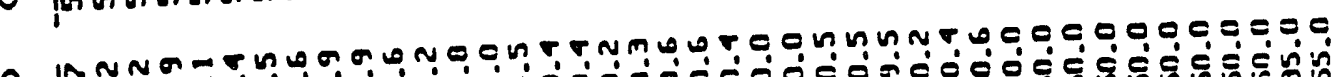

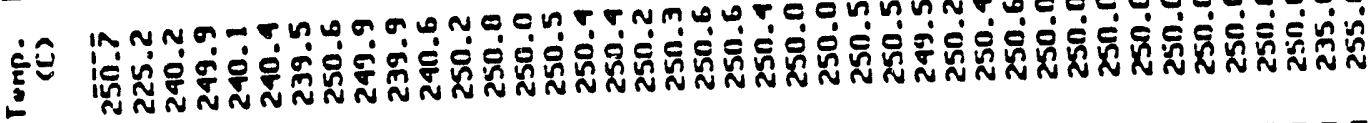

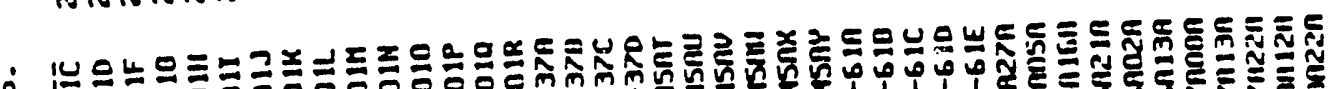

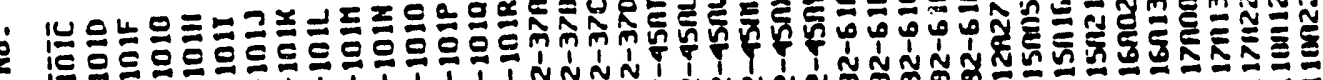

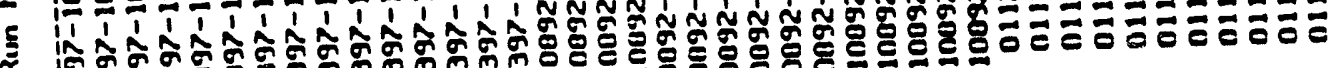

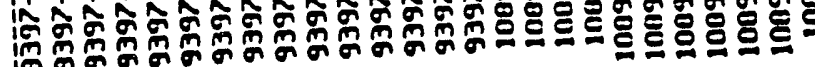

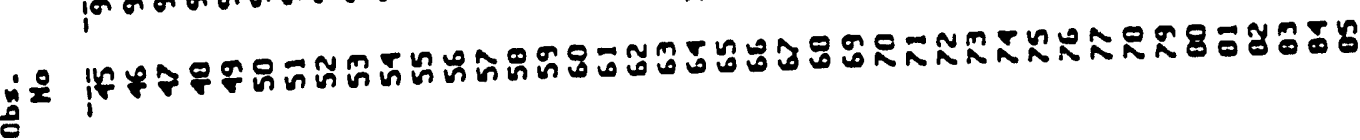
sis 
APPE NIX B 


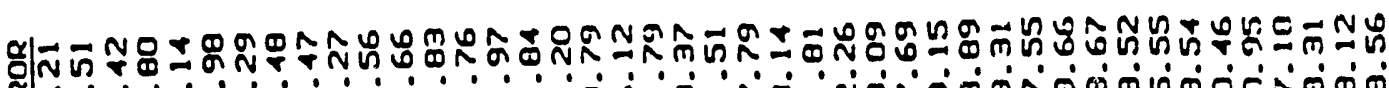

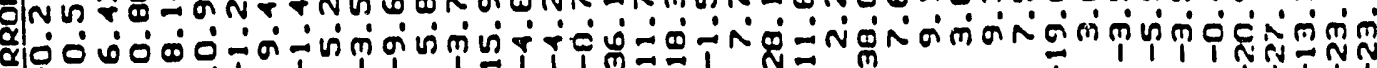
N

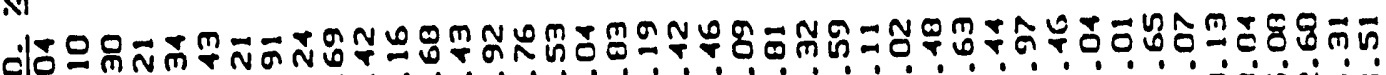
ज̆

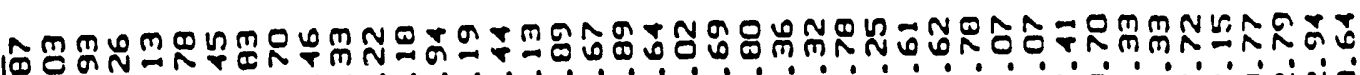
अ

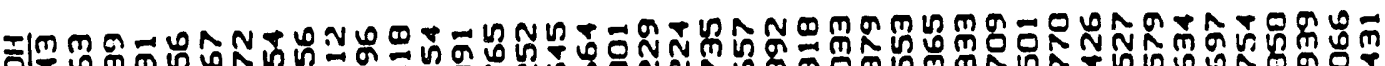
학유.

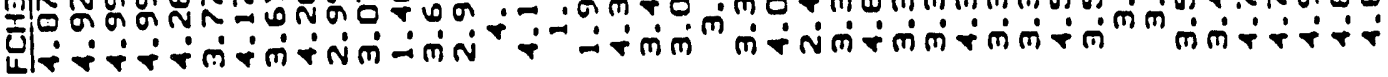

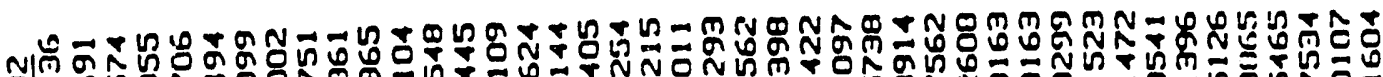

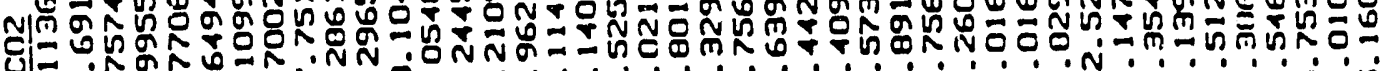
ن

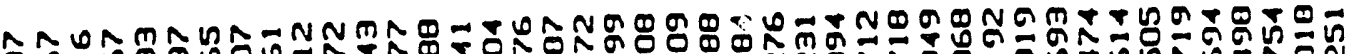

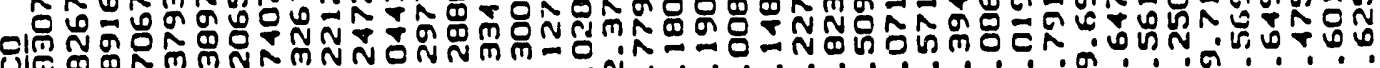
L)

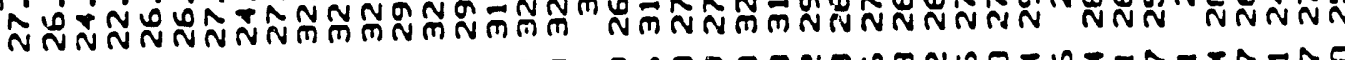

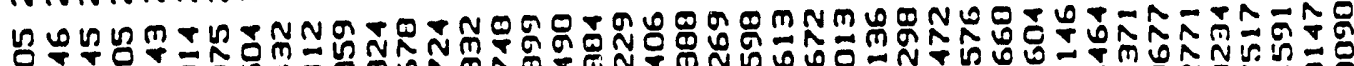

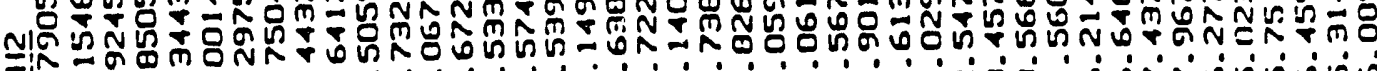

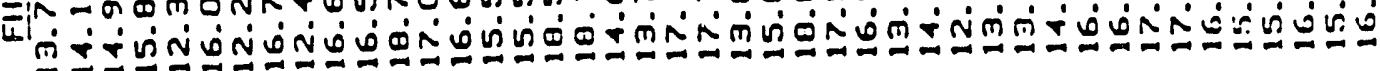

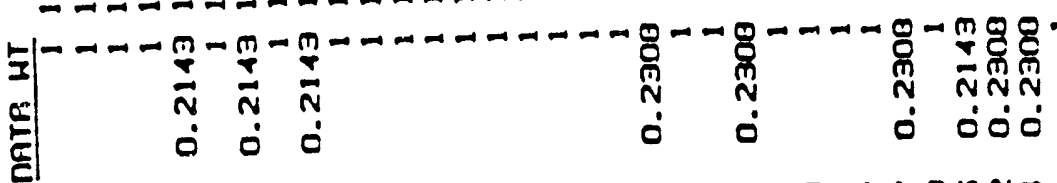

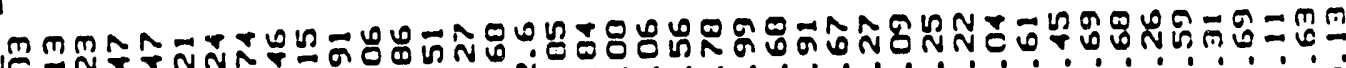

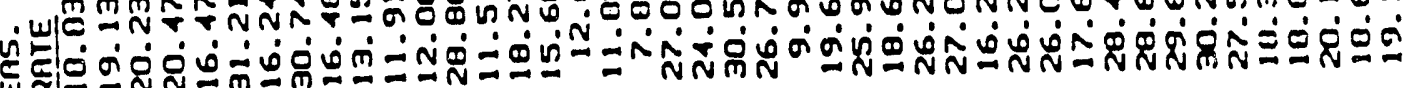
逭

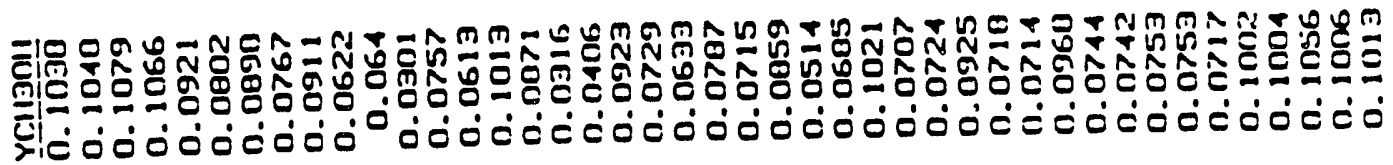

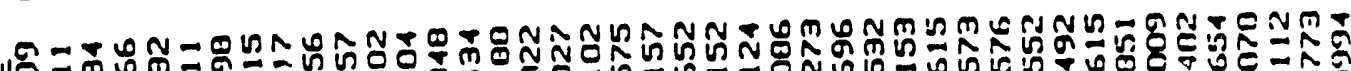
대든

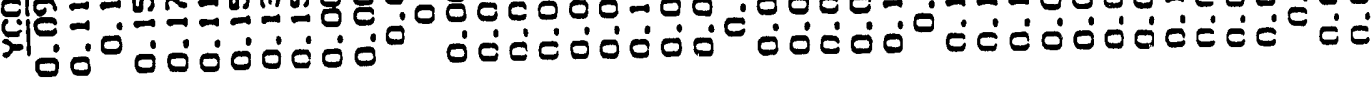

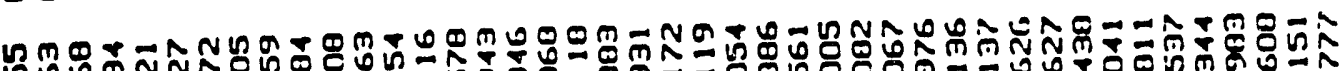

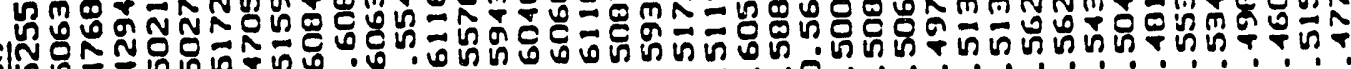

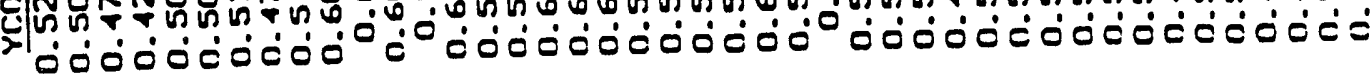

ヘ

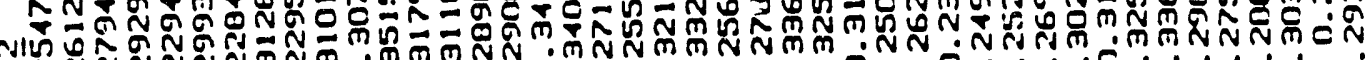

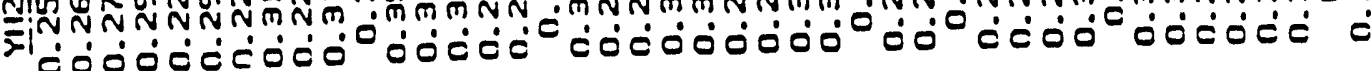

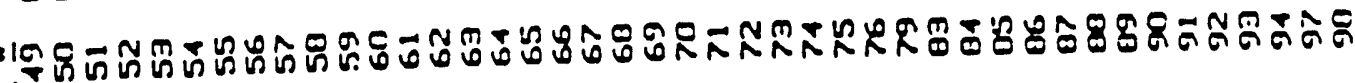
है। 


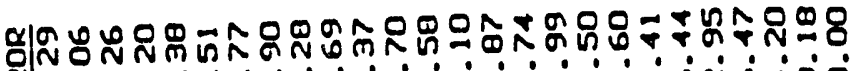
वं宀

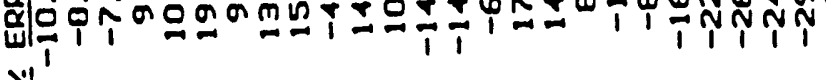

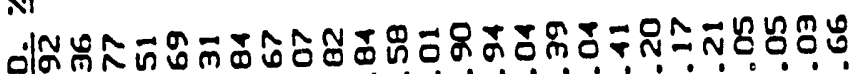

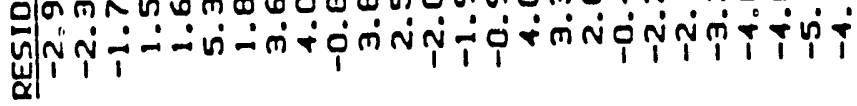

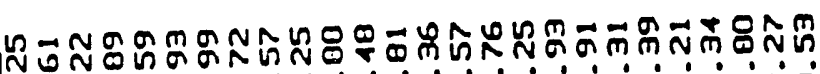
अँ

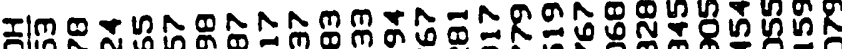

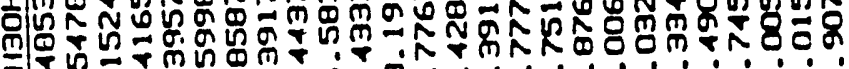

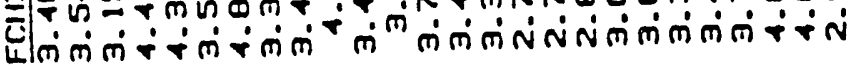

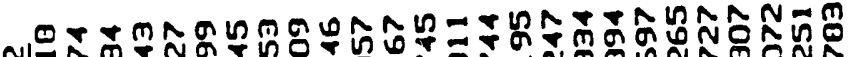

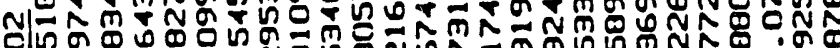
पै

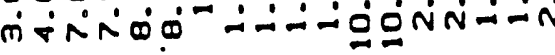

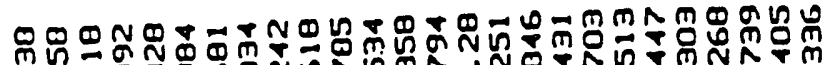

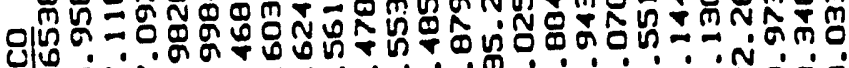

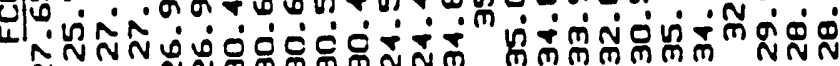

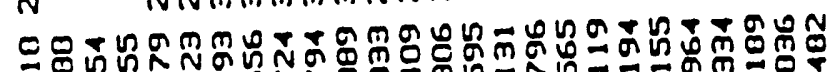

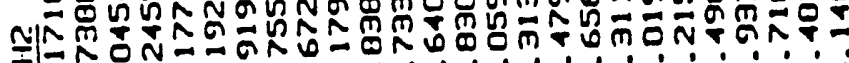

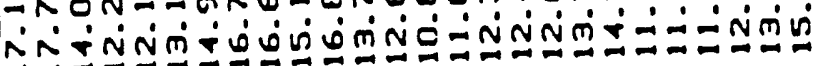

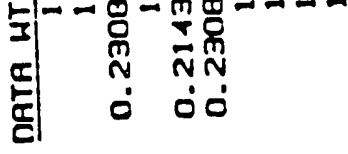

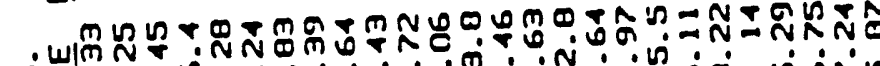
Cृ $\underline{\Sigma}$

它

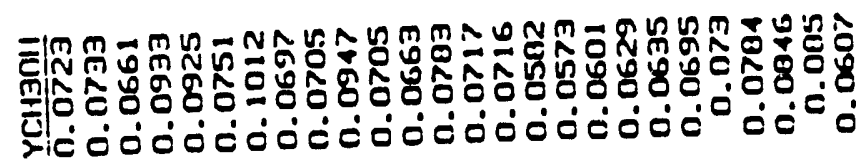

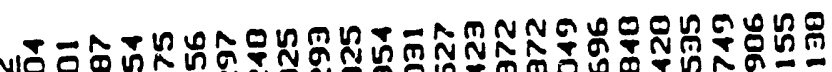
औरํำ

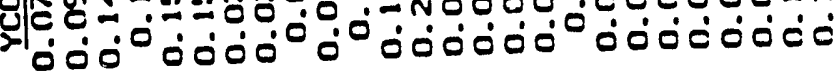
II

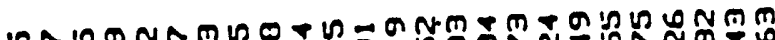

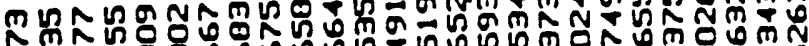

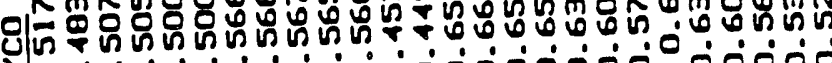

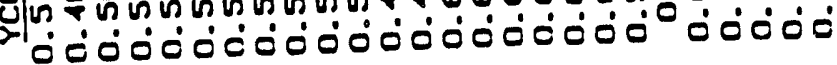

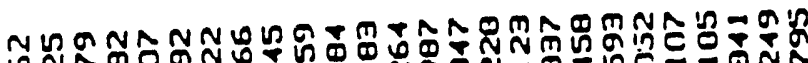

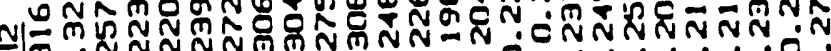

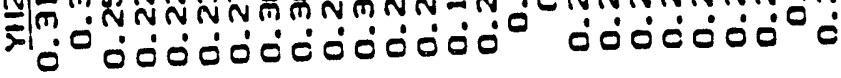

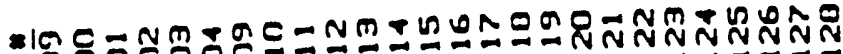
है। 


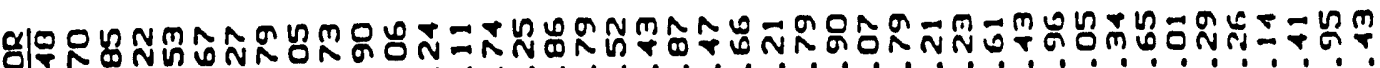

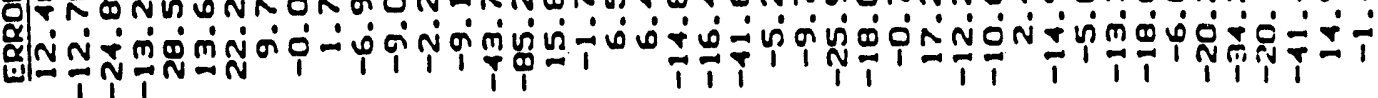
N

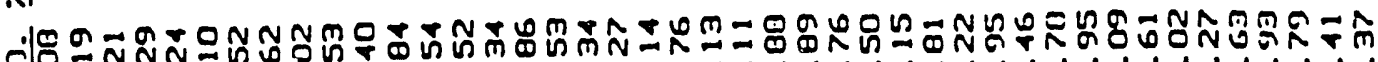
岁

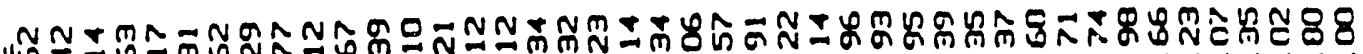

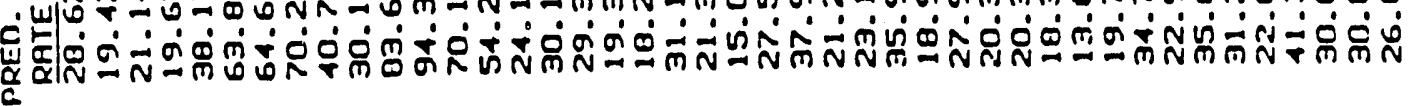

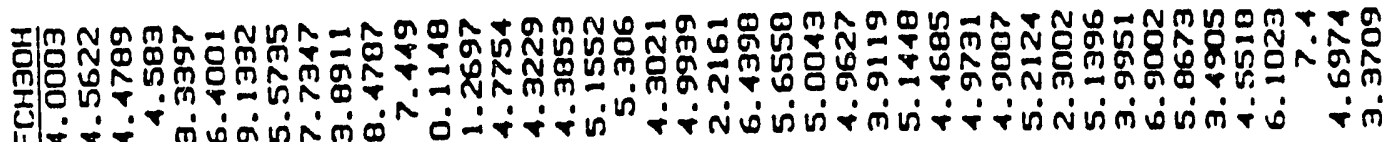

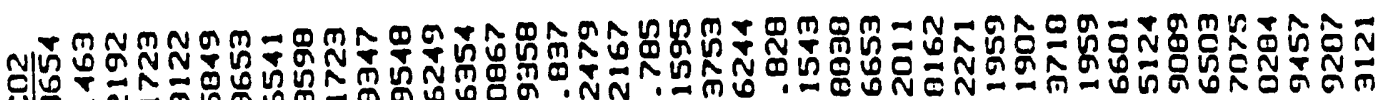

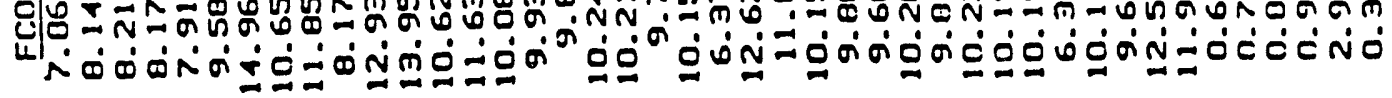

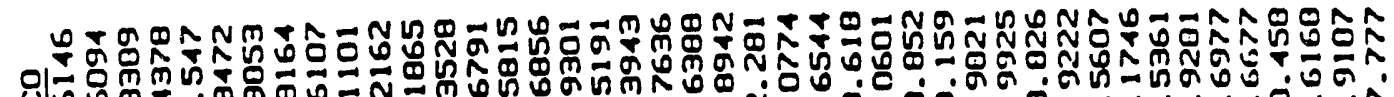

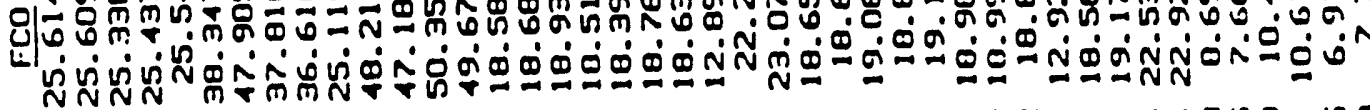

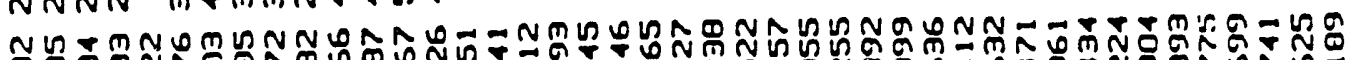

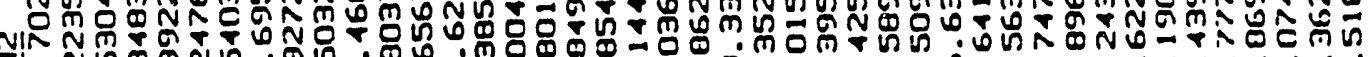

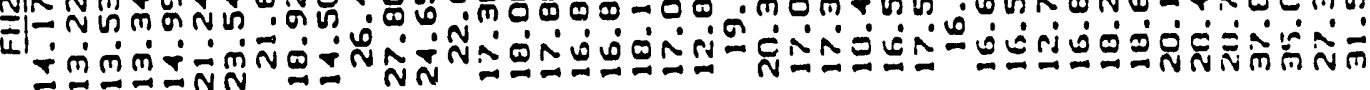

이

气

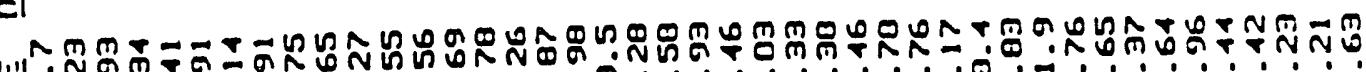

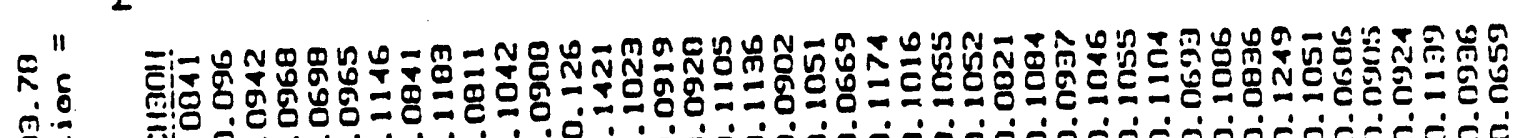

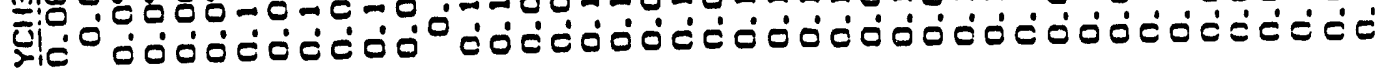

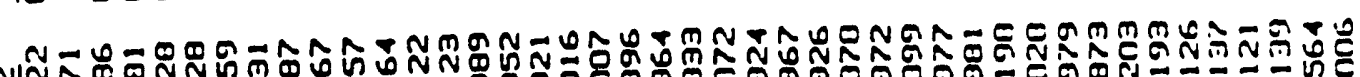

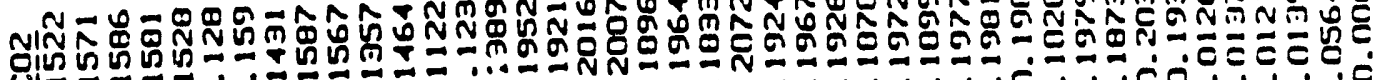

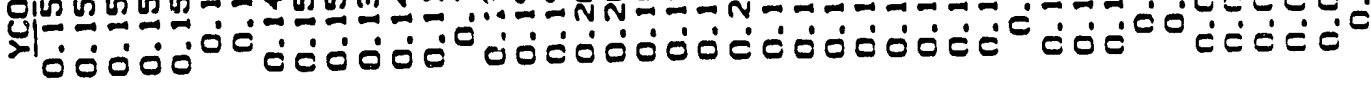

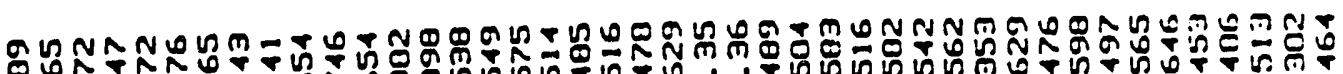

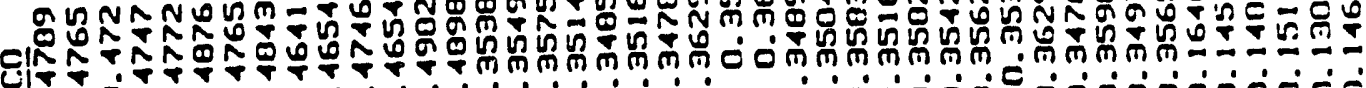

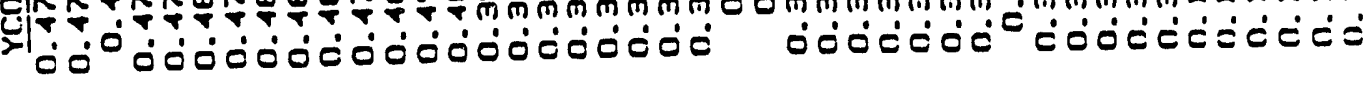

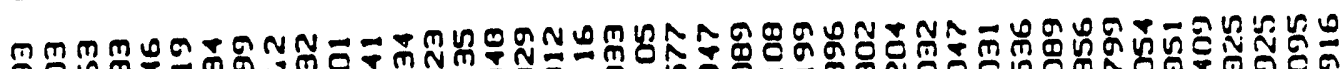

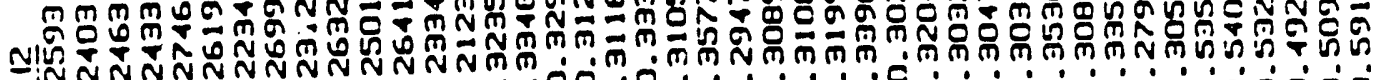

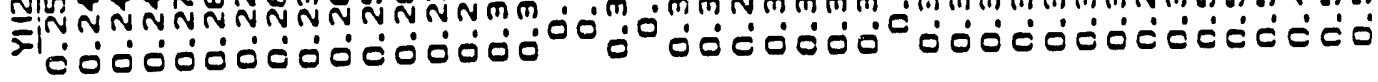

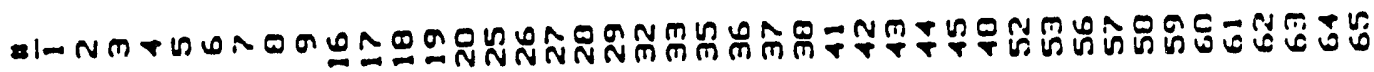
乩 


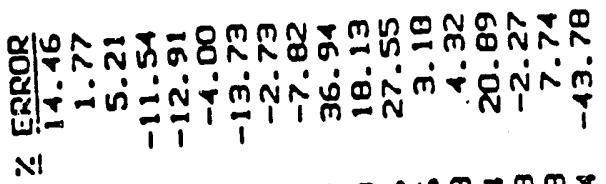

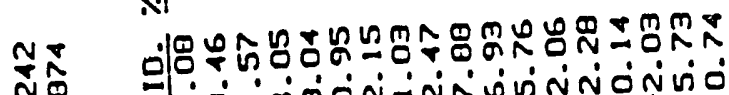

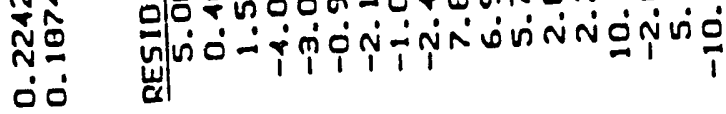

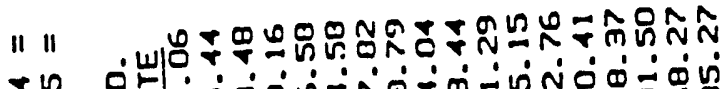

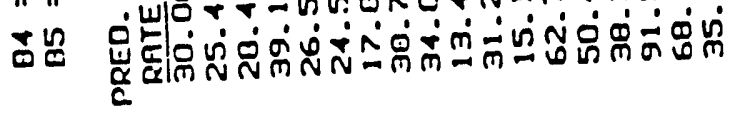

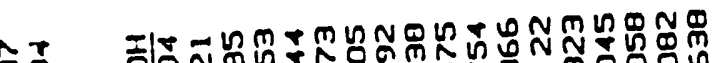

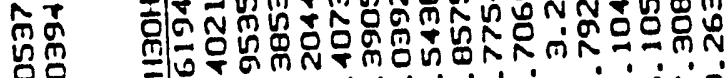

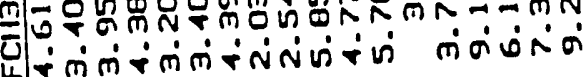

n

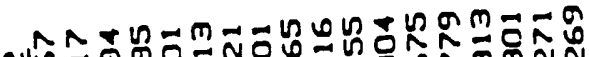

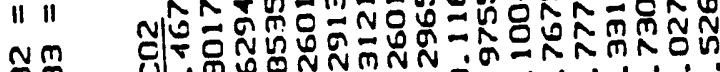

ه L L

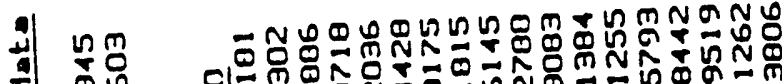

)

N 잉

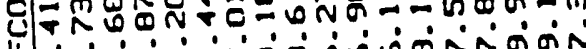

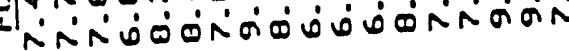

베 $=$ 믐

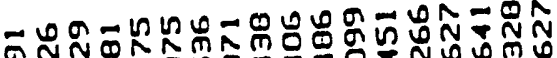

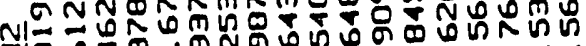

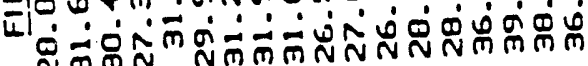

이

in

$$
\text { 틸 }
$$

$\frac{\mathbf{x}}{\mathbf{x}}$

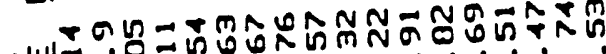

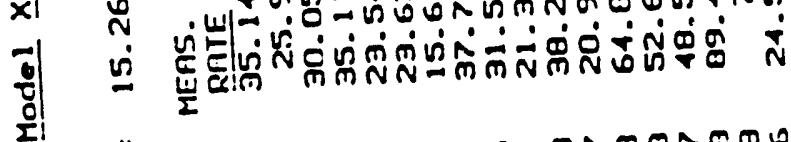

葛

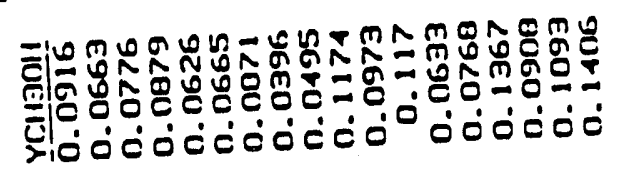

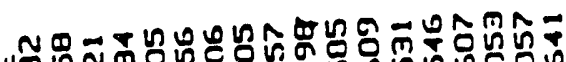

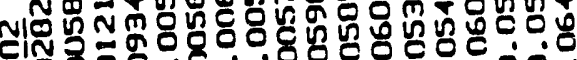

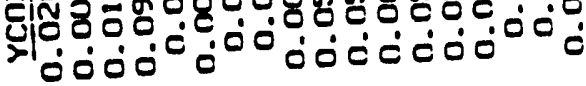

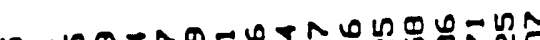

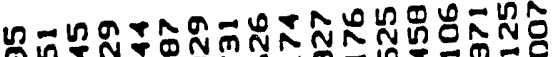

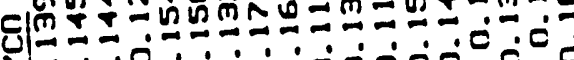

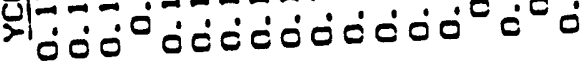

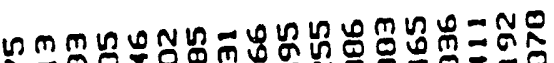

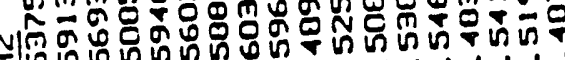
三أ

हैं 


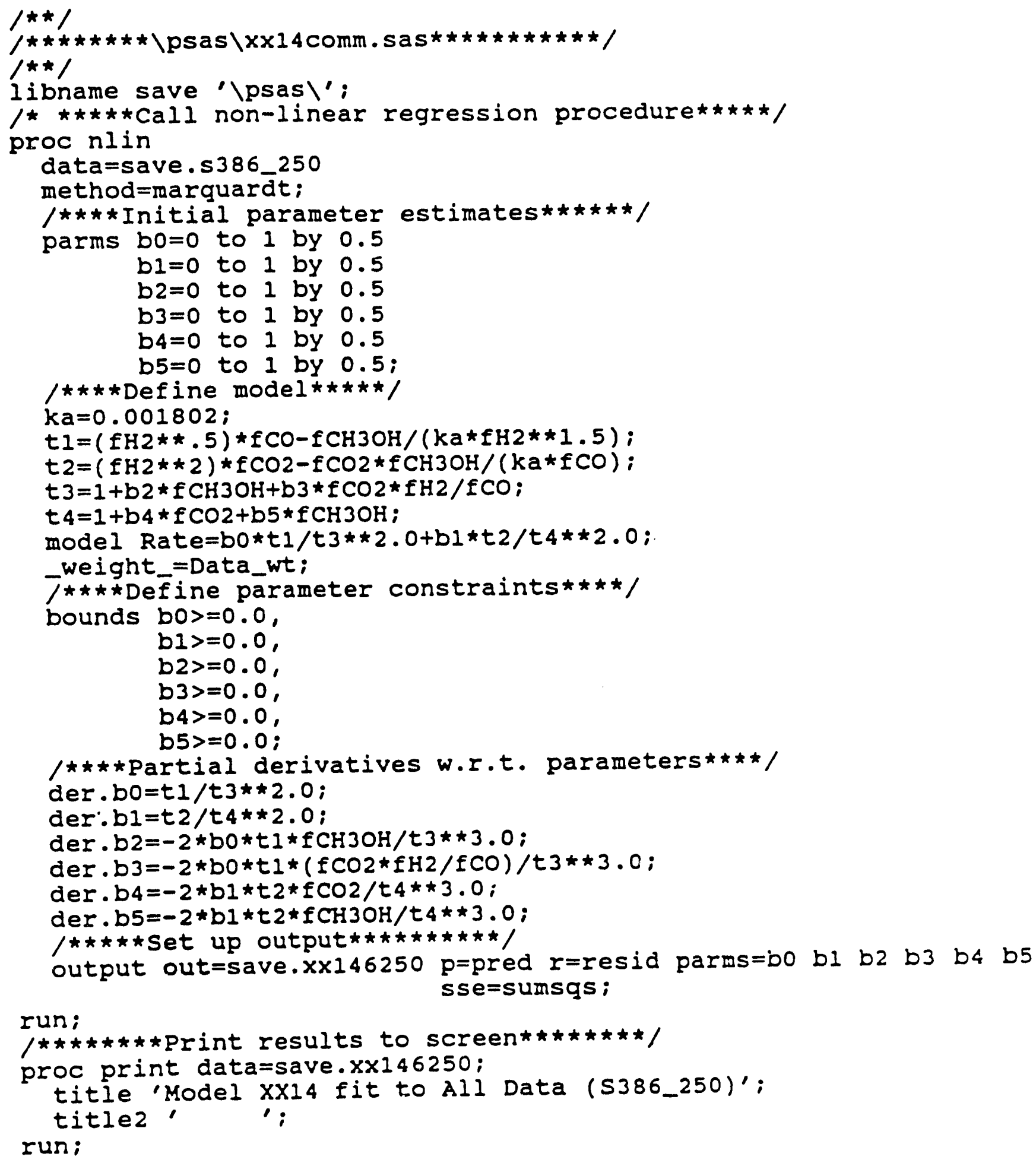


